\title{
CULTURE FACTOR DIFFERENCES BETWEEN MISSOURI'S HIGH POVERTY GOLD STAR AND HIGH POVERTY NON-GOLD STAR SCHOOLS AS DETERMINED BY THE MISSOURI ADVANCED QUESTIONNAIRE
}

A Dissertation presented to the Faculty of the Graduate School University of Missouri - Columbia

In Partial Fulfillment

Of the Requirements for the Degree

Doctor of Education

by

BRIAN D. SHINDORF

Dr. Timothy J. Wall, Dissertation Supervisor

MAY 2015 
(C) Brian D. Shindorf 2015

All Rights Reserved 
The undersigned, appointed by the dean of the Graduate School, have examined the dissertation entitled

\title{
CULTURE FACTOR DIFFERENCES BETWEEN MISSOURI'S HIGH POVERTY GOLD STAR AND HIGH POVERTY NON-GOLD STAR SCHOOLS AS DETERMINED BY THE MISSOURI ADVANCED QUESTIONAIRE
}

\author{
presented by Brian D. Shindorf, \\ a candidate for the degree of \\ Doctor of Education \\ and hereby certify that, in their opinion, \\ it is worthy of acceptance.
}

Dr. Timothy J. Wall, Dissertation Supervisor

Dr. Carole Edmonds. Committee Member

Dr. Matt Symonds, Committee Member

Dr. William Hedge, Committee Member 


\section{ACKNOWLEDGEMENTS}

Taking on a challenge of this level of accomplishment and professional growth came with a great deal of contemplation. Being the first in my family to attend college was one thing, but completing the doctoral process would be another. It would require years of commitment and a considerable amount of time away from home, but my family didn't waver. They encouraged me to pursue the degree and then backed up their words with support. Thank you Carrie, Ashley, Jessica, Hannah, and Caleb for being my support structure. Our home is where my heart.

Thank you to Doug Flowers and Beery Johnson, my summer roommates in Columbia; we spent many hours on the road. The time with you was well spent and it helped me through a process that I wasn't sure I wanted to go through. Exploring this journey with friends made it worth the time and effort. You are both men of character.

There is no doubt, from my viewpoint, that I would not have managed this process with the support and guidance of Dr. Tim Wall and Dr. Carole Edmonds. There were far too many times I needed a vision for where to go next in my writing and the two of you took the time to read, listen, and provide direction. I didn't always welcome the feedback, but in every instance, it helped me be a better writer. Thank you for your support, patience and guidance.

Finally, to my mom, there is no question that had you stayed with us to this point you would be making the trip from Michigan to be part of the culmination of this journey. You never missed or overlooked the milestones in the lives of our family, and this would be no different. Although I know you're not absent with us completely, you are greatly missed and loved. 


\section{TABLE OF CONTENTS}

ACKNOWLEDGEMENTS ..............................................................

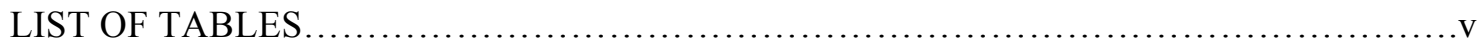

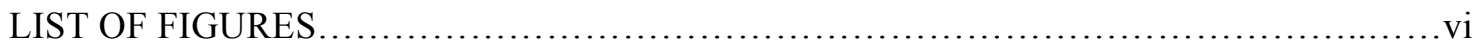

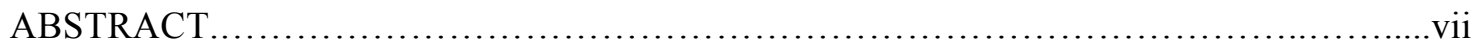

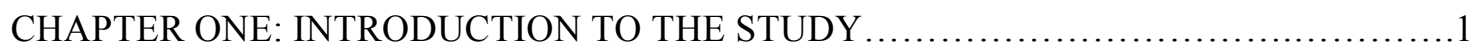

Background..............................................................

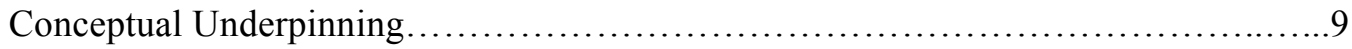

Statement of the Problem...................................................13

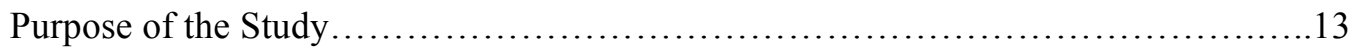

Research Questions....................................................15

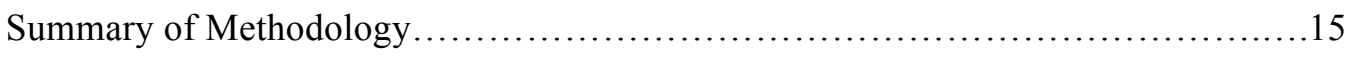

Definition of Key Terms............................................... 18

Limitations.......................................................... 19

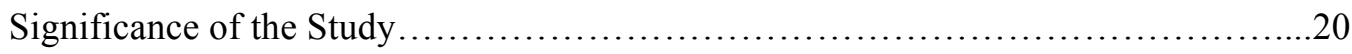

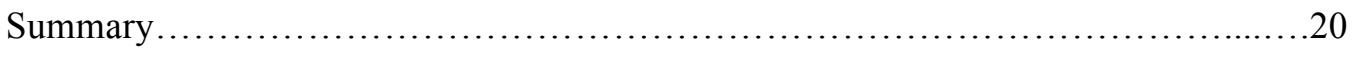

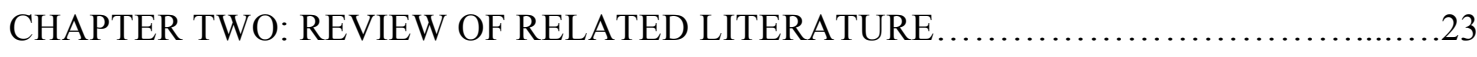

School Culture ......................................................... 25

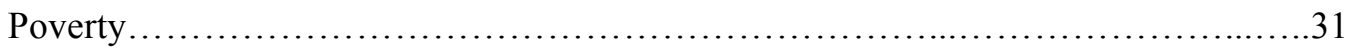

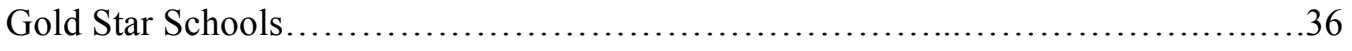

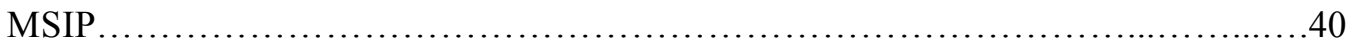

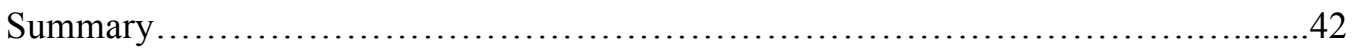

CHAPTER THREE: RESEARCH DESIGN AND METHODOLOGY ......................44

Purpose of the Study........................................................46 
Research Questions and Null Hypotheses....................................49

Research Design...................................................... 50

Setting and Population...................................................... 51

Data Collection and Instrumentation....................................... 52

Data Analysis Procedures.................................................55

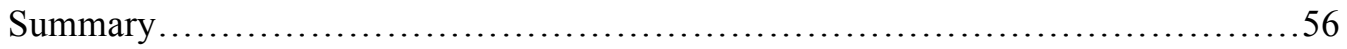

CHAPTER FOUR: PRESENTATION AND ANALYSIS OF DATA $\ldots \ldots \ldots \ldots \ldots \ldots \ldots \ldots . \ldots \ldots$

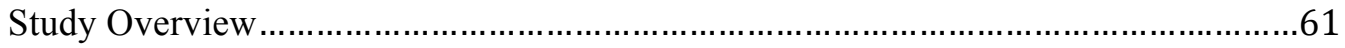

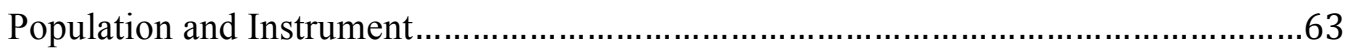

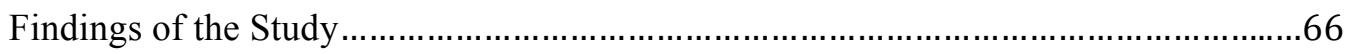

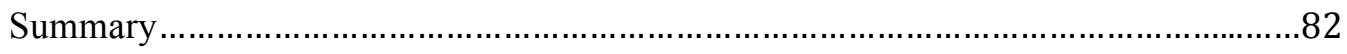

CHAPTER FIVE: FINDINGS, CONCLUSIONS, IMPLICATIONS, AND

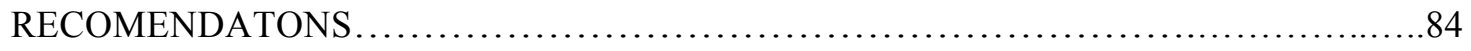

Research Questions and Null Hypotheses...................................8 87

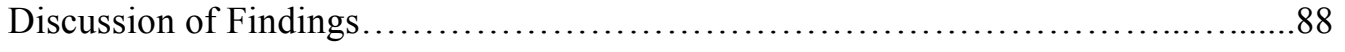

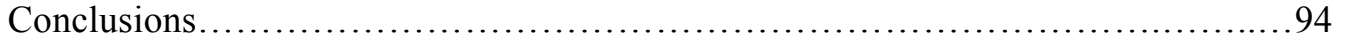

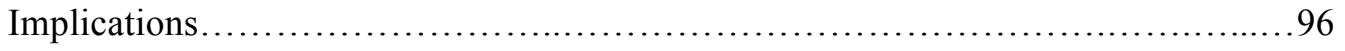

Recommendations....................................................... 103

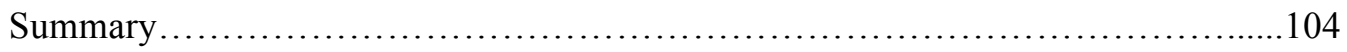

REFERENCES.................................................................

APPENDIXES

A. Advanced Questionnaire Certified Faculty Questionnaire......................119

B. List of Missouri Gold Star Schools by County ............................ 126

C. $T$-test Data Analysis.............................................. 128

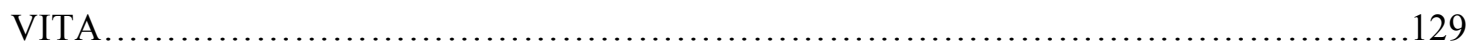




\section{LIST OF TABLES}

\section{TABLE}

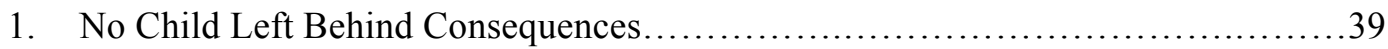

2. Types of the schools studied and number of participants.........................52

3. Types of the schools studied and number of participants..........................66

4. Gold Star Schools across Missouri by county ................................. 71

5. Individual t-test analysis for research question two.......................... 72

6. Individual $t$-test analysis for research question three........................ 74

7. Individual $t$-test analysis for research question four..........................76

8. Individual $t$-test analysis for research question five.......................... 79

9. Individual $t$-test analysis for research question two through five combined.........81

10. Total average scores by research question and type of schools...............81 


\section{LIST OF FIGURES}

\section{FIGURE}

1. Dissertation Concept Map............................................... 48

2. Map of Total Gold Star Schools in Missouri from 2007-2012 _..................68

3. Map of High Poverty Gold Star Schools in Missouri from 2007-2012.............69

4. Average Scores for Research Question Two.................................73

5. Average Scores for Research Question Three.................................75

6. Average Scores for Research Question Four...................................77

7. Average Scores for Research Question Five....................................79

8. Total Average Scores for Research Questions $2-5 \ldots \ldots \ldots \ldots \ldots \ldots \ldots \ldots \ldots \ldots \ldots 1$ 


\title{
CULTURE FACTOR DIFFERENCES BETWEEN MISSOURI'S HIGH POVERTY
} GOLD STAR AND HIGH POVERTY NON-GOLD STAR SCHOOLS AS DETERMINED BY THE MISSOURI ADVANCED QUESTIONAIRE Brian D. Shindorf

Dr. Timothy J. Wall, Dissertation Supervisor

\begin{abstract}
This study sought to identify if differences existed in the responses collected from Missouri's Advanced Questionnaire survey between high achieving and low-achieving schools across Missouri. Both groups of schools were identified as schools with greater than $50 \%$ of students on free or reduced lunch. In total, survey responses were collected from 1,645 faculty members between 2007-2012. A $t$-test analysis was conducted to determine if there were significant differences in the responses collected from the 2 groups of schools. Conclusions indicate the instrument was reliable and valid. The study revealed location characteristics with high poverty Gold Star Schools. Further, Survey response analysis yielded 3 of 4 components of culture that correlate with student achievement levels in high poverty schools across Missouri.
\end{abstract}




\section{CHAPTER ONE \\ INTRODUCTION TO THE STUDY}

The following study will examine culture factor differences between Missouri's high poverty Gold Star and high poverty non-Gold Star Schools. Potential differences are determining by the responses on the faculty survey from the Missouri Advanced Questionnaire (AQ) portion of the Missouri School Improvement Program (MSIP) accreditation process. The study will focus an analysis on two select groups of schools that includes high poverty, high achieving schools and high poverty, low-achieving schools between the years of 2007-2012. Schools in both groups report a free and reduced lunch rate of $50 \%$ or higher. In addition, the achievement levels for both sets of schools have been identified through the Missouri Assessment Program (MAP). Only schools that have been awarded Missouri's Gold Star School recognition will be used for the high achieving group of schools. Low performing schools have been identified as schools that did not qualify for Gold Star and have either one or both of English language arts or math MAP scores with less than 55\% of students scoring proficient or above.

All schools in this study have administered the AQ survey and the data are collected and provided by the Missouri Department of Elementary and Secondary Education (DESE). The AQ provides a valid dataset for determining if there are differences in the responses given by faculty of both sets of schools on the AQ survey.

\section{Background}

The No Child Left Behind Act (NCLB) was signed into law on January 8, 2002 by President Bush (U.S. Department of Education, 2010) requiring 100\% of students to achieve either a proficient or advanced level on reading/language arts and mathematics 
tests by 2014. NCLB did not define the accountability measures for each state, rather, progress towards the 2014 goal was measured by means of Adequate Yearly Progress (AYP), which is a measure defined by each state according to the assessment chosen for accountability by the individual state departments. National data provided at the end of the 2003-2004 school year showed that $25 \%$ of schools across the country did not meet AYP and by 2011 that number rose to 49\% (U.S. Department of Education, 2011). Shortly after the release of the 2011 results Secretary of Education Arne Duncan warned that by 2012 it was predicted that $80 \%$ of the nation's schools would not meet AYP standards (Duncan, 2011). In order for schools to make the progress outlined by the U.S. Department of Education there had to have been a continual increase in the percentage of students scoring proficient or above on state assessments in order to meet the rising criteria. When schools failed to make AYP, sanctions outlined by NCLB were applied. The list of schools not making AYP steadily rose each year (Center on Education Policy, 2011).

A contributing factor to the decline in schools making AYP may have been the structure in which students were categorized. The Missouri Department of Elementary and Secondary Education (DESE) categorizes the total student population into nine subgroups. Subgroups are made up of students that meet specific criteria. One of the subgroups is comprised of low-income students that qualify for free or reduced lunch. In the state of Missouri schools with greater than $35 \%$ of the student-body qualifying for free or reduced lunch are entitled to federal assistance, yet only schools above $75 \%$ are required to receive funding if federal assistance is accepted by the district. The U.S. Department of Education, however, groups schools into four range groups made up of the 
percentage of students in the school on free or reduced lunch. The four ranges consist of one to twenty-five percent; twenty-six to fifty percent; fifty-one to seventy-five percent; and seventy-six to one hundred percent of students (National Center of Education Statistics, 2010). For this study the top two ranges will be used to identify high poverty schools. Therefore, only schools that have $50 \%$ or more of the student body on free or reduced lunch will be studied.

Neill (2003) noted that low-income students enter school substantially less prepared to do academic work than their middle-income peers. This is an issue for high poverty schools because the expectations established through NCLB are that all students, regardless of economic status, score proficient or above on state assessments.

Impoverished schools that are not meeting the expectations of NCLB are faced with the task of identifying school improvement strategies to prevent the mandated sanctions under the initiative (DESE, 2014). However, research is very broad on the topic of school improvement and often does not address criteria specific to unique school environments. The established culture of the school may prove to be a defining factor in regards to student achievement and therefore provides substance to this study.

\section{School Culture}

Regardless of a school's academic standing, school leaders must routinely question what factors contribute to student achievement. The Missouri Advanced Questionnaire (AQ) survey collects data that may provide insight into one possible factor. In fact, one subset of questions on the AQ pertains to "climate" and provides data relevant to the school environment. It is important to note that although the subset items are believed to gather data pertaining to the perceived climate of the school, the items 
may very well be far more reaching (Gruenert, 2008). Gruenert compared climate and culture and found that "climate is the main leverage point for any culture" (p. 2). Gruenert explained that climate can be described as the day to day feelings of the group and can change daily based on emotion, yet culture is defined as long term commitments of a group. The AQ items that address climate represent embedded behaviors that are developed over time and do not represent behaviors that would change on a daily basis. For example, the climate in a building can change on a given day of the week based on an event that occurred recently, whereas the culture would remain in place regardless of the day's events. Gruenert separated climate and culture with climate being the way people feel and an organization's culture being the way things are done. Bolman and Deal (2008) supported Gruenert's work by describing culture as an anchor to an organization's identity and defining it as "the way we do things around here" (p. 269). The findings of Gruenert and Bolman and Deal support the use of the AQ questions chosen for this study. The AQ questions asked of faculty relate to the embedded behaviors that are established within the culture. The AQ questions that will be used for the purpose of analyzing culture are numbers $26,38,69$, and 70 . These questions make up the survey item 6.5.1.3a; the degree to which all students feel respected and valued (DESE, 2011). Stolp and Smith (1995) presented school culture as an alternative method of capturing the powerful transformational force in schools. Bolman and Deal (1997) suggested the success or failure of a school rests upon how the school is perceived by the constituents, including students, staff, and parents. The perceptions and interaction of and among these groups determine the culture of the school. 
This study seeks to identify if differences in the perceived culture exist between Gold Star Schools and non-Gold Star Schools as determined by results collected from the Missouri AQ survey. Both high performing and low performing schools for the study are schools with a free and reduced lunch participation rate of $50 \%$ or greater. Performance rates are determined by the percentage of students scoring advanced or proficient on the MAP assessment that are provided through DESE.

\section{Poverty}

Adding to the challenges that school leaders face is the element of poverty. Literature clearly shows that poverty is one obstacle that transcends cultural boundaries and impacts student performance (Muhammad, 2009; Neill, 2003). Additionally, Noguera (2014) claimed, "Despite compelling evidence that education policy must mitigate the harmful effects of poverty on student achievement and child development, most states and federal policies have failed to do so" (p. 1). Noguera elaborated that although obstacles do exist for impoverished students, research does not suggest poor children are incapable of learning. Studies have been completed that identify strategies and instructional practices that support students of poverty (Marshall, 2004; Lippman, L., Burns, S., McArthur, E., 1996). However, there is insufficient information to tie specific factors of school culture, as determined by the AQ, to student achievement in high poverty, high achieving schools in relation to high poverty, low-achieving schools. Manwaring (2012) stated that currently there was no research base to support how to raise student achievement in high poverty schools, supported by the fact that if there were we would not have so many low performing impoverished schools. 
The U.S. Government identifies schools with heightened levels of poverty, as measured by the percentage of free and reduced lunch among the student population. Schools with $35 \%$ or more students on free or reduced lunch qualify for Title 1 services which have existed since the Elementary and Secondary Education Act (ESEA) of 1965 (Kirby, McCombs, Murry, Naftel, 2003). Title I funds are federal dollars targeted at highpoverty schools for districts to use to provide educational services for students who are educationally disadvantaged or at risk of failing to meet state standards. This is significant because according to Dr. Paul Houston (1997), former Executive Director of the American Association of School Administrators, students in high-poverty schools have historically scored between 50 to 70 percent lower in reading and math than students in low-poverty schools. More recent researchers have noted that low-income students enter school substantially less prepared to do academic work than their middle and upper income peers (Neill, 2003; Payne, 2005; Noguera, 2014). Further complicating the issue is that schools with high poverty rates that accept federal dollars are subject to higher NCLB sanctions than low poverty schools. The NCLB sanctions range from changes in curriculum, closing of schools, and the release of staff (U.S. Department of Education, 2010).

\section{Gold Star}

In contrast to struggling schools, The Missouri Department of Elementary and Secondary Education (DESE) identifies high performing schools as Gold Star Schools. The Missouri Gold Star Schools Program honors public and private schools that are either academically superior or that demonstrate dramatic gains in student achievement to high levels. Since 1991, the DESE has recognized high performing schools through the 
Gold Star Schools Program. Recognitions are currently based on results of the Missouri Assessment Program (MAP) (DESE, 2014). MAP is an annual series of assessments administered through the DESE, in which all students in grades 3-8 take a grade level assessment in communication arts and mathematics. In addition, a science assessment is administered in 5th and 8th grades. The assessments are designed to see if students are meeting the academic standards set by the DESE (DESE, 2012). Results of these assessments are reported annually to the public.

In the years between 2007 and 2012 only 40\% of the schools recognized for Gold Star have been above the $50 \%$ poverty rate (DESE, 2014). Poverty levels are not a factor in determining Gold Star Schools; however, impoverished schools that are academically superior are eligible for the award. Schools facing high poverty that meet this status have changed the perception that schools of high poverty cannot compete with affluent schools or meet the increasing demands of NCLB. In fact, some have surpassed their affluent counterparts that are now facing sanctions as a result of not making required gains. Although obtaining Gold Star recognition is determined through an application process,

only schools showing significant gains towards school improvement or schools sustaining high achievement are eligible (DESE, 2014). Gold Star status, therefore, provides an identifiable select group of schools to examine for commonalities and to compare against a low performing group of schools.

\section{Missouri School Improvement}

The Missouri School Improvement Program (MSIP) began in 1990 and is mandated by state law and State Board of Education regulations to review and accredit 520 school districts in Missouri (DESE, 2014). As NCLB began to show signs of being 
ineffective at raising student achievement some states began developing more local improvement plans and in 2009, as part of MSIP, the Missouri Department of Elementary and Secondary Education (DESE) launched Top 10 by 20, an improvement effort that aims for student achievement in Missouri to rank among the top 10 states by 2020 (DESE, 2014).

In 2012 DESE reported that $75 \%$ of high school students take the ACT. Missouri's ACT composite score is 21.6, which ranked Missouri $26^{\text {th }}$ (DESE, 2014). In order to rank $10^{\text {th }}$ the composite score would have needed to be 22.8 . Additionally, results on the National Assessment of Education Progress (NAEP), a measurement of student achievement in the United States since 1969, indicated Missouri ranked $24^{\text {th }}$ in math and $22^{\text {nd }}$ in reading for fourth graders. DESE suggested that these achievement levels ultimately resulted in 100,000 high school dropouts and only $35 \%$ of graduates enrolling in college courses. To combat the lack of student success Top 10 by 20 outlined a course of action through four goals; first, to increase the number of students who are college and career ready; second, to expose 3 and 4 years old children to quality learning experiences; third, to prepare and retain effective teachers and leaders; and finally to improve department efficiencies and operational effectiveness (DESE, 2014).

As part of the MSIP accountability the AQ survey is administered to districts across the state. The statewide survey is administered to evaluate educational processes in districts. Each of the 520 districts across Missouri is responsible to administer three separate surveys to staff, parents, and students as part of the review process. The AQ is organized into categories that reflect practices that can be identified as part of school life. 
One category that spans all three surveys is school culture. All three groups surveyed are asked to provide perceptual data through the survey that reflects school culture factors.

The national NCLB, Missouri's Top 10 by 20, and MSIP were initiatives designed to increase student performance through school improvement efforts (U.S. Department of Education, 2012; DESE, 2014). To support these efforts this study will seek to identify if there are differences in the responses from high achieving Missouri schools compared to low-achieving schools when asked about school culture on Missouri's AQ survey.

\section{Conceptual Underpinning}

The conceptual underpinning of this study is driven by the concept that culture has a direct impact on the achievement level of a school and that if the right culture can be developed and maintained, student achievement improves. However, poverty impacts the culture of a school and therefore impacts achievement (Muhammad, 2009; Neill, 2003). As a result, this study will maintain a focus on two specific groups of schools that qualify as high poverty schools as determined through federal guidelines. All schools in this study report a free and reduced rate above $50 \%$ which means that a minimum of $50 \%$ of the students receive a free or reduced price lunch. This group was selected because the significant amount of research that shows high poverty schools perform lower than more affluent schools (Neill, 2003; Payne, 2005; Noguera, 2014). It has also been established that the school's culture impacts achievement (Bulach \& Berry, 2002). Therefore, this study will seek to determine in differences in the perceived culture can be identified through the responses given by faculty members of two distinctly different groups of high poverty schools across Missouri's. 
Organizational cultures is the study of organizations for the benefit of identifying common themes to solve problems, maximize efficiency and productivity, and meet the needs of the members (Turner \& West, 2007). Although there are numerous lenses through which to view organizational culture, there are primarily three subtopics: classical perspective, environmental perspective, and neoclassic perspective (Walonick, 1993). The classical perspective emerges from the industrial revolution and centers on theories of efficiency (Armstrong \& Daft, 2009). The most serious objections to classical theory are that it created over-conformity and rigidity, thus squelching creativity, individual growth, and motivation. The environmental perspective is tied to a contingency theory (Scott, 1981). Scott connected contingency theory to behavioral theory, in which there is no best way to organize a work force or to make decisions. For the purpose of this study, a neoclassical perspective will be viewed. The neoclassical perspective began with the Hawthorne studies in the 1920s and displays genuine concern for human needs. This perspective provides emphasis to affective and socio-psychological aspects of human behaviors in organizations, while primarily concentrating on morale, leadership, and factors that aid in the cooperation within the organization (Sapru, 2008).

Bolman and Deal (2003) supported the neoclassical perspective through four frames of organizational analysis: human resource, structural, political and symbolic. The human resource frame strives to maximize the fit between individuals and the organization. This relationship is an important factor in the development of organizational culture. The structural frame provides a lens to observe how order and control are maintained within organizations, providing an underpinning to the 
coordination of culture. In comparison, the political frame encompasses power, agenda setting, and decision-making strategies, while the symbolic frame highlights the value of ritual and ceremony in an organization.

Most researchers concede that culture is an all-encompassing learned phenomenon. Schein (1990) supported this central belief, "Culture is ubiquitous, it covers all areas of group life" (p. 112). Likewise, organizational culture represents the beliefs and values of the whole organization and not those of individuals (Peterson \& Deal, 2002). Some researchers contend organizations have cultures while others believe organizations are cultures (Bolman \& Deal, 1997). Schein supported the notion that culture makes up an organization and members do not exist outside of the culture of the organization in which the members work. According to Schein (2004), culture is both a dynamic phenomenon that surrounds us at all times, being constantly enacted and created by our interactions with others and shaped by leadership behavior, and a set of structures, routines, rules, and norms that guide and constrain behavior (p.1).

In comparison, Dufour and Eaker (1998) defined culture as "the assumptions, beliefs, values, and habits that constitute the norms for that organization" (p. 131). Other researchers define organizational culture as the common symbols, myths, and rituals that help define it to external constituencies (Bolman \& Deal, 1997; Rafaeli \& Worline, 2000; Schein, 2000). Bolman and Deal (2003) further argued the strength of a culture is tied to how well it is aligned with the goals and values of the organization. Alignment between cultural goals and values may dictate whether an organization has a strong culture capable of performing at a high level or, in contrast, a weak culture relying on policies 
and rules, thereby struggling to perform at a high level.

Regardless of the varied definitions or frames in which it is represented, culture is an important factor for organizational success. (Shafritz, Ott, \& Yang, 2005) proposed, "The primary question for organization theory thus involves how best to design and manage so that they achieve their declared purpose effectively and efficiently" (p. 352).

Turner and West (2007) defined organizational culture as "the essence of organizational life" (p. 300). Turner and West further framed organizational culture through three assumptions. The first assumption was that members of an organization develop and nurture a shared sense of reality that facilitates an improved understanding of values. Values were defined as "the standards and principles within a culture that have intrinsic worth to a culture" (p. 301-302). The second assumption maintained that understanding and using symbols is critical to the culture. Verbal and nonverbal symbols can be used daily as representations for meaning. The purpose of this study is framed around the premise of the third assumption, which maintains that various cultures exist across organizations and the actions that take place within organizations can be just as varied. As a result, cultures differ immensely; however, studies (Hirase, 2000; Erpelding, 1999) have shown that although all schools have a culture, it is the type of culture that makes a difference in student achievement.

The conceptual underpinning of this study centers on the definition of culture offered by Schein (2010),

the culture of a group can now be defined as a pattern of shared basic assumptions that was learned by a group as it solved its problems of external adaptation and internal integration, that has worked well enough to be considered valid and, 
therefore, to be taught to new members as the correct way to perceive, think, and feel in relation to those problems (p. 18).

A key facet of this definition is the idea of shared assumptions by the members. Specific shared assumptions may be necessary if an organization hopes to build a culture that promotes success.

\section{Statement of the Problem}

School leaders are held accountable for student achievement; however, the task of raising achievement can be daunting without clear direction on what produces high achievement. Muhammad (2009) contended, "There is still a lack of clear consensus about what is needed to ensure that all our schools perform at high levels and all of our students achieve success" (p. 5). The Institute for School Improvement (2006) conducted a study to examine if there was a relationship between school culture and student achievement; however, the study focused on only one school system and no connection between poverty level and achievement was made. Further research is needed to determine if there are differences in the school culture as determined by the Missouri Advanced Questionnaire (AQ) when comparing high performing and low performing schools of poverty.

\section{Purpose of the Study}

The purpose of this quantitative study is to investigate potential differences in school culture between high poverty Gold Star Schools and high poverty non-Gold Star Schools as measured by the Missouri Advanced Questionnaire (AQ) survey. For the purpose of this study high achieving schools are defined as schools that have obtained Missouri's Gold Star status. Gold Star status is determined through criteria established by the 
Missouri Department of Elementary and Secondary Education (DESE). Eligibility requires a school to either show substantial gains in student achievement or maintain a high level of achievement on the Missouri Assessment Program (MAP). Low performing schools have been identified as schools that did not qualify for Gold Star and have either one or both of English language arts or math MAP scores with less than $55 \%$ of students scoring proficient or above. It is anticipated that through a comparison of these schools it can be determined if there are differences in the perceived culture between the two groups of schools.

Fraenkel and Wallen (2003) define a representative sample as the "essential or relevant, characteristics of a population" (p. 110). In this study, a representative sample is from among school faculty members from across Missouri. The greater the number of responses or size of the sample responding could more than likely confirm the level and validity of the instrument (Fraenkel \& Wallen, 2003). Therefore, obtaining a representative sample was essential. This study collected survey data from 1,645 faculty members from schools across the state of Missouri.

Previous studies have been conducted that have collected data related to school culture. In some cases the purpose of the studies was to develop data collection tools for the purpose looking at school culture. One example, the School Culture Survey-Teacher Form (Gruenert \& Valentine, 1998) was designed to ascertain the cultural perceptions of certified staff in a high school setting. The purpose of this study is not to develop a survey capable of collecting data but rather to utilize current data from the Missouri Advanced Questionnaire, which was designed to gather cultural data from a variety of stakeholders. 


\section{Research Questions}

The research questions for this study, with the exception of RQ1, were taken directly from the questions asked to faculty on the Advanced Questionnaire survey. The key questions to be addressed are:

1. What are the geographic characteristics of the Missouri Gold Star Schools from 2007-2012?

2. Are there differences in Advanced Questionnaire responses between Gold Star and non-Gold Star Schools in regards to if the school promotes an environment of mutual respect among students?

3. Are there differences in Advanced Questionnaire responses between Gold Star and non-Gold Star Schools in regards to if the school makes students feel a sense of belonging?

4. Are there differences in Advanced Questionnaire responses between Gold Star and non-Gold Star Schools in regards to if teachers and administrators value student opinions?

5. Are there differences in Advanced Questionnaire responses between Gold Star and non-Gold Star Schools in regards to if teachers will listen and help if a student has a problem?

\section{Summary of Methodology}

The Missouri School Improvement Program (MSIP) uses Advanced

Questionnaire (AQ) survey data as part of the public school accreditation process. The AQ is administered in school districts once every five years in the semester prior to a MSIP review. The AQ is given in survey format to students, parents and school faculty 
across Missouri. The survey is administered online except for the parent survey, which is done by paper and pencil. Each questionnaire on the AQ contains a battery of questions, most of which are Likert-type scale questions (Missouri Department of Elementary and Secondary Education, 2011). Trochim (2001) and Folz (1996) disagreed on whether Likert scales represent interval data points. Trochim asserted that the data from a Likerttype instrument could be used as interval data. Folz (1996) indicated that Likert scales could be overused and misinterpreted. Folz's primary caution was that the results from Likert surveys should not be over-interpreted and used exclusively to make important policy decisions.

This study will utilize data collected from four questions extracted from the faculty survey. The survey is organized into 9 categories: (1) School Environment, (2) School/District Structure, (3) Communication, (4) Positive Performance Expectations, (5) Belonging, (6) Learning Environment, (7) Teacher/School Quality, (8) Counselor Quality, and (9) School Bonding. The Department of Elementary and Secondary Education (DESE) and The Office of Social and Economic Data Analysis (OSEDA) identified four questions from the school environment category as prime factors associated with school culture (DESE, 2011; Office of Social and Economic Data Analysis, 2014). The answers are connected to individual schools and when compiled may provide a clearer understanding of the perceived culture present in each school. Once collected and analyzed data may provide a comparison of the factors found in Gold Star Schools to non-Gold Star Schools.

Schools in this study are identified as either high performing or low performing as determined by the results collected through the Missouri Assessment Program (MAP) 
database from communication arts and mathematic assessments. High performing schools will be identified through the Missouri Gold Star Program. Only high poverty schools identified as Gold Star Schools are considered to be high performing for the purpose of this study. Only schools that fall below the criteria to apply for Gold Star status and have fewer than $55 \%$ of students scoring proficient or above on either one or both of the English language arts or math MAP test will be considered for the low performing subgroup. AQ data from the identified schools will be analyzed by the percentage of response from each category of the Likert scale. Responses range from strongly agree, agree, neutral, disagree and strongly disagree.

Fraenkel and Wallen (2003) defined a survey study as "an attempt to obtain data from members of a population (or a sample) to determine the current status of that population with respect to one or more variables" (p. G-8). The AQ survey questions are tied to 9 categories, one of which relates to school culture. It is believed that an analysis of these variables will reveal the perceived status of the culture as seen by the study participants. In addition, Ury (2003) stated, "surveys are good tools for bringing out the perceived reality of those involved while educating participants and providing a sense of ownership" (p. 42). The AQ allows for the collection of perceptual data through a series of survey questions. Although the respondents' answers are based on their perceptions, these perceptions represent the reality of their beliefs towards the school's culture. Fink (2009) believed surveys "are information collection methods used to describe, compare, or explain individual and societal knowledge, feelings, values, preferences, and behavior" (p. 1). Once collected and analyzed, the AQ data will be used to compare the results between the Gold Star School group and the non-Gold Star School group. 
An independent $t$-test assesses whether the means of two groups are statistically different from each other (Field 2005). This study utilizes data collected from two groups, Gold Star Schools and non-Gold Star Schools. Both groups were given the Advanced Questionnaire survey. The Gold Star Schools were given the AQ within a twoyear period of being recognized by the DESE as a Gold Star School.

\section{Definition of Key Terms}

In research, studies may have various definitions for the same term or phrase. To help frame this study, the following definitions were used:

Adequate Yearly Progress (AYP). The amount of progress schools and districts are required to make in achievement each year. The definition is determined by each state according to the assessments by each state.

Climate. The way people of a group feel on a daily basis. Dictated by the attitudes and feelings of the members. Subject to frequent change based on emotion.

Culture. Values, beliefs, perceptions, behavioral norms, and patterns of behavior shared by all or most members of the group. Deeply held values requiring time to change or develop.

Free/ Reduced Lunch. Free and reduced lunch is a program provided through the U.S Department of Education and the Missouri Department of Elementary and Secondary Education. Eligibility is determined by a family's income in relation to the number of family members.

High Poverty. For this study high poverty schools are defined as schools with greater than $50 \%$ of the students receiving free or reduced lunch. 
High Performing Schools. Elementary schools recognized as Missouri Gold Star Schools by the Missouri Department of Elementary and Secondary Education (DESE).

Missouri Assessment Program (MAP). A series of assessments for Communication Arts, Mathematics and Science at grades 3-8; and Communication Arts, Mathematics, Science and Social Studies in high school. (Missouri Department of Elementary and Secondary Education, 2001).

Missouri Advanced Questionnaire (AQ). The Missouri School Improvement Program (MSIP) uses AQ survey data obtained from multiple groups as part of Missouri's public school accreditation process.

Subgroup. A set of students grouped according to a set of criteria. There are nine identifiable subgroups: Asian/Pacific Islander, black, Hispanic, American Indian, white, multi-racial, students with disabilities, English language learners, and low income.

\section{Limitations}

A primary limitation of this study is that it relies on one-shot voluntary responses that are based on individual perception of the culture. Perception can be influenced by relationships among members at any given time. The AQ survey offers participants five options for their response. One of the options is to reply as "neutral" to the question. Folz (1996) observed that a neutral response option allows respondents to be non-committal and may cause the survey to yield less definitive results.

Additionally, the researcher was a school principal in a high poverty school that made significant gains in student achievement during his five-year tenure. Under his tenure, the school was named a Missouri Gold Star School. The experiences from that position could bias the researcher's thinking. 
Finally, staff turnover can be significant and may impact the responses given on the survey depending on the length of tenure by the respondents. Schein (2010) reported, "Organizational culture will vary in strength and stability as a function of the length and emotional intensity of their actual history from the moment they were founded" (p. 3). Respondents that have been members of a building for a short time may not have the schema or experience needed to provide valid input on the school's culture.

\section{Significance of the Study}

Higher expectations have been outlined at the national, state, and local levels with an emphasis on academic standards tied to high-stakes testing. Policy makers and educational leaders have unveiled a series of measures through NCLB, holding educators accountable to taxpayers (Schiff, 2001). As such, the advent of state and federal mandates through accountability initiatives has underscored the need for school reform.

Schools serving high poverty populations face additional sanctions when the school fails to meet state and federal mandated levels of achievement. This is an issue because principals whose schools do not meet Adequate Yearly Progress (AYP) can now be held directly accountable under the NCLB law. The most stringent provisions of NCLB require the restructuring of a school not making AYP for five years in a row. As part of restructuring, all staff, including the principal, can be released from their position. The implication of this study is that high poverty schools can benefit if differences in school culture that impact student achievement within high poverty schools can be identified and replicated. 


\section{Summary}

Closing the achievement gap is crucial to the school improvement process and becomes a monumental task when leaders face socioeconomic barriers. As a result, school leaders across the nation are analyzing school data and seeking assistance wherever possible to show gains in student achievement. Unfortunately, this form of school improvement is reactive in nature and producing limited results. The struggle to transform schools is exacerbated by elements of poverty. Research shows that some students from low-income families come to school inadequately prepared. As a result, many high poverty schools across the nation have struggled to increase achievement levels.

Current research provides information essential to school leaders and their endeavor towards raising student achievement. Various studies provide insight into instructional practices that transcend the barriers to school improvement, however, the research is vast and it can be difficult to narrow down the specific strategies. As a result, meeting the increasing demands set forth by state and federal mandates is becoming more difficult for school leaders. As policy makers continue to place leadership development on the top of the list for school reform, it is done hoping school leaders have the ability to learn the necessary skills to confront the challenges leaders face with school improvement (Bishop \& Gray, 2009). According to Daggett (2014) a critical skill to school reform is culture building. Additionally, Wagner (2006) reported there are nuances in every culture that set them apart, but there may also be some characteristics or norms found within the culture of successful high poverty schools. 
School culture emerged from organizational culture and is composed of values, beliefs, assumptions, perceptions, behavioral norms, artifacts and patterns of behavior (Shafritz, Ott, \& Yang, 2005). If school leaders can influence and change the school culture, under the premise that culture can impact student achievement, there may be promise that schools can improve as a result of the decisions a leader makes towards improving the culture. 


\section{CHAPTER TWO}

\section{REVIEW OF RELATED LITERATURE}

The purpose of this quantitative study is to investigate if there are differences in the responses collected from school faculty when asked about school culture. An analysis will compare responses between high poverty Gold Star Schools and high poverty nonGold Star Schools as reported on Missouri's Advanced Questionnaire (AQ) survey. For the purpose of this study high achievement is determined by identifying schools that have obtained Missouri's Gold Star status. Although the Gold Star recognition is voluntary for schools, only schools achieving at high levels or schools with substantial improvements in student achievement are eligible. It is anticipated that this study will reveal if there are differences in the responses given on the AQ between high and low performing schools.

Unprecedented federal and state requirements for educational accountability are shaping school reform with an emphasis on standardized assessment as the predominant measure of student success (Whitaker, 2004). The national No Child Left Behind Act of 2002 (NCLB) (U.S. Department of Education, 2010) and Missouri's Top 10 by 20 (DESE, 2014) initiatives focuses attention on the academic performance of children in public schools. The NCLB law mandated that by the year 2014 public schools must ensure all students minimally perform at a proficient level in reading and math as determined by state assessments. Furthermore, NCLB outlined sanctions for schools that accept federally allocated funding known as Title I, which is determined by the percentage of students receiving free and reduced lunch assistance. Title I funds are federal dollars targeted at high-poverty schools and districts and used to provide educational services for students who are educationally disadvantaged or at risk of failing 
to meet state standards. Title I schools not meeting achievement levels mandated by NCLB faced sanctions requiring the provision of school choice and supplemental educational services, similar to after school tutoring (Pascopella, 2005).

One area of contention with NCLB was that the mandate provided no single definition for means towards accountability. In fact, districts were allowed to choose the accountability measures which allowed for an unbalance among states (U.S. Department of Education, 2012). Further complicating matters is NCLB did not take into account socioeconomic status or the circumstances of special needs students. Although Title I schools faced higher sanctions than non-Title I schools, student achievement expectations were the same for both groups. In fact, NCLB mandates are the same regardless of a school population, including poverty, special education, and non-English speaking students. High poverty schools were expected to perform at the same level as highly affluent schools with little or no consideration for impoverished or non-English speaking students (U.S. Department of Education, 2012). Research revealed; however, that many students of high poverty schools struggled academically and were less likely to graduate from high school. On average $68 \%$ of 12 th grade students in high poverty-schools graduated with a diploma in $2007-2008$, compared to $91 \%$ at low poverty schools. In fact, the numbers have progressively gotten worse for students at high poverty schools, dropping to $68 \%$ from $86 \%$ in $1999-2000$ (Armario, 2010).

The literature review for this study will focus on three constructs. First, an examination of organizational culture and, more specifically, school culture will be offered. This section will provide comprehensive definitions of organizational and school culture in order to support the definition of culture offered by Schein (2004), which 
serves as the central conceptual underpinning to this study. Second, research on the topic of school improvement and the mandates established by NCLB and Top 10 by 20 will be explored. Third, current research will be reviewed concerning poverty and the impact poverty has on school improvement efforts; more specifically, how poverty impacts the work being done in schools to meet the rigorous demands set forth by state and federal initiatives.

\section{School Culture}

Although once thought of as a soft approach to school improvement efforts, school culture has finally amassed the depth of research necessary to qualify as a mainstay in a school leader's annual improvement plans (Wagner, 2007). Several authors and researchers (Levine \& LeZotte, 1995; Sizer, 1988; Phillips, 1996; Peterson \& Deal, 1998; Frieberg, 1998) agreed and have referred to school culture as an important but often overlooked component towards raising student achievement. As a result, school culture has long been a topic of interest for educational stakeholders. In fact, school culture gained attention shortly after the Coleman Report (1966) was released and researchers began to refute the findings concerning socioeconomic status. Researchers believed that other predictors, beyond socioeconomic factors, needed to be explored. New research focused on the impact of school culture on student achievement (Coleman et al., 1966).

School culture research suggests that culture embedded within a school is a critical factor contributing to the variability in student achievement. Bulach, Malone, and Castelman (1995) cited 17 references that support this relationship and later research found "significant differences in student achievement between schools with good school 
climate and those with a poor school climate.” (Bulach \& Berry, 2002; p. 1). Other researchers have also noted that a positive school culture contributes to higher academic achievement (Hirase, 2000; Erpelding, 1999). Over time research has delved deeper into specific elements of school culture and the finding have brought to light factors such as relationships among the individuals in the school community, which include trust and respect (Manning, 1996). Marshall (2004) supported previous findings and presented the additional factors of academic feedback, caring attitudes, and opportunities for input. The findings by Manning and Marshall correlate with the AQ questions used in this study, as all four AQ questions relate to the level of belonging, mutual respect and caring attitudes of faculty.

Research conducted by The Leadership and Learn Center (Reeves, 2000) on the “90/90/90 Schools" provided specific findings that link instructional practices and strategies to school improvement. The study included elementary through high school settings ranging from overwhelmingly poor to economically affluent. As a result of the study, five characteristics were found to be common to all 90/90/90 schools. These characteristics include a focus on academic achievement, curriculum choices, formative assessments, non-fiction writing emphasis, and collaborative scoring of student work. Reeves made no claim that any single intervention caused the changes identified. Reeves did, however, recognize that changing instructional practices in a few classrooms impacts a percentage of instruction while changing practices across the building directly impacts the culture. The overhauling of culture is not a single act, rather, a transformational process that occurs when the majority of the staff support and implement the philosophies that make up the culture. Therefore, it requires the collective work of teachers, students, 
parents, and leaders (Peery, 2010). Manwaring (2012) supported this belief by claiming that research should stop focusing on specific strategies and begin exploring the process of change that low performing schools go through to become high performing; a process that ultimately changes the culture of the school.

The demand for school improvement highlights the importance of formalizing positive cultural structures that are built around common beliefs and behavioral patterns by which the organization is characterized by united people (Bolman \& Deal, 2003). A formalized school culture has the potential to energize people, in turn supporting and driving school improvement. In contrast, a weak culture may very likely diminish a school's ability to create or maintain high student achievement. Snowden and Gorton (2002) maintained that an important element of an effective school is a positive organizational culture. School leaders who understand the significance of cultural proficiency may be able to create a more cohesive and effective organization so long as the cultural patterns, values, and beliefs are aligned with the challenges leaders face.

Guerra and Nelson (2012) outlined a multistep process for developing cultural proficiency. In the initial stage members must learn the unwritten rules and aspects of the culture. This includes the values and beliefs of the culture members are assimilating to; next, members identify the barriers to equity engrained in the organization. Obstacles are often established by long standing faculty; finally, members hone cultural skills to include mindfulness and cultural responsiveness. Guerra and Nelson (2012) further maintained that in the pursuit of proficiency and sustainability members face the prospect of transcending these foundational skills at the risk of criticism by other members. In comparison, Snowden and Gorton (2002) offered the following five important cultural 
elements of an effective school: (a) a positive organizational culture, (b) emphasis on academic effort and achievement, (c) belief that all students can learn, (d) ongoing faculty development and innovation, and (e) a safe and orderly learning environment (pp. 116-117). Snowden and Gorton (2002) reported that each of these elements could be influenced and changed over time if the right circumstances exist. Aside from ongoing faculty development, each of the elements presented by Snowden and Gorton correlate with the AQ questions relative to this study.

Schein (2010) complimented the elements presented by Snowden and Gorton by offering a method by which to analyze culture at different levels. Schein states, Some of the confusion surrounding the definition of what culture really is results from not differentiating the levels at which it manifests itself. These levels range from very tangible overt manifestations that you can see and feel to the deeply embedded, unconscious, basic assumptions that I am defining as the essence of culture (p. 23).

The shared basic assumptions play a significant role in culture. Shared assumptions amount to how people perceive, think, and feel about the routines and rituals that make up the culture. School cultures are no different, in that, there are behaviors and practices that occur over and over, day after day with very little thought as to why the behaviors occur. These actions are embedded in the attitudes and behaviors of the members, making up the culture. The daily routines carried out will either breed success or failure for the group (Bolman \& Deal, 2003).

Schein (2010) expounded upon his definition by offering three levels of culture; (1) artifacts, which include visible structures, processes and observed behavior, (2) 
espoused beliefs and values including goals, values, aspirations, ideologies and rationalizations, (3) basic underlying assumptions which are viewed as unconsciously taken. Members of a faculty are able to observe Schein's levels of culture, however, when faculty members don't hold these as truths the members can be viewed as nonmembers of the group since they do not subscribe to the basic beliefs of the group. The definition provided by Schein highlights the human need for stability provided through the culture. Additionally, members of a group seek consistency, and meaning in their daily work. The human needs are met through accumulated learning among a group. As a group learns together the members develop unique qualities and nuances that ultimately become the foundational components of the culture the members will function within. Individuals may find themselves putting aside personal beliefs in order to find a fit within the group the members work with. Conversely, individuals' own beliefs and practices may shape the direction of the culture. Over time the daily functions of the group shape the embedded culture and as time progresses the culture is passed on to new generations. The dynamics that make up culture are not written down and handed to new members of the group; rather, the rituals are discovered as new members gain a more permanent status. "Culture is a mechanism of social control and can be the basis of explicitly manipulating members into perceiving, thinking, and feeling in certain ways" (Schein, p. 20-21).

Hoy and Tarter (1992) presented their own dimensions of culture described as levels of organizational health. The first level is defined as technical and includes morale, cohesiveness, and academic emphasis. Morale suggests there is a degree of openness, trust, friendliness and enthusiasm among staff members while cohesiveness refers to the 
extent to which teachers and administrators identify with each other. The academic component is represented by the teachers' belief systems along with the level of respect, academic expectations, order, and seriousness within the learning environment. Level two is comprised of a managerial component and directly relates to the ability of the principal to establish and articulate task and achievement oriented behavioral standards. The behaviors include influence, consideration, and initiation structures. Consideration entails collegiality, supportiveness, openness, and friendliness on the part of the leader. The final level is referred to as the institutional level. The focus here is on the manner in which the environment is managed to maintain integrity of the educational programs.

In an attempt to sustain integrity to embedded practices Fullan (2005) established eight elements of sustainability for school culture that include: (a) public service with a moral purpose, (b) commitment to changing context at all levels, (c) lateral capacity building through networks, (d) intelligent accountability and vertical relationships, (e) deep learning, (f) dual commitments to short-term and long-term results, (g) cyclical energizing, and (h) the long lever of leadership (p. 14). Fullan established that these elements support and drive school culture and that each element could be influenced and changed over time if the right circumstances exists.

Finally, sustainability of an effective school culture can prove to be difficult during staff turnover. New members of the organization may not value the same cultural elements as current staff members, thereby, affecting the culture either positively or negatively. Adverse working conditions in high poverty settings may elevate the number of teachers seeking transfers to more affluent schools (Muhammad, 2009). High poverty schools face additional challenges in the form of unprepared students and low parental 
support. These factors affect culture through the academic expectations and the lack of relationships between parents and school staff (Payne, 1998).

\section{Poverty}

In education, achievement gaps refer to the disparity in academic performance between groups of students. Achievement gaps are most often used to describe the range in datasets like achievement, attendance, and graduation rates between African-American and Hispanic students at the lower end of the performance scale, and their white peers. Additionally, educators often analyze the academic disparity between high poverty and affluent students. The disaggregation of data became more pronounced after the signing of NCLB and the disparity between subgroups became more evident as educators identified specific areas of deficit in student performance. These findings became more significant when coupled with current research on poverty that found low student achievement to be closely correlated with lack of resources, and studies have documented the correlation between low socioeconomic status and low achievement (Hodgkinson, 1995). There is evidence that current practices are not producing the results needed for the changing demographics within our schools. More specifically, student achievement showed sharp declines when the school poverty concentration rose above $40 \%$ (Lippman, Burns, \& McArthur, 1996).

An important aspect of this study is the level of poverty and the impact poverty has on education. Poverty encompasses many aspects of society, and education is not immune to the effects poverty has on people and organizations. There are over 16,000 public schools, with roughly 17\% considered "high-poverty" (Green, 2011). Additionally, of the 16 million poor children in 2010 an estimated 6.5 million children under the age of 
18 lived with an unemployed parent (Issaacs, 2011). Issaacs also found that childhood poverty had risen by at least one percentage point per year from 2007 to 2010, increasing from 18 to 22 percent (p. 2). Furthermore, Srauss (2010) reported that a government analysis of schools in the U.S. indicates one in six students attending a public school do so in a high poverty school and the percentage of high-poverty schools has significantly increased over the past decade. Eric Jensen (2009) maintained that we currently have a very broad research base outlining the educational ramifications of living in poverty. Strauss further supported Jensen's notion by stating "It also confirms what we've long known: student achievement at high-poverty schools is lower than at other public schools" (p. 1).

Poverty status is determined by comparing annual income to a set of dollar values called thresholds that vary by family size, number of children, and age of householder (Bishaw \& Macartney, 2011). If a family's before tax money income is less than the dollar value of their threshold, then that family and every individual in it are considered to be in poverty. For people not living in families, poverty status is determined by comparing the individual's income to his or her threshold. For the purpose of determining a school's poverty level the number of free and reduced lunch students are calculated. President Harry S. Truman signed the Richard B. Russell National School Lunch Act into law in 1946. This United States federal law created the National School Lunch Program (NSLP) to provide reduced price or free school meals to low-income families. The program was originally intended to increase food prices by absorbing farm surpluses while proving help to school age children. School districts are reimbursed for meals served and the program serves 30.5 million children each day. In 2007 the program cost 
$\$ 8.7$ billion (U.S. Department of Agriculture, 2014). The U.S. Department of Education identifies schools with $35 \%$ of the student body on free and reduced lunch as high poverty, and schools with $75 \%$ or more students as very high poverty (U.S. Department of Education, 2010).

Ruby Payne (2005) presented generational and situational as two types of poverty affecting children. Families in generational poverty were identified as living in poverty for at least two generations, whereas, situational poverty is exacerbated due to a particular event. The two groups live by different hidden rule within their culture. These rules are carried over to the school setting and have an impact on the interaction parents of poverty have within the school culture, thereby impacting student achievement. Jensen (2009) agreed with Payne's two classifications and further elaborates by adding four more dimensions to poverty; the dimensions include absolute poverty, relative poverty, urban poverty, and rural poverty. Absolute poverty entails a rare yet deep level of poverty in the United States. Absolute encompasses a struggle to attain the basics of food, water, and shelter. Relative poverty is formed around the relationship of a family's income and the average standard of living. The latter two forms of poverty outlined by Jensen are defined by the population size in the community. Jensen proposed that each of these forms of poverty pose risk factors that make everyday living a struggle for families living in poverty. Perhaps more concerning is Jensen's notion that these risk factor are interwoven with one another, thereby causing a perpetual cascade of consequences that materialize at home and school, placing poor children at risk for low academic performance and failure to complete school. Jensen reported the two most significant factors that impact student achievement in high poverty settings are attendance and 
parental involvement. As a remedy, Jensen proposed that the school culture must transform from pity to empathy in which teachers express a feeling of caring rather than giving up. Jensen's notion was that by changing the cultural foundation there would be an identifiable impact on the students' desire to attend school and the parents' feelings of acceptance within the school.

A better understanding of poverty and the implications for students and their behaviors is needed for educators to overcome the hurdles faculty confront at school (Payne, 2005). Evans (2004) explained, "Poor children confront widespread environmental inequities. Compared with their economically advantaged counterparts, they are exposed to more family turmoil, violence, separation from their families, instability, and chaotic households" (p. 77). Additionally, Evans (2004), Bennett et al. (2004), and Barton (2003) found that school environments differ among students from low-income families and their more affluent peers. They found, for example, that schools with high percentages of low income students were at an increased risk of facing lower quality teachers, less rigorous curriculum, reduced expectations for academic performance and students were less likely to enroll in rigorous course work. Additionally, researchers found a lower rate of parent engagement in terms of volunteering at school, attending school functions, and follow-through with homework completion. Furthermore, Muhammad (2009) found "Minority students and students of poverty have much lower graduation rates than the national average" (p. 6). Families living in poverty usually do not value school or education (Payne, 2005). As a result, students from impoverished families often come to school already lagging behind their more affluent counterparts. Hodgkinson (1995) found low achievement to be closely 
correlated with a lack of resources for students of poverty. Connell (1999) reported that the lack of resources hinders progress towards higher achievement; therefore, students typically score lower on standardized tests and are more likely to be retained.

The impact of poverty on academic success should alarm school leaders when coupled with the fact that NCLB and Top 10 by 20 specifically targeted schools receiving Title I funds that are not keeping pace academically with more affluent schools. Schools are eligible for Title I assistance if their poverty rate is at least equal to the district-wide average or is at least $35 \%$; however, districts may choose to target their Title I funds to schools with higher poverty levels as long as there is consistency in how the schools are identified and served. The purpose of Title I funding is to ensure that all children have a fair, equal, and significant opportunity to obtain a high-quality education and reach, at a minimum, proficiency on challenging state-level academic achievement standards and state academic assessments (U.S. Department of Education, 2010). Meeting NCLB proficiencies requires school leaders to close the achievement gaps between subgroups. Closing the achievement gap, however, becomes a monumental task for school staff when faced with socioeconomic barriers. In fact, Muhammad (2009) found that "Since the implementation of NCLB, we have seen no significant progress in closing achievement gaps in student performance" (p. 9). "To improve achievement, however, we will need to rethink our instruction and instructional arrangement" (Payne, 1998, p. 116). The problem is there are no school improvement models supported by a research base (Manwaring, 2012). "If there was such a clear research-based model for turning around low-performing schools, then there would not be so many of them" (Manwaring, p. 13). 
Noguera (2014) stated "School reform efforts can't ignore the effects of poverty on children's lives or on the performance of schools" (p. 1). Transforming high poverty schools from low achieving to high performing is one thing, creating a culture that can sustain continual growth over time is another. High poverty schools face addition challenges towards meeting the demands of school improvement. Ultimately all schools, including high poverty schools, are expected to produce high achieving students. Poverty, although a factor in this success, cannot be an excuse for not obtaining the goal.

\section{Gold Star Schools}

The Gold Star Schools Program, which started during the 1991-92 school year, honors public and private elementary, middle and high schools that are either academically superior or that demonstrate dramatic gains in student achievement. There are three phases that the Gold Star Program has gone through. The precursor to Gold Star began in the first phase, which ran from 1982-1991, consisting solely of the U.S. Department of Education's Blue Ribbon Schools Recognition Program. During the first three years of phase one only secondary schools were recognized and later elementary school were included on alternating years by the Missouri Department of Elementary and Secondary Education (DESE). The second phase ran from 1991-2002 and included both state and national recognitions. It was during this time that Missouri adopted the Missouri Gold Star Schools Program. Only schools that were identified as Gold Star would be nominated for the national Blue Ribbon Award. Missouri can nominate up to eight schools for the national Blue Ribbon Award and three of the nominees must represent disadvantaged schools. As in previous years, the program honored elementary and secondary schools in alternating years. The third phase of the program began in 2002 and 
the order for identifying schools was reversed. During this phase schools that met the U.S. Department of Education's criteria for high performance or dramatic improvement would then be invited to apply for the Missouri's Gold Star School Program. While the national program placed emphasis on assessment data, additional criteria was established for Missouri's program, As a result, some schools that were recognized as Blue Ribbon Schools nationally, either did not apply for, or did not qualify for the Gold Star Program (DESE, 2014).

The criterion to apply for the Gold Star Award has changed over time. Schools in Missouri must meet the national Blue Ribbon criteria to be considered for the Gold Star Award. Current criterion requires schools to be in the top $15 \%$ in the most recent year tested, based on student performance in both reading and math, or the performance of all students tested in each of the school's subgroups in the most recent year in reading and math be in the top $40 \%$ of all schools in the state (DESE, 2014). Missouri identifies these two criteria through Annual Measurable Objectives (AMO). Missouri reports AMO determinations for students in the aggregate, low-income students, students with disabilities, English Language learners, and the state's major racial and ethnic subgroups. The established AMO proficiency targets for 2014 are $60.80 \%$ for math and $59.60 \%$ for language arts. The AMO's refer to the percent of proficient students on the Missouri Assessment Program (MAP) tests (DESE, 2014).

Applying for the Gold Star recognition is voluntary and not all schools that apply are chosen. In fact, up until 2010 only 48\% that applied received the award. Since 2010 all school that have applied for the award have received it. Since the inception of the Gold Star Program 533 schools have applied, and 264 (49\%) have received the award. 
Only $40 \%$ of the recognized schools between $2007-2012$ have a poverty rate above $50 \%$ (DESE, 2009). For the purpose of this study high achieving schools are identified as Missouri Gold Star Schools between 2007-2012. In contrast, low performing schools in this study do not meet the criteria for Gold Star status and are below the $55^{\text {th }}$ percentile on the MAP and fall below the top 10\% of all schools across Missouri between 2007-2012.

\section{Student Performance}

Currently the U.S. Department of Education defines school improvement through NCLB as the ability for schools to make Adequate Yearly Progress (AYP) (U.S. Department of Education, 2011). The NCLB guidelines for AYP are dictated by increasingly higher criteria for the number of students identified as proficient or advanced on state administered assessments.

The 2002 No Child Left Behind Act stipulates that states receiving Title I federal funds under the Elementary and Secondary Education Act (ESEA) must have a statewide accountability system (U. S. Department of Education, 2007) which is based on the premise of making adequate yearly progress (AYP). AYP measurements target the performance of various subgroups based on race or ethnicity, socioeconomic status, disability, and English proficiency. Each state determines the assessment that will be used as the measurement. Chosen assessments must provide criteria that can identify students as below proficient, proficient, or above proficient. The goal of NCLB was to have $100 \%$ of students proficient in reading/language arts and mathematics by 2014. McNeil (2012) found that the percentage of the nation's schools that failed to make AYP hit nearly $50 \%$ in 2011. Even more concerning, U.S. Secretary of Education Arne Duncan warned Congress that $82 \%$ of schools in America might not reach AYP in 2013. The sanctions 
placed on school districts failing to make AYP are steep. Federal law allows districts to determine how their schools get restructured; however, past experience has shown drastic outcomes including staff changes, school closures, and even state takeovers. Table 1 depicts the consequences outlined by No Child Left Behind for schools not making AYP. Table 1

NCLB Consequences by Year

\begin{tabular}{lccccc} 
Consequences & Year 1 & Year 2 & Year 3 & Year 4 & Year 5 \\
\hline School Choice & $\mathrm{X}$ & $\mathrm{X}$ & $\mathrm{X}$ & $\mathrm{X}$ & $\mathrm{X}$ \\
Supplemental services & & $\mathrm{X}$ & $\mathrm{X}$ & $\mathrm{X}$ & $\mathrm{X}$ \\
Corrective action & & & $\mathrm{X}$ & $\mathrm{X}$ & $\mathrm{X}$ \\
Restructuring (planning) & & & & $\mathrm{X}$ & $\mathrm{X}$ \\
Restructuring (implementation) & & & & & $\mathrm{X}$ \\
\hline
\end{tabular}

In Missouri assessment criteria is tied to the Missouri Assessment Program (MAP) data governed by the Missouri Department of Elementary and Secondary Education (DESE). The MAP assessment is administered in grades 3-8 for mathematics and communication arts. Results from the assessment identify students as below basic, basic, proficient, or advanced according to the overall scale score. Scores are then totaled for individual sub groups and AYP is determined by the percentage of students that scored proficient or advanced within each subgroup. Subgroups include Asian/Pacific Islander, American Indian/Alaskan Native, Black, Hispanic, White, Multi-Racial/Other, Limited English Proficient (LEP), Individual Education Program (IEP), and free and reduced lunch (F/R). Additionally, the total group within a grade level is also considered a subgroup, and the combined subgroups for a building are referred to as the Supersubgroup (DESE, 2014). For the purpose of AYP any given student can be included in more than one group as long as the students meet the criteria for the group the students are attached to. When any one or more subgroups do not meet the established percentage 
of students in advanced or proficient in the same content area for two consecutive years the school as a whole does not make AYP, thereby placing the school in year one school improvement (DESE, 2014).

\section{Missouri School Improvement Program}

In 1990 Missouri began using the Missouri School Improvement Program (MSIP) as the accountability system for schools. MSIP works to prepare every child for success in school and life. The current version, MSIP 5, is the state's school accountability system for reviewing and accrediting the 520 public school districts in Missouri. The process is driven through the four goals of articulating the state's expectations for student achievement with the ultimate goal of all students graduating ready for success in college and careers; distinguishing performance of schools and districts in valid, accurate, and meaningful ways so that districts in need of improvement can receive appropriate support and interventions, and high-performing districts can be recognized as models of excellence; empowering all stakeholders through regular communication and transparent reporting of results; and promoting continuous improvement and innovation within each district (DESE, 2014).

In 2012 Missouri applied for, and obtained, a waiver as part of the Elementary and Secondary Education Act (ESEA) (DESE, 2012). As part of the ESEA/ NCLB Waiver and the MSIP process, Top 10 by 20 was adopted. Top 10 by 20 was designed to utilize Missouri's Annual Performance Report (APR) system to identify Reward, Focus and Priority schools. Focus schools are Title I schools where the Student Gap Groups are among the lowest performing in the state over a three year period. The Gap Group is defined by the difference in student achievement in state assessments between the total 
student population and the Super-subgroup. The Super-subgroup is made up of all students that fall into one of nine identifiable subgroups: Asian/Pacific Islander, black, Hispanic, American Indian, white, multi-racial, students with disabilities, English language learners, and low income. The number of Focus Schools must equal or exceed $10 \%$ of the state's Title I schools. In addition, some schools are identified as Priority Schools; these are among the lowest performing Title I schools in the state for overall student achievement in English language arts and mathematics on state assessments over a three year period, or Title I participating or eligible high schools that have a graduation rate below $60 \%$ for three consecutive years. The total number of Priority Schools is at least five percent of all Title I schools in the state. Reward School are schools that are in the top $15 \%$ of school across the state in regards to the percent of students that are proficient on the state assessments (DESE, 2012).

An additional aspect of the MSIP accountability is the Advanced Questionnaire (AQ) survey. AQ is used by the state to evaluate educational processes in a district. The survey was developed and is revised each MSIP cycle by a team of DESE staff, Office of Social and Economic Data Analysis (OSEDA) staff, and practicing educators. AQ collects data from staff, students, and parents during the year the district is going through the MSIP review process. For this study four questions on the staff survey were extracted for analysis. The four faculty items are:

1. This school makes students feel they belong.

2. Our school promotes an environment of mutual respect among students.

3. Teachers and administrators value student opinions.

4. If students on this school have a problem, teacher will listen and help. 
The Office of Social and Economic Data Analysis (OSEDA) identified these specific survey components as key indicators of school climate. These items, however, meet the findings by Gruenert (2008) as defining culture as apposed to climate. Gruenert established that culture is represented by the long-term commitments of a group, whereas climate is viewed as behavioral changes impacted by day-to-day events. The AQ items for this study represent embedded behavior.

\section{Summary}

This literature review focused on four key concepts. First, an examination of organizational culture was presented as the theoretical framework for this study. The review then funneled down to more specific school culture to include past research and current findings. Additionally, elements of school culture were presented and the notion of long-term sustainability of culture was discussed. Findings from multiple researchers were presented for the purpose of exploring culture in a more comprehensive manner. Research indicates that for sustainability of school culture the members of the organization must identify and share common values and beliefs. It was further established that culture might have some level of impact on student achievement. Next, research was presented to better understand school improvement along with background information concerning Adequate Yearly Progress (AYP) and the implications for schools. Additionally, the Missouri Gold Star Schools Program was presented which supported the rationale for determining the schools in this study. Lastly, the review presented findings on poverty and the effects on school culture and school improvement.

Fraenkael and Wallen (2003) noted that when observing a relationship between two or more variables a correlation is being sought. "One of the basic purposes of 
correlation studies is to predict likely outcomes" (p. 338). If a correlation is found it is likely that if one element is in place, another is likely to occur. For this study, the potential relationship between perceived school culture, as determined by results from the Missouri's Advanced Questionnaire survey, and student achievement is being considered. 


\section{CHAPTER THREE}

\section{RESEARCH DESIGN AND METHODOLOGY}

Schools across the nation are required to maintain or progressively increase the number of students scoring proficient or advanced on state administered assessments (U.S. Department of Education, 2010). School improvement is an ongoing process since the proficiency bar continues to climb each year, requiring schools to continuously show growth in student achievement. Schools that do not make Adequate Yearly Progress (AYP) are identified for improvement. Unfortunately, Muhammad (2009) discovered that districts across the country have not been able to close the achievement gaps among subgroups since the inception of NCLB. The ramifications for this are steep for two reasons; first, at some point in the process, if achievement gaps are not being closed among subgroups, it becomes near impossible to meet AYP targets; second, schools not meeting AYP targets face serious state and federal sanctions. As part of the Elementary and Secondary Education Act (ESEA) waiver offered by the U.S. Department of Education, Missouri has implemented the Top 10 by 20 initiative to support districts and hold them accountable to raising student achievement.

Extensive research has been done to better understand student achievement as it relates to specific factors (Jensen, 2009; McNeil, 2012; Manwaring, 2012). However, Muhammad (2009) maintained that research has yet to confirm the specific elements that contribute to raising school achievement across multiple school settings. Consequently, school leaders are unclear on the exact recipe for success. Bush (2003) proposed that leaders' time is generally consumed by more managerial duties as apposed to instructional leadership. Although managing the day to day activities is important there 
are other components to school improvement that must be addressed and leaders must take a comprehensive viewpoint if achievement is expected to continue to rise to mandated levels. One perspective often overlooked by school leaders is the impact school culture can have on student achievement. School culture has been portrayed as an important but often overlooked component of school improvement by several authors and researchers (Levine \& LeZotte, 1995; Sizer, 1988; Phillips, 1996; Peterson \& Deal, 1998; Frieberg, 1998). Stolp and Smith (1995) presented culture as a means to transcend other methods of capturing the powerful transformational force in schools. If specific elements of culture can be identified in successful high poverty schools, the findings may be helpful to school leaders towards overhauling low performing schools.

Some schools across Missouri have met or exceeded expectations of state and federal mandates and have achieved Gold Star status as outlined by the Missouri Department of Elementary and Secondary Education (DESE) (DESE, 2014). The Gold Star Schools Program honors public and private schools that are either academically superior or that demonstrate dramatic gains in student achievement. Only schools that meet either of these two criteria are eligible to apply for the Gold Star Award. Not all schools that apply receive the award because the DESE limits the number of schools recognize each year. For the purpose of this study data will be collected from high poverty schools that have received the award and used to compare against high poverty school that were not eligible to receive the award.

This study is designed to utilize the Missouri Advanced Questionnaire (AQ) portion of the Missouri School Improvement Program (MSIP) accreditation process (Missouri Department of Elementary and Secondary Education [DESE], 2011). The 
Office of Social and Economic Data Analysis (OSEDA) identified specific survey components as key indicators of school culture. The questions extracted from AQ are from survey item 6.5.1.3a; the degree to which all students feel respected and valued. The four faculty questions are: (a) this school makes students feel they belong, (b) our school promotes an environment of mutual respect among students, (c) student opinions are valued by teachers and administrators, and (d) if students in this school have a problem, teachers will listen and help. These items will be extracted from the survey data and used to compare results between two groups of school, both with a free and reduced lunch rate of $50 \%$ or higher. As outlined earlier in this study, the first group will be identified as high performing and the second group identified as low performing. The performance is determined by student achievement results collected through the Missouri Assessment Program (MAP).

This chapter will first outline the purpose of the study and the research questions to be answered. Next, this chapter will articulate the overall design of the study including the population studied, the methods of data collection and the type of analysis to be conducted.

\section{Purpose}

For the purpose of this study the Advanced Questionnaire (AQ) survey responses between high and low performing schools will be compared. More specifically, this quantitative study will examine the potential differences in AQ responses, between high poverty, high achieving schools and high poverty, low-achieving schools. Both groups maintain a free and reduced lunch rate of $50 \%$ or higher. As a result of this study it is anticipated that an examination of the potential relationship between the perceived school 
culture and student achievement may reveal whether there are elements of school culture that lead to or impede student achievement in high poverty schools.

This study will utilize survey data collected through the AQ survey administered to school staffs, parents, and students across the State of Missouri. Portions of data collected through the AQ are directly tied to school culture, therefore, provides a dataset meaningful to this study. The Missouri Department of Elementary and Secondary Education (DESE) report AQ survey results by school and district on an annual basis. All schools across Missouri do not administer the AQ within the same year; however, regardless of the year administered the same survey items are given to all schools. Therefore, the results collected are consistent across years. A concept map of the study is outlined in Figure 1. 


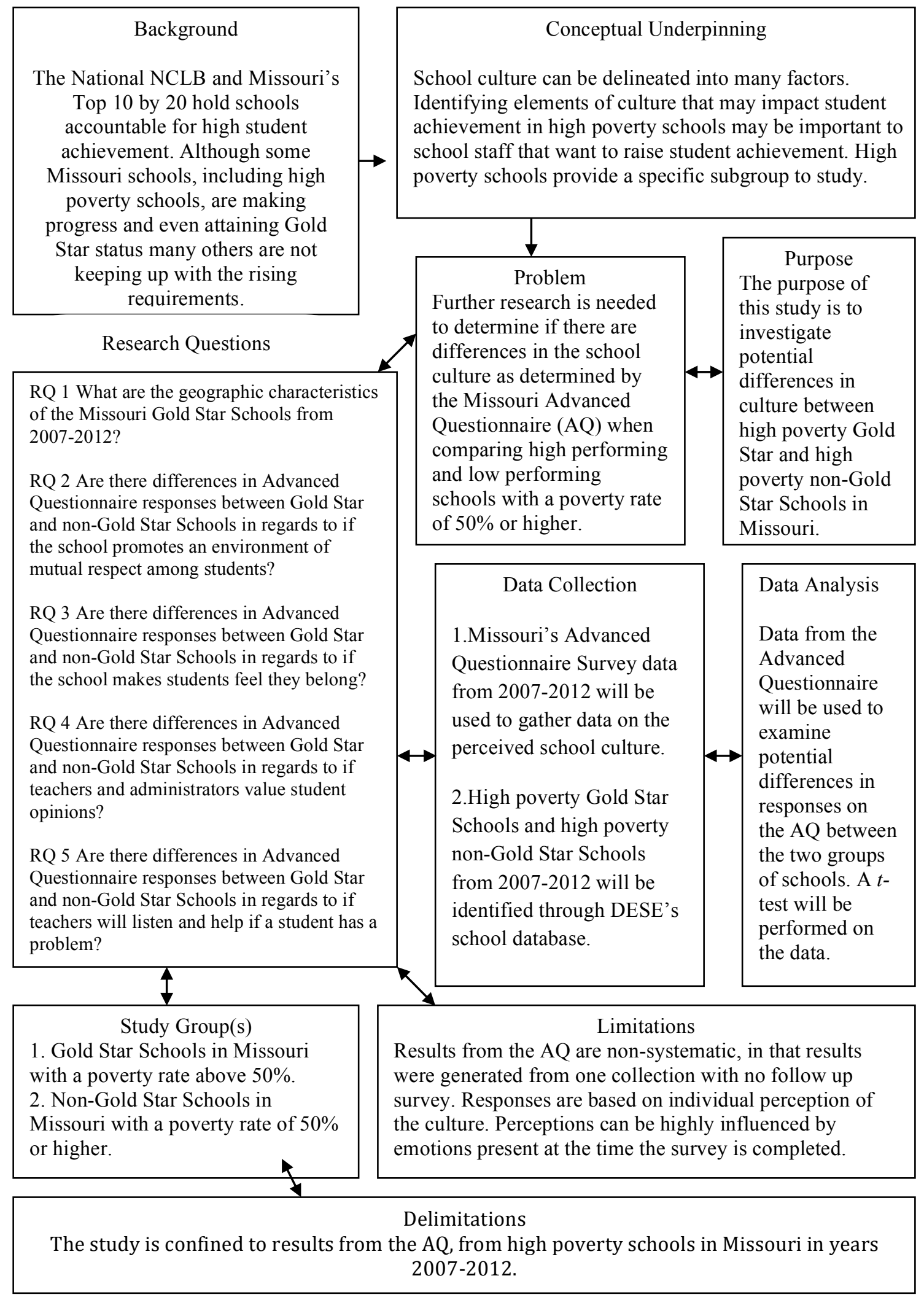

Figure 1. A concept map outlining the structure of this research study 


\section{Research Questions}

With the purpose of this study in mind, four primary questions were extracted from the Advanced Questionnaire (AQ) survey that focuses the context of this study. As a result, the following key questions are addressed:

1. What are the geographic characteristics of the Missouri Gold Star Schools from $2007-2012 ?$

2. Are there differences in Advanced Questionnaire responses between Gold Star and non-Gold Star Schools in regards to if the school promotes an environment of mutual respect among students?

3. Are there differences in Advanced Questionnaire responses between Gold Star and non-Gold Star Schools in regards to if the school makes students feel they belong?

4. Are there differences in Advanced Questionnaire responses between Gold Star and non-Gold Star Schools in regards to if teachers and administrators value student opinions?

5. Are there differences in Advanced Questionnaire responses between Gold Star and non-Gold Star Schools in regards to if teachers will listen and help if a student has a problem?

\section{Null Hypotheses}

The study tested the following null hypotheses:

$\mathrm{H}_{0}$ 1. There are no differences in Advanced Questionnaire responses between Gold Star and non-Gold Star Schools in regards to if the school promotes an environment of mutual respect among students. 
$\mathrm{H}_{0} 2$. There are no differences in Advanced Questionnaire responses between Gold Star and non-Gold Star Schools in regards to if the school makes students feel they belong.

$\mathrm{H}_{0} 3$. There are no differences in Advanced Questionnaire responses between Gold Star and non-Gold Star Schools in regards to if teachers and administrators value student opinions.

$\mathrm{H}_{0} 4$. There are no differences in Advanced Questionnaire responses between Gold Star and non-Gold Star Schools in regards to if teachers will listen and help if a student has a problem.

\section{Research Design}

This study seeks to identify if there are climate factor differences between high poverty Gold Star and high poverty non-Gold Star Schools in Missouri.

Muhammad (2009) states:

An examination of the current environment and conditions in our schools can help us understand the myriad of paradigms that exist within the walls of our public schools and therefore help us strategize to transform the environment into a healthy one, (p. 17)

The research design for this study will consist of a one-shot non-experimental quantitative design. A quantitative design is being utilized due to the number of responses needed, allowing the researcher to collect input from a higher number of participants in a short amount of time. Due to the large quantity of data, statistical computer software (SPSS) will be used to conduct data analysis through an independent $t$-test, as this will allow for a comparison of two independent groups. An independent means $t$-test "is used 
when there are two experimental conditions and different participants were assigned to each condition" (Field, 2009, p. 324). In essence, the $t$-test for this study will be used to test whether two group means are significantly different. When the independent $t$-test is used to test different groups of people it can be assumed that variances in these populations are roughly equal (Field, 2009).

\section{Setting and Population}

Utilizing Advanced Questionnaire (AQ) data, this study seeks to identify if there are differences in survey responses that pertain to cultural factors between two groups of schools from across Missouri between the years of 2007 and 2012. One group is made up of high poverty schools that have excelled in student achievement and have earned the Missouri Gold Star award through the Missouri Department of Elementary and Secondary Education (DESE). The recognition is tied directly to the number of students scoring advanced or proficient on the Missouri assessment Program (MAP). The second group of schools is made up of high poverty non-Gold Star Schools that have been identified as schools that did not qualify for Gold Star and have either one or both of English language arts or math MAP scores with less than $55 \%$ of students scoring proficient or above. Both groups of schools have a free/reduced lunch rate of $50 \%$ or above.

A total of 65 schools from across Missouri make up this study, which includes 26 Gold Star Schools representing the high achieving, high poverty schools and 39 schools representing high poverty, low-achieving schools. Responses were collected from 1,645 participants. Respondents are made up from across elementary, middle and high schools. Table 2 delineates the demographic of the participating schools. 
Table 2

Types of Schools Studied and the Number of Participants

\begin{tabular}{lccc}
\hline Data Subset & Gold Star & Non-Gold Star & Totals \\
\hline Elementary schools & 16 & 37 & 52 \\
Middle schools & 1 & 1 & 2 \\
High schools & 9 & 1 & 10 \\
Total Schools & 26 & 39 & 65 \\
Elementary participants & 335 & 996 & 1,331 \\
Middle school participants & 13 & 33 & 46 \\
High school participants & 228 & 40 & 268 \\
Total Participants & 576 & 1,069 & 1,645 \\
\hline
\end{tabular}

\section{Data collection and Instrumentation}

\section{Advanced Questionnaire}

This study utilizes data collected from the Advanced Questionnaire (AQ) survey developed by the Office of Social and Economic Data Analysis (OSEDA). The mission of OSEDA is to collaborate with agencies to collect and analyze social and economic data for the purpose of enhancing the well being of people, enterprises and communities (OSEDA, 2014). The AQ was originally developed in the late 1980's through a team effort involving researchers with survey experience (OSEDA-University of Missouri) and educators who were members of the statewide Missouri School Improvement Program (MSIP) committee responsible for setting up the MSIP standards at that time, along with some participants from DESE. The first AQs were administered in the spring of 1990 in preparation for the first MSIP reviews the following year. Many of the items included in the original AQ were based upon the Effective Schools literature (Edmonds, 1979), and also reflected the judgments of the MSIP state advisory committee. Some of the items on the original AQ were also adapted from the National Educational Longitudinal Study 
(NELS), conducted by the U.S. Department of Education. The AQ use a "census" methodology so that a high percentage of teachers and students respond.

The AQ was developed based on current research in school effectiveness and best practices and includes questions about the learning environment of the school. Means for individual questions are grouped thematically, and scale variables are created for the different indicators (Preis, 2009). The AQ provides perceptual data through questionnaires that offer school stakeholders with a voice concerning various aspect of school life. Survey questions are derived from research-based elements pertaining to multiple aspect of school life, including school culture. Longitudinal data are available from 1990 to present in the form of legacy scales and items. Unlike many perceptual data collection tools and processes, the AQ offers reliability and validity checks (DESE, 2011).

Fink (2009) describes surveys to be "information collection methods used to describe, compare, or explain individual and societal knowledge, feelings, values preferences, and behaviors" (p. 1). The MSIP uses AQ survey data obtained from multiple groups as part of Missouri's public school accreditation process (DESE, 2011). The AQ consists of six separate questionnaires specific to the following audiences: 1) elementary students in grades 3-6, 2) secondary students in grades 6-12,3) parents, 4) faculty, 5) support staff, and 6) district-level Board of Education. All parents of students (grades K-12) enrolled in the district and all staff members are provided the opportunity to complete a survey as part of the MSIP process. Additionally, students in grades 3-12 are invited to complete a student survey. The AQ is offered to school districts during the semester prior to a scheduled five-year MSIP review. Districts are given an option to add 
up to an additional ten questions to all surveys with the exception of the elementary (grades 3-4) and the elementary (grade 5) forms. The additional questions were not chosen for this study due to the lack of consistency and validity in the questions formulated by districts.

Each questionnaire on the AQ contains a battery of questions, most of which are Likert-type scale questions. Each questionnaire presents a series of declarative statements, and provides the respondent with a mechanism to indicate their response corresponding to one of five alternatives: strongly disagree, disagree, neutral, agree, or strongly agree. These response types are assigned numerical values from one to five respectively. Any district reporting significant deficiencies in the return rate of the surveys from any group are given an option to re-administer to the specific group identified, or to not have disaggregated results for any particular building. Deficiencies in survey responses are based on the following return rate percentages: staff $-73 \%$, student$85 \%$, and parent-53\% (Missouri Department of Elementary and Secondary Education [DESE], 2011).

The AQ consists of 261 questions with 104 on the faculty questionnaire, 59 parent questions, 19 for elementary students, and 79 for high school. Fourteen of the 261 questions pertain to school culture. This study will utilize data collected from four questions extracted from the faculty questionnaire. Each of the four questions has been identified by the DESE and the OSEDA as prime indicators associated with school culture (Office of Social and Economic Data Analysis, 2014). The faculty survey yielded four questions identified as "prime" climate factors encompassed in the AQ survey item 6.5.1.3a; the degree to which all students feel respected and valued and derive from the 
following four faculty questions:

Question \#69- this school makes students feel they belong.

Question \#38- our school promotes an environment of mutual respect among students.

Question \#26- student opinions are valued by teachers and administrators.

Question \#70- if students in this school have a problem, teachers will listen and help.

The questions from the AQ survey correlate with the findings of Hoy and Tarter (1992) and the later work of Muhammad (2009) and in which the beliefs, practices, behaviors, and norms are identified as the key elements of school culture. Muhammad states, "These elements make up a very sensitive system known as a school's culture" (p. 12). Additionally, Muhammad explained the notion that universal school improvement rests in our ability to address these elements in our schools. He further stated, "This is where many school officials and reformers fear to tread, but it is the place that holds the biggest key to unlocking the potential of our public schools" (p. 12).

\section{Data Analysis Procedures}

This study examines multiple elements of school culture as determined by data collected from the Missouri Advanced Questionnaire (AQ). Data from the AQ is readily available for Missouri schools depending on the MSIP cycle each participating school is in. The Missouri Department of Elementary and Secondary Education (DESE) provides AQ data to the public through their website. Data are provided through distribution summaries and frequency distribution reports. Both sources provide building averages from survey responses. Averages are separated into faculty, parents, and students. In addition, the building averages and respondent type averages are provided by prime indicators, allowing the researcher to extract data that pertains specifically to faculty 
responses specific to indicators relative to school culture. Only schools identified by the DESE as having a free and reduces lunch rate of $50 \%$ or higher will be extracted for this study. Once extracted the building averaged were transferred to an Excel spreadsheet in preparation for use with SPSS. Results were then grouped according to whether the school is high achieving or non-high achieving as determined by the 2007-2012 MAP results. For the purpose of this study assessment data from the DESE database was used. High achievement is defined by the Gold Star status and low achievement is defined as schools that do not meet the criteria for Gold Star status and are below the $55^{\text {th }}$ percentile within the Missouri Assessment Program results.

From this point, high achieving schools were analyzed to determine if they had been identified by the DESE as a Gold Star School between 2007 and 2012. From this work, the data were organized into two groups; first, high achieving schools that received the Gold Star Award and have a greater than 50\% free and reduced rate; second, lowachieving schools that have never been eligible to obtained Gold Star status and have a free and reduced rate of greater than $50 \%$.

Once organized, the researcher analyzed the data for possible similarities or differences between the AQ survey responses on the cultural indicators between the two groups. A $t$-test was administered on the data to identify potential differences between the two groups.

\section{Summary}

Moore (2001) asserts educational reform will only "take place under certain conditions and in specific settings" (p. 12). Continuous reform requires the right combination of elements present in the school's culture. Muhammad (2009) contends 
When a school has a healthy culture, the professionals within it will seek the tools that they need to accomplish their goal of universal student achievement; they will give a school new life by overcoming the staff division that halts transformation (p. 16).

Within this paper, the researcher explained the purpose for this study and identified research questions that would be addressed. The theoretical framework was outlined for this study along with subsequent methods of surveying participants. The researcher then described the thinking behind the population chosen. In addition, the design of this study was explained. The researcher described the methods of data collection and the instruments to be utilized. Finally, the researcher articulated how the data would be analyzed and the methods used in developing the findings. 


\section{CHAPTER FOUR}

\section{PRESENTATION AND ANALYSIS OF DATA}

The problem and purpose of this study established the methodology and analysis of data. The researcher ascertained there was no known study that determined if there are differences in the responses collected from the faculty portion of Missouri's Advanced Questionnaire (AQ) survey when asked about the school culture. Differences in AQ responses were analyzed between two contrasting groups of high poverty schools. One group of schools, identified as high performing, had been recognized by the Missouri Department of Elementary and Secondary Education (DESE) as Gold Star Schools (DESE, 2014). The second group of schools was identified as low-achieving schools. The achievement levels of both groups were measured by their performance on the Missouri Assessment Program (MAP) from 2007-2012. MAP is an annual series of assessments administered through the DESE, in which students in grades 3-8 take grade level assessments in communication arts and mathematics. A science assessment is administered in $5^{\text {th }}$ and $8^{\text {th }}$ grades (DESE, 2011).

The purpose for using the MAP assessments to help guide this study was to utilize a valid and reliable dataset that was administered across the state of Missouri by all of the participating schools in the study. The MAP assessments are given annually to all public schools in Missouri and the guidelines for administering the tests are consistent across the state and are monitored by the DESE. The assessment data are collected, maintained and provided by the DESE and can be retrieved for present years along with historical data by state, district and building levels. Although all of the assessments given by the DESE are used for accountability measures towards the Missouri School Improvement Program 
(MSIP), only the communication arts and math assessment components of Map between 2007-2012 were used for this study. The science assessments were not chosen as part of this study because these assessments are grade-span tests that are only given in the fifth and eighth grades and do not provide as wide of a representation of the student body as the communication arts and math assessments. In addition, the results of the science assessments are not taken into consideration for the Gold Star Schools program, which represents one group in this study.

Both groups of schools in this study were identified as high poverty schools and have a minimum of $50 \%$ of the student body accessing the free and reduced lunch program offered by the National School Lunch Program (NSLP). The criterion of 50\% was established as a result of the U.S. Department of Education guidelines, which categorizes schools into four ranges determined by the percentage of students in the school on free or reduced lunch. The four ranges consist of: (a) one to 25 percent; (b) 26 to 50 percent; (c) 51 to 75 percent; and (d) 76 to 100 percent of students (National Center of Education Statistics, 2010). For this study the top two ranges will be used to identify impoverished schools. It should also be noted that although these ranges have been established, federal guidelines allow for schools with free and reduced lunch rates as low as $35 \%$ to receive federal funding referred to as Title I. Although schools with rates as low as $35 \%$ are eligible, districts are not mandates to provide Title I funding to schools until the free and reduced rate reaches $75 \%$ (U.S. Department of Agriculture, 2014). School districts have the flexibility to decide which schools will receive Title I funding based on the needs of the district as long as the federal guidelines are followed. 
There are 524 public school districts and 2,432 public schools across Missouri. In $201475.5 \%$ of the schools were Title I, which means they had at least $35 \%$ of the student body receiving a free or reduced priced lunch (DESE, 2014). Although $75.5 \%$ of the public schools qualify as being impoverished enough to receive Title I funding, only $40 \%$ of the schools recognized as Missouri Gold Star Schools were schools with high proportions of impoverished learners. It was the disparity in these percentages that lead the researcher to investigate if the school culture, as determined by the AQ survey results, could in some way reveal if there were differences between the high poverty Gold Star Schools and the high poverty non-Gold Star School between the years of 2007-2012 across Missouri. In order to determine if there were differences, the AQ survey was examined and found to have questions directly related to school culture. The following research questions are addressed in this study:

1. What are the geographic characteristics of the Missouri Gold Star Schools from 2007-2012?

2. Are there differences in Advanced Questionnaire responses between Gold Star and non-Gold Star Schools in regards to if the school promotes an environment of mutual respect among students?

3. Are there differences in Advanced Questionnaire responses between Gold Star and non-Gold Star Schools in regards to if the school makes students feel they belong?

4. Are there differences in Advanced Questionnaire responses between Gold Star and non-Gold Star Schools in regards to if teachers and administrators value student opinions? 
5. Are there differences in Advanced Questionnaire responses between Gold Star and non-Gold Star Schools in regards to if teachers will listen and help if a student has a problem?

\section{Study Overview}

As stated in the review of literature, the conceptual underpinning of this study centered on the definition of culture offered by Schein (2010) in which he stated, the culture of a group can now be defined as a pattern of shared basic assumptions that was learned by a group as it solved its problems of external adaptation and internal integration, that has worked well enough to be considered valid and, therefore, to be taught to new members as the correct way to perceive, think, and feel in relation to those problems (p. 18).

Schein's definition was key to this study because it expounded upon the idea of shared assumptions by the members, which reflects the basic underpinnings of the AQ questions extracted from the faculty questionnaire for this study. The four faculty questions are derived from the AQ survey item 6.5.1.3a, from which faculty members were asked to rate their school in terms of the embedded behaviors of the staff in relation to the survey questions. These behaviors make up the shared assumptions referenced by Schein.

Schein's work supported the earlier findings of researchers that found relationships among the individuals in the school community, which include trust and respect, as being key component of a successful culture (Manning, 1996). Marshall (2004) later presented the additional factors of academic feedback, caring attitudes, and opportunities for input. The findings by Manning and Marshall correlate with the AQ 
questions used in this study, as all four AQ questions relate to the level of belonging, mutual respect and caring attitudes of faculty.

The subgroups in this study were instrumental since both groups had a free and reduced lunch participation rate above $50 \%$, which by federal guidelines qualifies them as impoverished. Studying only high poverty schools, not only provided a very distinct group of school, but also provided some analysis of a potentially underrepresented group of schools being recognized as Gold Star Schools in Missouri between the years of 20072012.

The facet of poverty in this study was significance as Jensen (2009) found that we currently have a very broad research base outlining the educational ramifications of poverty. Strauss (2010) further supported Jensen's notion by stating “Research confirms what we've long known: student achievement in high-poverty schools is lower than at other public schools" (p. 1). Srauss further reported that a government analysis of schools in the U.S. indicated one in six students attend a public school in a high poverty school and the percentage of high-poverty schools has significantly increased over the past decade. Equally concerning is that $75.5 \%$ of the public schools in Missouri are Title I school that receive federal assistance based on their poverty level and yet only $40 \%$ of the school recognized for Gold Star are high poverty schools (DESE, 2014).

The Gold Star Award has been used across Missouri since the 1991-92 school year and has provided a means to honor elementary, middle and high schools that are either academically superior or that demonstrate dramatic gains in student achievement. Academically superior schools rank in the top $15 \%$ in the most recent year tested, based on the total student performance in both reading and math. Schools demonstrating 
dramatic gains are represented by scoring in the top $40 \%$ of all schools in the state when comparing the performance of subgroups in reading and math for the most recent year's scores (DESE, 2014). Applying for the Gold Star recognition is voluntary and not all schools that apply are chosen. In fact, until 2010 only $48 \%$ that applied received the award. There are 2,432 schools across Missouri and since the inception of the Gold Star Program 533 schools have applied, with 264 (49\%) receiving the award. Only 40\% of the recognized schools between $2007-2012$ had a poverty rate above $50 \%$ as determined by the percentage of students receiving free or reduced lunch (DESE, 2009).

The high poverty Gold Star Schools were chosen for this study because they provide a very select group of schools. The researcher believed the group was underrepresented in relation to the total population of school that had received the Gold Star Award in Missouri between 2007-2012. In contrast, low performing schools in this study do not meet the criteria for Gold Star status and are below the $55^{\text {th }}$ percentile on the MAP and fall below the top 10\% of all schools across Missouri between 2007-2012. The purpose of the study was to determine if there were differences in the AQ responses between the high achieving Gold Star Schools and low-achieving non-Gold Star Schools when asked about school culture. Therefore, this study sought to investigate any potential relationship between the elements of high poverty, school culture and student achievement.

\section{Population and Instrument}

A total of 65 schools from across Missouri between the years of 2007-2012 make up this study, which included 26 Gold Star Schools representing the high achieving, high poverty schools and 39 schools representing high poverty, low-achieving schools. 


\section{Advanced Questionnaire Background}

Responses from the Advanced Questionnaire (AQ) were collected from 1,645

participants. The AQ has been in use since the 1980's and was developed by researchers along with educators who were members of the statewide Missouri School Improvement Program (MSIP) committee responsible for developing school accountability standards at that time (OSEDA, 2014). Many of the items the developers included in the original AQ were based upon the Effective Schools literature (Edmonds, 1979). In addition, some of the items on the original AQ were adapted from the National Educational Longitudinal Study (NELS), conducted by the U.S. Department of Education. The first AQs were administered in the spring of 1990 in preparation for the first round of MSIP reviews the following year (OSEDA, 2014).

The intent of the AQ was to develop a method of collecting data pertaining to school life that would provide the DESE officials data for accountability and to support school improvement efforts (DESE, 2011). Historically the AQ has been administered in school districts during the semester prior to a scheduled five-year MSIP review. Districts are given an option to add up to an additional ten questions to all surveys with the exception of the elementary (grades 3-5) forms. The additional questions are generated by individual districts and therefore provide no consistency or validity; therefore the added questions were not included in this study.

\section{Research Design}

The research design was a quantitative study of Advanced Questionnaire responses collected from school faculty members from elementary, middle and high schools across Missouri. Staff members from both of the study groups participated in the 
AQ survey and results were collected and made available through the Missouri Department of Elementary and Secondary Education (DESE).

The faculty portion of the AQ survey consisted of 66 total questions with four questions specific to school culture that were extracted for the purpose of the data collection (Appendix A). Each of the four questions was identified by the DESE and the OSEDA as prime indicators associated with school culture (Office of Social and Economic Data Analysis, 2014). The questions presented on the AQ are in Likert-scale format (Field, 2009). Each questionnaire presents a series of declarative statements, and provides the respondent with a mechanism to indicate their response corresponding to one of five alternatives: strongly disagree, disagree, neutral, agree, or strongly agree. These response types are assigned numerical values from one to five respectively. All surveys are collect by the DESE and results are published and released to the public

The Department of Elementary and Secondary Education provides the data in PDF format with building averages for each question on the survey, as well as a total average for the four questions related to culture. The researcher imported the data into an Excel spreadsheet so it could then be imported into the Statistical Package for the Social Sciences (SPSS) for analysis. The data were divided into two groups; one group of data expressed the survey results from the high achieving Gold Star group and the second group represented the low-achieving non-Gold Star group. The average response scores from the two groups could then be analyzed.

\section{Population}

The 1,645 participants for this study were made up from elementary, middle and high schools across Missouri. The AQ data were only analyzed for the faculty members 
of impoverished schools from 2007-2012. Table 3 depicts the numbers of participants by school type and the school type.

Table 3

Types of Schools Studied and the Number of Participants

\begin{tabular}{lccc} 
& Gold Star & Non-Gold Star & Totals \\
\hline Data Subset & 16 & 37 & 53 \\
Middle schools & 1 & 1 & 2 \\
High schools & 9 & 1 & 10 \\
Total Schools & 26 & 39 & 65 \\
\hline Elementary participants & 335 & 996 & 1,331 \\
Middle school participants & 13 & 33 & 46 \\
High school participants & 228 & 40 & 268 \\
Total Participants & 576 & 1,069 & 1,645 \\
\hline
\end{tabular}

\section{Findings of the Study}

For this study a $t$-test was conducted to determine is there were differences in the $\mathrm{AQ}$ results between the two groups studied. Results yielding a p-value of .05 are considered on the borderline of statistically significant. If a p-value is under .01, results are considered statistically significance and if the p-value below .05 results are considered highly statistically significant (Field, 2009). Field explained that, "The pvalue should be above the bare minimum of .05 for all variables" (p. 8). For research questions two through five the level of statistical significance used was $p<.05$. In research "significant" represents probably true or not due to random chance. Therefore, for this study any research questions that result in a p-value of .05 or less can be presumed to have statistical significance. The findings of the study are organized by research question and statistical analysis.

As part of the $t$-test for this study, a test for equality of variances was performed. Variances measures how far a set of numbers is spread out. In this case the average 
scores reported by each group were compared. A variance of zero indicates that all the values are identical. A small variance indicates that the data points are likely very close to the mean and hence to each other, while a high variance indicates that the data points are spread out around the mean and from each other (Field, 2009).

The $t$-test assumes that the variability of each group is approximately equal. The Levene's Test for Variances was examined to determine whether an assumption of equality had been met for this study. If the significance ( $p$ value) is equal to or greater than this study's p-value of .05 it can be assumed that the variances are equal (Field, 2009). Appendix E shows that each of the four research questions from this study has a significance level found to be greater than .05 and therefore it can be assumed that the variances are equal.

\section{Research Question 1}

Research question one addressed the geographic characteristics of the Missouri Gold Star Schools from 2007-2012. Data revealed that Gold Star Schools were spread out across the state, with higher concentrations in St. Louis County, which includes the city of St. Louis; Jackson County, which includes the areas of Blue Springs and Lees Summit; and finally, Christian County that includes the area of Nixa and Ozark City. St. Louis County far surpassed all other counties with 14 Gold Star Schools within the six-year span. There were 114 counties across Missouri, only 30 that had a Gold Star School residing within them. Figure 2 shows the counties across Missouri in which all of the Gold Star Schools from 2007-2012 were located. 
All Missouri Gold Star Schools by County from 2007-2012

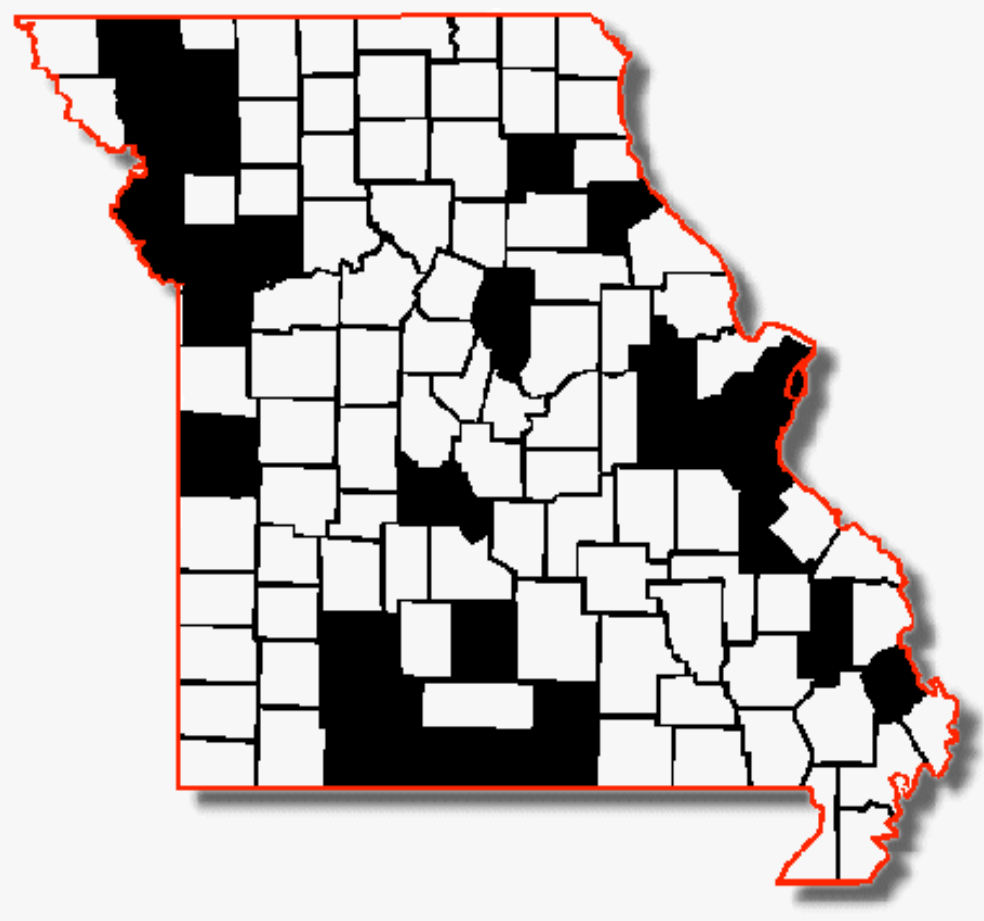

Source: diymspenct (c)

Figure 2. Map of all Missouri counties with at least one Gold Star School between 20072012.

Additional analysis found that counties with high poverty Gold Star Schools were more concentrated within Missouri. In fact, of 114 counties across Missouri, only 12 counties had a high poverty Gold Star School. Figure 3 shows the location of all Gold Star Schools from 2007-2012 with a free and reduced lunch rate above 50\%. 


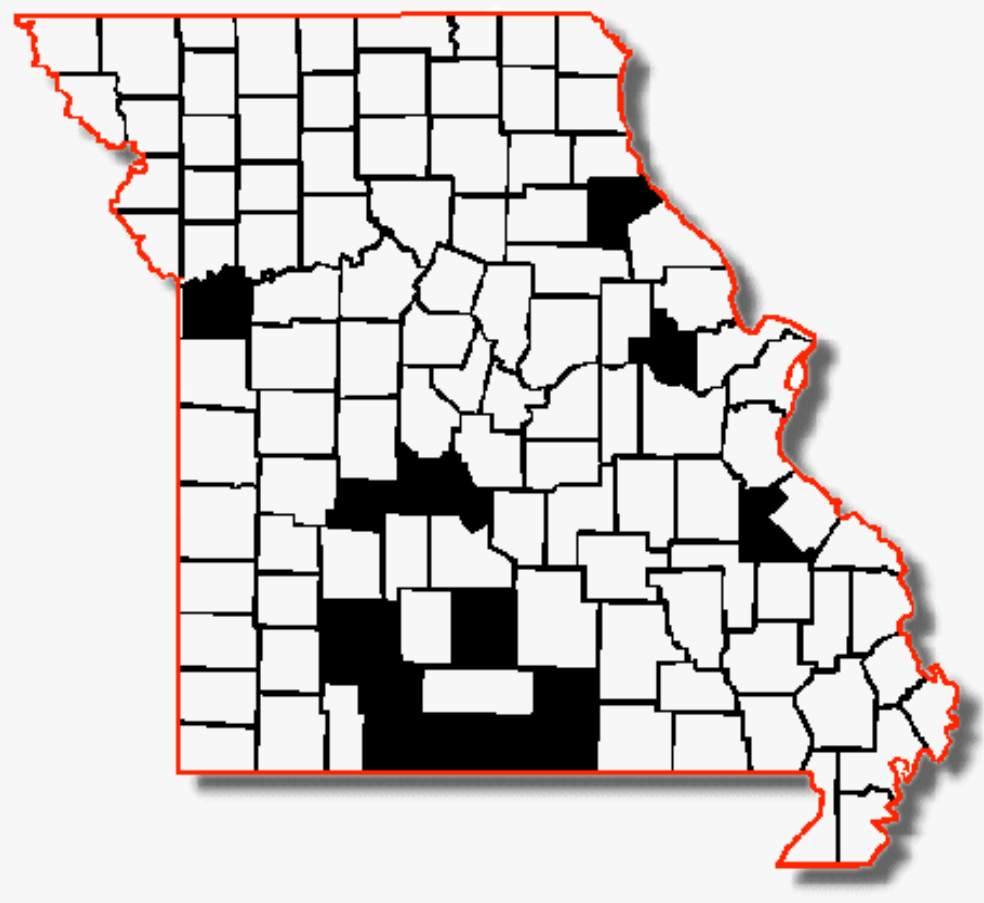

Source: diymopenct (c)

Figure 3. Map of Missouri counties with Gold Star Schools from 2007-2012 with a free and reduced lunch rate of $50 \%$ or above.

Finally, a table (Appendix B) was created to show the names of Gold Star Schools, the district and county they were located in, and the year the school was awarded the Gold Star recognition.

\section{Locale Codes}

Although the focus of this study was not on the size of the county that schools were located within, it may warrant describing some of the findings pertaining to locale codes. Schools across the nation are given a locale code. Locale codes are derived from a classification system originally developed by the National Center or Education Statistics (NCES) in the 1980's to describe a school's location ranging from "large city" to 
"rural". The codes are based on the physical location represented by an address that is matched against a geographic database maintained by the Census Bureau. A school district's locale code is not assigned on the basis of the central office address. It is derived from the locale codes of the schools in the district. If $50 \%$ or more of the public school students attend schools with the same locale code, that locale code is assigned to the district. If no single locale code accounts for $50 \%$ of the students, then the major category with the greatest percent of students determines the locale (National Center for Education Statistics, 2012).

The United States Department of Justice identifies district in locale codes as follows; an urban area is defined as a Census Block Group with a density greater than or equal to 2,000 people per square mile with a population greater than or equal to 100,000 , or a place that has a total population greater than or equal to 200,000 people. A suburban area is defined as a Census Block Group no more than thirty miles from urban areas or a Census Block Group with a density greater than or equal to 500 people per square mile and less than 2,000 people per square mile. A rural area is defined as a Census Block Group with a density less than 500 people per square mile (U.S. Department of Justice, 2012).

There were 26 high poverty Gold Star Schools studied and it was found that 21 (81\%) are located in rural locations within Missouri. Only five (19\%) were located in a large city, urban or suburban area. Additionally, there were 39 non-Gold Star Schools studied and it was found that $19(49 \%)$ were located in a rural location as opposed to 20 (51\%) located in a large city, urban or suburban location. Table 4 shows the number of Gold Star Schools by county. 
Table 4

Gold Star Schools across Missouri by County Between 2007-2012

\begin{tabular}{|c|c|c|}
\hline Missouri County & \# of Gold Star schools & \# of high poverty Gold Star schools \\
\hline Andrew & 1 & $\theta$ \\
\hline Bates & 1 & $\theta$ \\
\hline Bollinger & 1 & $\theta$ \\
\hline Boone & 1 & $\theta$ \\
\hline Buchanan & 2 & $\theta$ \\
\hline Camden & 1 & 1 \\
\hline Christian & 4 & 2 \\
\hline Clay & 2 & $\theta$ \\
\hline DeKalb & 1 & $\theta$ \\
\hline Franklin & 2 & $\theta$ \\
\hline Gentry & 1 & $\theta$ \\
\hline Greene & 2 & 1 \\
\hline Hickory & 1 & 1 \\
\hline Howell & 1 & 1 \\
\hline Jackson & 6 & 3 \\
\hline Jefferson & 2 & $\theta$ \\
\hline Nodaway & 4 & $\theta$ \\
\hline Ozark & 2 & 2 \\
\hline Platte & 1 & $\theta$ \\
\hline Ralls & 1 & 1 \\
\hline Ray & 1 & $\theta$ \\
\hline Scott & 1 & $\theta$ \\
\hline Shelby & 1 & $\theta$ \\
\hline St. Francois & 3 & 2 \\
\hline St. Louis & 14 & $\theta$ \\
\hline St. Louis City & 3 & $\theta$ \\
\hline Stone & 1 & $\theta$ \\
\hline Taney & 2 & 2 \\
\hline Warren & 1 & 1 \\
\hline Wright & 2 & 2 \\
\hline
\end{tabular}

Note. Some schools listed in the table may have been recognized as a Gold Star school for multiple years.

There were a total of 66 Gold Star Schools between the years of 2007-2012 with 26 of them reporting a free and reduced lunch rate above $50 \%$ some time during the 5year span. 


\section{Research Question 2}

Research question two sought to explore if there were differences between Missouri high poverty Gold Star Schools and high poverty non-Gold Star Schools in relation to the responses given when faculty were asked whether the school promotes an environment of mutual respect among students. Independent samples $t$-test was conducted to determine if differences in faculty responses existed on the Advanced Questionnaire survey. Results showed a statistically significant difference $(p=0.03)$ in the responses between Gold Star and non-Gold Star Schools. Data analysis revealed that the high achieving Gold Star group reported a mean score of 4.45, whereas the lowachieving non-Gold Star group reported a mean of 4.28. Table 5 and Figure 4 show the $t$ test analysis and a visual representation of the average scores for research question two.

Table 5

t-test analysis for Gold Star vs. non-Gold Star Schools from 2007-2012

\begin{tabular}{lcccccc} 
Groups & $\mathrm{n}$ & Mean & SD & Mean D & $t$-test & p-value \\
\hline 1, Gold Star & 26 & 4.45 & .28 & & & \\
2, Non-Gold Star & 39 & 4.28 & .32 & -.17 & -2.20 & 0.03 \\
\hline
\end{tabular}

* Note. Statistically significant at the 0.05 level. 


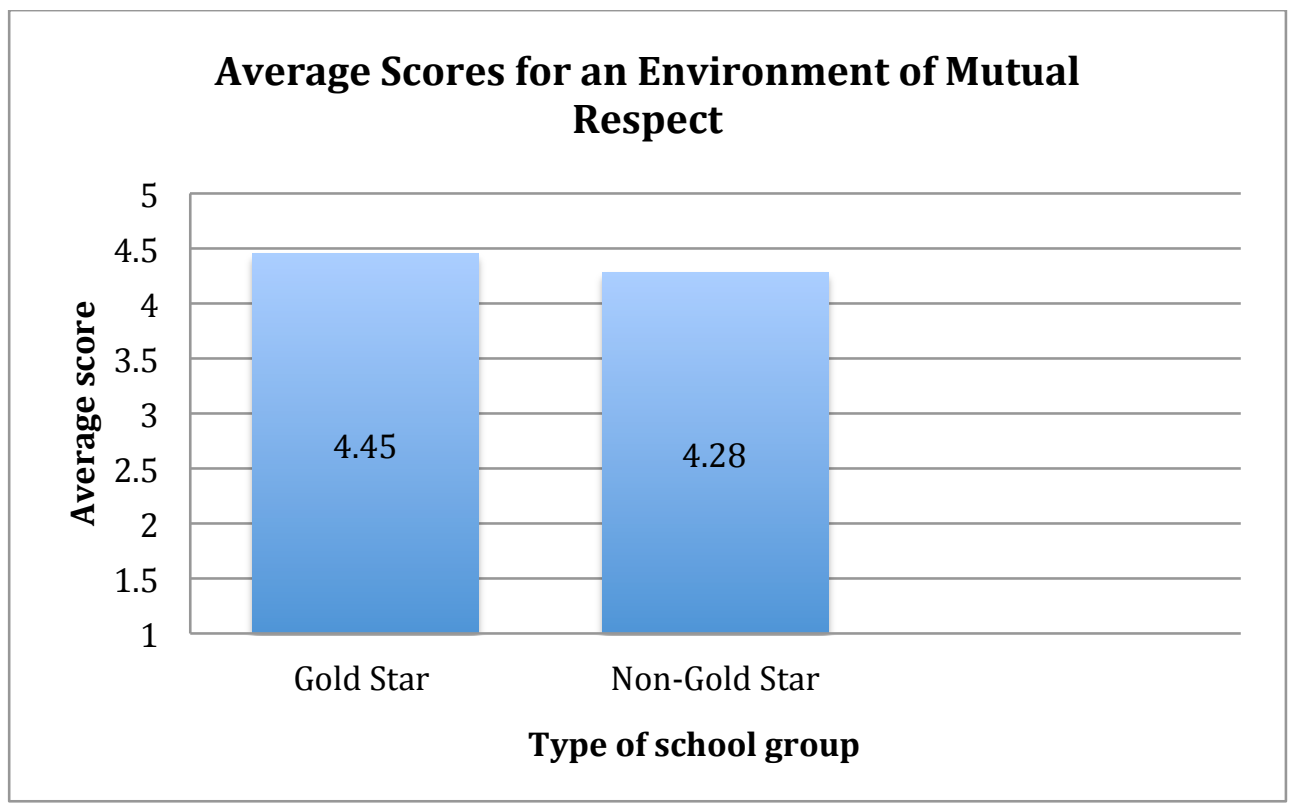

Figure 4. Average scores when faculty members are asked if the school promotes an environment of mutual respect.

The results from research question two reveals that faculty members in Gold Star Schools reported their school having an environment of mutual respect among students, whereas non-Gold Star Schools are less likely to report an environment with mutual respect.

These findings are consistent with the findings of Hoy and Tarter (1992) that provided dimensions of culture, which they described as levels of organizational health. Within the first dimension Hoy and Tarter explained an academic component that was represented by the teachers' belief systems. The system of beliefs was directly tied to the level of respect found throughout the organization. In addition, Manning (1996) delved deeper into specific elements of school culture and his finding brought to light the correlation of relationships among the individuals in the school community, and the level of respect found throughout the organization. Without a high level of respect among the individuals, relational capacity is simply not present and therefore hinders the success of 
the organization. Additionally, Reeves (2000) found that in high poverty schools the level of respect and caring attitudes was instrumental in the success of the school culture and, therefore the level of student achievement.

\section{Research Question 3}

Research question three sought to explore if there were differences between Missouri high poverty Gold Star Schools and high poverty non-Gold Star Schools in relation to the responses given when faculty were asked if the school makes students feel they belong. Independent samples $t$-test was conducted to determine if differences in faculty responses existed on the Advanced Questionnaire survey. An analysis revealed that although the high achieving Gold Star group reported a mean score of 4.29 and the low-achieving non-Gold Star group reported a mean of 4.20 there was not a statistically significant difference $(\mathrm{p}=0.32)$ in the responses between the Gold Star and non-Gold Star groups. Table 6 and Figure 5 show the $t$-Test analysis and a visual representation of the average scores for research question three.

Table 6

t-test analysis for Gold Star vs. non-Gold Star Schools from 2007-2012

\begin{tabular}{lcccccc} 
Groups & $\mathrm{n}$ & Mean & $\mathrm{SD}$ & Mean D & $t$-test & $\mathrm{p}$-value \\
\hline 1, Gold Star & 26 & 4.29 & .31 & & & \\
\hline 2. Non-Gold Star & 39 & 4.20 & .38 & -.09 & -1.00 & 0.32 \\
\hline
\end{tabular}

* Note. Not statistically significant at the 0.05 level. 


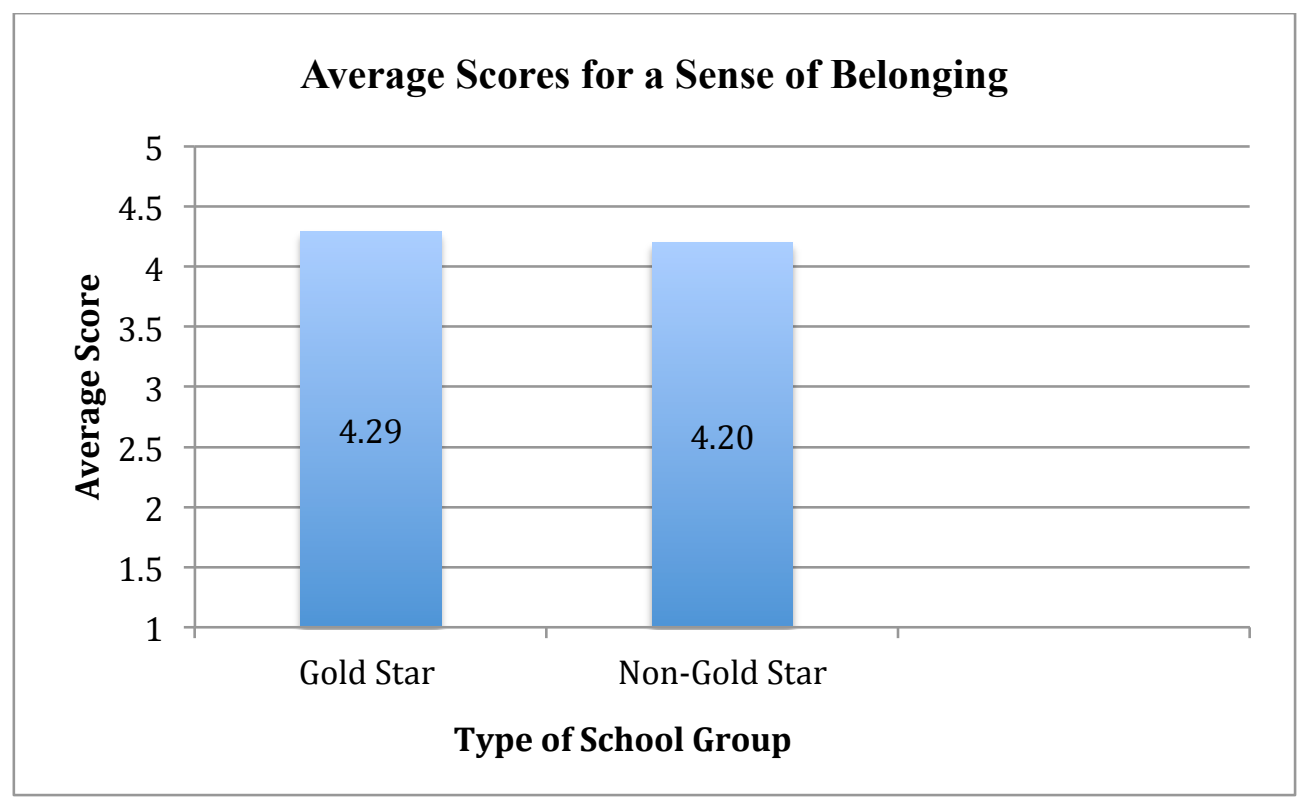

Figure 5. Average scores when faculty members are asked if the school promotes an environment that makes students feel they belong.

Figure three shows that there was very little gap between the responses from the Gold Star and non-Gold Star Schools. The results do not indicate that student achievement is not impacted in terms of whether the school environment is one in which students feel they belong; rather, the results simply indicate that whether or not the school is high achieving or low-achieving, the level at which the school makes students feel they belong does not differ significantly.

The findings of Marshall (2004) clearly indicated that a successful school culture is one in which the members are caring and supportive of one another. Marshall's research clearly shows that many of the problems plaguing schools today is rooted in the lack of the fundamental ability of leaders to build a culture in which students feel a sense of belonging to a group. When a culture fails to provide the feelings of belonging, respect and support, students feel a sense of isolation and they will disengage academically. The work of Reeves (2000) clearly shows that high achieving schools are more nurturing and 
far more engaged with the members of the organization. Reeves focused his research on high poverty school settings and found the schools that performed well on achievement tests were more inclusive of children with poor academic skills than schools that did not perform well.

\section{Research Question 4}

Research question four sought to explore if there were differences between Missouri high poverty Gold Star Schools and high poverty non-Gold Star Schools in relation to the responses given when faculty were asked if teachers and administrators value student opinions. Independent samples $t$-test was conducted to determine if differences in faculty responses existed on the Advanced Questionnaire survey. Analysis revealed that there was a statistically significant difference $(p=0.01)$ in responses between the two groups. The high achieving Gold Star group reported a mean score of 4.28, whereas the low-achieving non-Gold Star group reported a mean of 4.11. Table 7 and Figure 6 show the $t$-Test analysis and a visual representation of the average scores for research question four.

\section{Table 7}

t-test analysis for Gold Star vs. non-Gold Star Schools from 2007-2012

\begin{tabular}{lcccccc} 
Groups & $\mathrm{n}$ & Mean & SD & Mean D & $t$-test & p-value \\
\hline 1, Gold Star & 26 & 4.28 & .20 & & & \\
\hline 2. Non-Gold Star & 39 & 4.11 & .28 & -.17 & -2.70 & 0.01 \\
\hline
\end{tabular}

* Note. Statistically significant at the 0.05 level. 


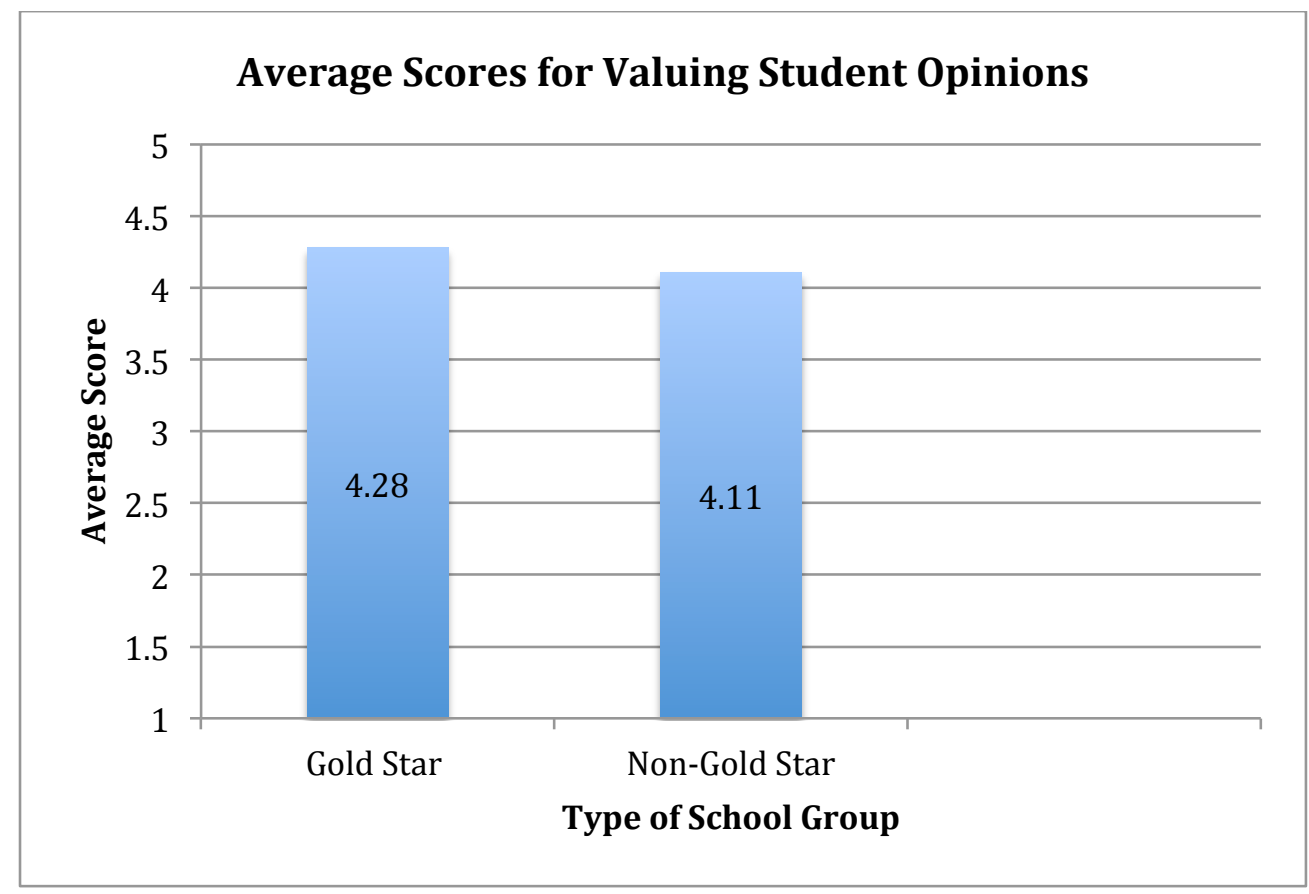

Figure 6. Average scores when faculty members are asked if teachers and administrators value students' opinions.

This indicates that Missouri schools with high student achievement report having a culture in which teachers and administrators value students' opinions. In contrast, schools with low student achievement are less likely to report having a similar culture.

Fletcher (2005) presented the practice of valuing students' opinions to support school culture through an extensive guide, which encouraged adults and students to work together towards a common cause. Fletcher's work outlines a process in which the members of the organization develop a meaningful partnership by placing value on the thinking evoked by students as well as adults. Fletcher's validates the thinking and input of all members. Fletcher further described this structure in which students are given a voice through student involvement. Fletcher's work supports the results of this study, which indicated the practice of valuing students' opinions and developing a common 
purpose was more prevalent in high achieving schools of poverty than it was in lowachieving schools across Missouri from 2007-2012.

A significant pillar to the current study was the impact of poverty on school culture and student achievement. The review of literature for this study clearly established that high poverty schools face additional barriers than more affluent schools. Evans (2004) explained that poor children confront widespread environmental inequities. Compared with their economically advantaged counterparts, they are exposed to more turmoil and instability; as a result they feel less valued and are less likely to express their opinions. Additionally, Evans (2004), Bennett et al. (2004), and Barton (2003) found that school environments differ among students from low-income families and their more affluent peers. They found, for example, that schools with high percentages of lowincome students were at an increased risk of facing lower quality teachers and reduced expectations for academic performance. Jensen (2009) found that lower expectations were likely the result of faculty members that develop a sense of pity towards student, thus hindering success. Jensen proposed that faculty would need to establish empathy towards students and express feelings of caring and valuing students' thinking. Jensen's notion was that by changing the cultural foundation there would be an identifiable impact on the students' desire to attend school and their academic performance.

\section{Research Question 5}

Research question five sought to explore if there were differences between Missouri high poverty Gold Star Schools and high poverty non-Gold Star Schools in regards to if teachers will listen and help if a student has a problem. Independent samples $t$-test was conducted to determine if differences in faculty responses existed on AQ 
survey responses. Results showed a statistically significant difference $(p=0.01)$. The high achieving Gold Star group reported a mean score of 4.56, whereas the low-achieving non-Gold Star group reported a mean of 4.39. Table 8 and Figure 7 show the $t$-test analysis and a visual representation of the average scores for research question five.

Table 8

t-test analysis for Gold Star vs. non-Gold Star Schools from 2007-2012

\begin{tabular}{lcccccc} 
Groups & $\mathrm{n}$ & Mean & SD & Mean D & $t$-test & $\mathrm{p}$-value \\
\hline 1, Gold Star & 26 & 4.56 & .21 & & & \\
\hline 2. Non-Gold Star & 39 & 4.39 & .25 & -.17 & -2.85 & 0.01 \\
\hline
\end{tabular}

* Note. Statistically significant at the 0.05 level.

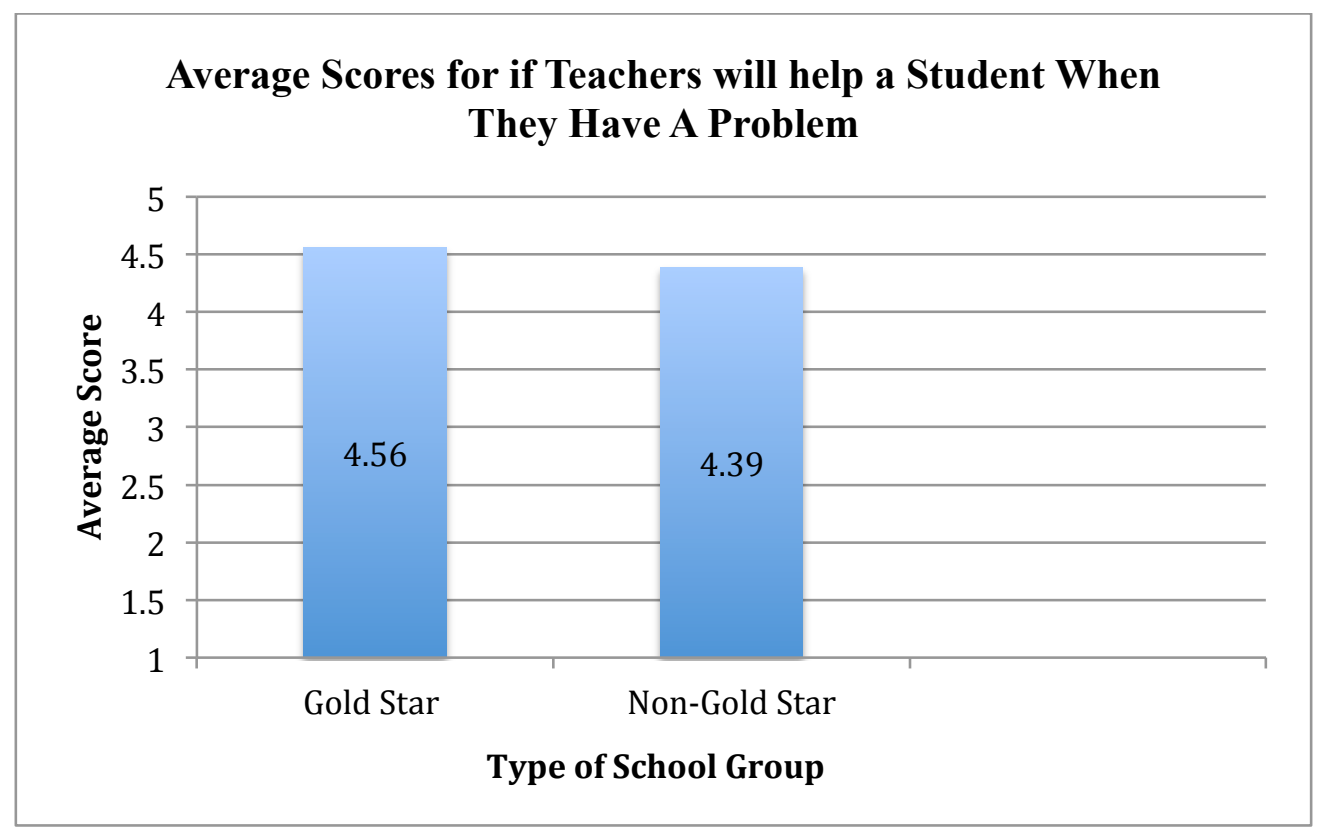

Figure 7. Average scores when faculty members are asked if teachers will listen and help if a student has a problem.

Analysis indicates that schools with high student achievement report having faculty that listen and provide assistance to students when they need it than schools with low student achievement. 
These findings are consistent with the findings of Snowden and Gorton (2002). The research of Snowden and Gorton offered five important cultural elements of an effective school: (a) a positive organizational culture, (b) emphasis on academic effort and achievement, (c) belief that all students can learn, (d) ongoing faculty development and innovation, and (e) a safe and orderly learning environment (pp. 116-117). Faculty that embrace the concept that every student can learn and are willing to provide the support structure to ensure student success support a successful culture of learning.

Research by The Leadership and Learn Center (Reeves, 2000) on the "90/90/90 Schools" provided specific findings that link instructional practices and teacher support to school improvement. Reeves studied elementary through high school settings of overwhelmingly poor schools and found five characteristics to be common to impoverished schools. Reeves' characteristics included curriculum choices, formative assessments, non-fiction writing emphasis, and collaborative scoring of student work. More importantly, the fifth characteristic was faculty focused on academic achievement and a willingness to extend support to students when needed.

\section{Additional Findings}

In addition to looking at the analysis of individual questions the researcher also looked at the total average for questions two-five combined. It was found that the high achieving Gold Star group reported a total average score of 4.34, whereas the lowachieving non-Gold Star group reported an average of 4.23. There was not a significant difference $(p=0.13)$ between the two groups when the scores from the four questions were averaged together. Tables 9 and 10, along with Figure 8, show the $t$-test analysis and a visual representation of the total averages of questions two through five combined. 
Table 9

Total Average Scores by Research Question and Type of Schools

Schools

Gold Star Non-Gold Star Schools

\begin{tabular}{lll} 
Research Question 2 & 4.45 & 4.28 \\
Research Question 3 & 4.29 & 4.20 \\
Research Question 4 & 4.28 & 4.11 \\
Research Question 5 & 4.56 & 4.39 \\
\hline Research Questions 2-5 combined & 4.34 & 4.23
\end{tabular}

Table 10

t-test analysis for Gold Star vs. non-Gold Star Schools from 2007-2012

\begin{tabular}{lcccccc} 
Groups & $\mathrm{n}$ & Mean & SD & Mean D & $t$-test & p-value \\
\hline 1, Gold Star & 26 & 4.34 & .27 & & & \\
\hline 2. Non-Gold Star & 39 & 4.23 & .31 & -.11 & -1.53 & 0.13 \\
\hline
\end{tabular}

* Note. Not statistically significant at the 0.05 level.

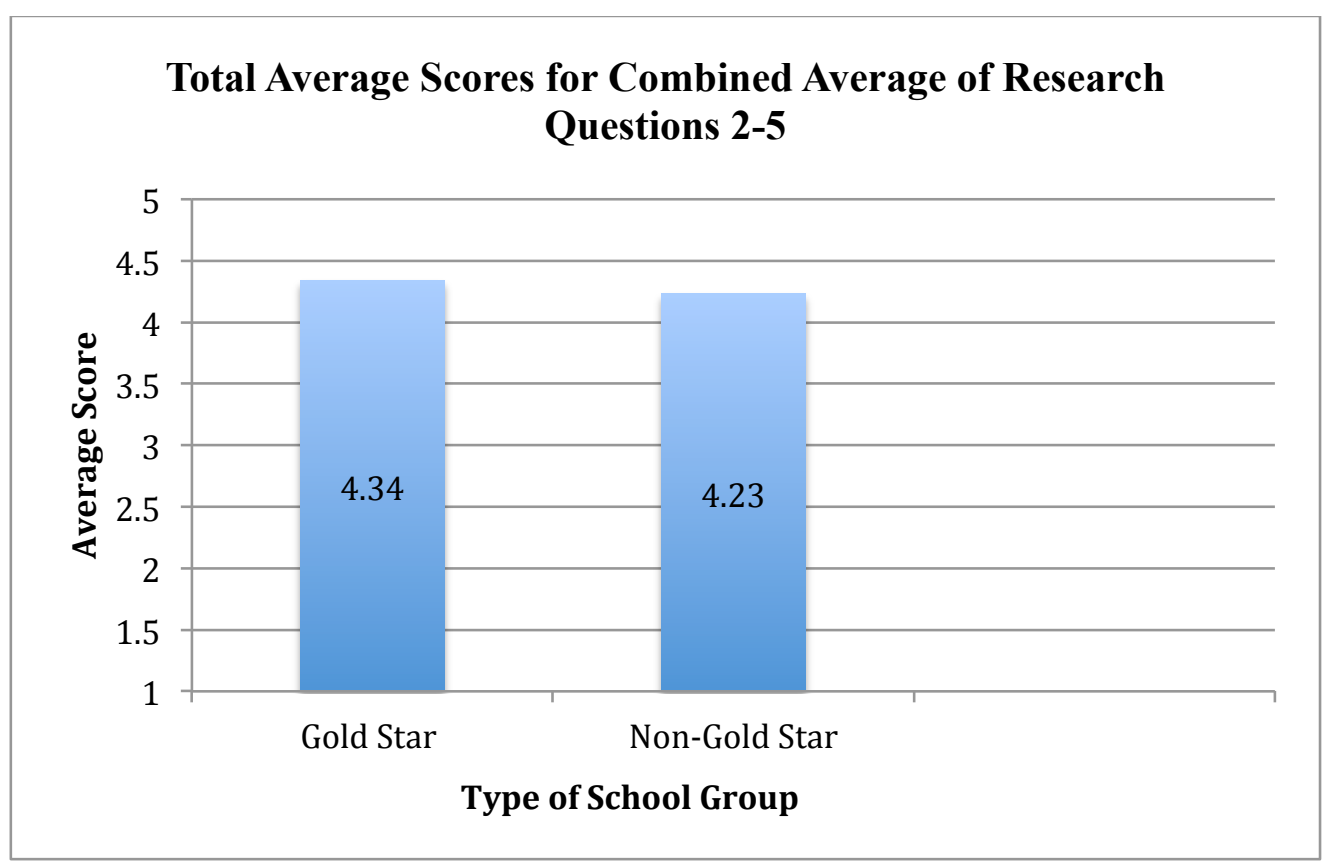

Figure 8. Total combined averages for research questions two through five. 


\section{Summary}

A discussion of results and findings was presented in Chapter four for research questions one through five. For research question one a descriptive map was provided that details the location of Gold Star Schools across Missouri. This study revealed that between the years of 2007-2012 the total population of Gold Star Schools stretched across the state with no discernable characteristics in terms of location. In contrast, the total population of high poverty Gold Star Schools can be found concentrated primarily in the south central area of the state.

Findings for research question two indicate that there was a statistically significant difference between the AQ responses of Gold Star and non-Gold Star Schools when asked whether the school promotes an environment of mutual respect among students. Findings for research question three reveal there was not a statistically significant difference between the AQ responses of Gold Star and non-Gold Star Schools when asked if the school makes students feel they belong. Next, Findings for research question four reveal there was a statistically significant difference between the AQ responses of Gold Star and non-Gold Star Schools when asked if teachers and administrators value student opinions. Finally, there was a statistically significant difference between the AQ responses of Gold Star and non-Gold Star Schools when asked if teaches will listen and help if a student has a problem.

The current study also investigated whether there was a statistically significant difference in the total responses collected when all four AQ question totals were averaged together for the Gold Star and non-Gold Star groups. An analysis revealed that there was not a statistically significant difference. 
The null was rejected for research questions two, four, and five but the research failed to reject the null for question three. One explanation for this may pertain to the context of research question three in relation to the other questions. Research question three relates to how students may feel whereas questions two, four and five relate to how staff behave towards students. It may be difficult for faculty to score question three given they are being asked to determine how students may feel, as compared to the other questions on which they rate their own behaviors and the actions of the faculty.

This study was designed in a manner in which it did not matter whether the null was rejected or accepted. The findings, either way, are relevant in regards to providing insight into the potential elements of culture found in high achieving schools as compared to low-achieving schools. Had the findings revealed no significant difference between the high achieving and low-achieving schools for this study, it would have informed school leaders that focusing attention on developing a particular school culture may not lead to higher achievement. However, this study did find that high poverty schools with high achievement are more likely to have cultures that instill mutual respect among students, have teachers and administrators that value student opinions and are willing to listen and help if a student has a problem. These findings along with the implications and recommendations in chapter five should inform school leaders that developing these traits in the school culture could impact student achievement. 


\section{CHAPTER FIVE}

\section{DISCUSSION OF THE FINDINGS, CONCLUSIONS, IMPLICATIONS, AND RECOMMENDATONS}

In 2002 No Child Left Behind (NCLB) mandates established a level of urgency for districts in regards to student achievement, requiring $100 \%$ of students to perform either a proficient or advanced level on reading/language arts and mathematics tests by 2014 (U.S. Department of Education, 2010). National data provided at the end of the 2003-2004 school year showed that $25 \%$ of schools across the country had not met the goals set by NCLB and by 2011 that number rose to $49 \%$ (U.S. Department of Education, 2011).

In addition, Muhammad, 2009; Neill, 2003; and Noguera, 2014 found that schools with heightened levels of poverty faced additional barriers with students that were less prepared for school than their affluent counterparts. However, in spite of potential barriers to academic achievement of students in high-poverty schools found that there are exceptions and some high poverty school were succeeding despite economic disparity (Neill, 2003; Casbarro, 2005; Bickman, Davis \& Hallinger 1996).

\section{Overview of Conceptual Framework}

As a result of these accountability measures established by NCLB in addition to the impact of poverty on education this study was designed to determine if differences existed in Advanced Questionnaire (AQ) responses collected from school faculty members of high poverty schools across Missouri from 2007-2012. The AQ responses consisted of four questions determined by The Office of Social and Economic Data Analysis (2014) as prime indicators of school culture. Since no research could be found 
that tied the cultural questions from AQ to student achievement in high poverty schools, it warranted a study.

The conceptual framework of this study rested on the premise that school culture and heightened levels of poverty affect student achievement. Therefore, this study began by exploring the definition of culture and the conceptual underpinning of this study centered on the definition of culture offered by Schein (2010),

the culture of a group can now be defined as a pattern of shared basic assumptions that was learned by a group as it solved its problems of external adaptation and internal integration, that has worked well enough to be considered valid and, therefore, to be taught to new members as the correct way to perceive, think, and feel in relation to those problems (p. 18).

The literature review for this study revealed that school culture has a significant impact on student achievement (Bulach \& Berry, 2002; Marshall, 2004; Reeves, 2000; Wagner, 2007). More specifically, the embedded practices that Schein expounded upon determine how students feel about the school environment and therefore impact their learning. The shared basic assumptions Schein refers to have garnered numerous studies and several researchers have proposed their own remedy for an effective culture (Beaudin, Thompson \& Jacobson, 2002; Brownson, Kahlert, Picucci \& Sobel, 2004; Thompson, 2003).

Regardless of the elements or wording used to explain an effective culture, common themes emerge from the varied studies. The universal belief of researchers is that culture does impact achievement and that poverty presents its own barriers to school culture. The changing of practices or strategies used in school have minimal impact on 
the overall achievement levels, but a cultural change produces a lasting and substantial impact on student achievement (Reeve, 2000).

This research study was conducted based on the problem that there was no known research investigating differences in responses pertaining to school culture from Missouri's Advanced Questionnaire (AQ) survey (OSEDA, 2014).

\section{Advanced Questionnaire Background}

Educators, along with researchers, developed the AQ as part of the statewide Missouri School Improvement Program (OSEDA, 2014). Many of the items the developers included in the original AQ were based upon the Effective Schools literature (Edmonds, 1979). The intent of the AQ was to develop a method of collecting data pertaining to school life that would provide the DESE officials data for accountability and to support school improvement efforts (DESE, 2011). The AQ is currently given in school districts during the semester prior to a scheduled five-year MSIP review. The AQ consists of six separate questionnaires specific to the following audiences: 1) elementary students in grades 3-6, 2) secondary students in grades 6-12, 3) parents, 4) faculty, 5) support staff, and 6) district-level Board of Education (DESE, 2011). This study only analyzed the survey results from the faculty portion of the questionnaire in order to gain the perspective of school faculty in relation to the perceived culture.

The purpose of this study was to determine if differences in AQ responses exist between high poverty, high achieving and high poverty, low-achieving schools across Missouri. It was believed that if a relationship could be established or discredited in relation to the AQ faculty responses about culture and the achievement levels of high poverty schools it would provide insight to school leaders of high poverty schools. 


\section{Research Questions and Null Hypotheses}

This study set out to answer the following research questions and the null hypotheses, where appropriate:

1. What are the geographic characteristics of the Missouri Gold Star Schools from 2007-2012?

2. Are there differences in Advanced Questionnaire responses between Gold Star and non-Gold Star Schools in regards to if the school promotes an environment of mutual respect among students?

$\mathrm{H}_{0}$ 1. There are no differences in Advanced Questionnaire responses between Gold Star and non-Gold Star Schools in regards to if the school promotes an environment of mutual respect among students.

3. Are there differences in Advanced Questionnaire responses between Gold Star and non-Gold Star Schools in regards to if the school makes students feel they belong?

$\mathrm{H}_{0} 2$. There are no differences in Advanced Questionnaire responses between Gold Star and non-Gold Star Schools in regards to if the school makes students feel they belong.

4. Are there differences in Advanced Questionnaire responses between Gold Star and non-Gold Star Schools in regards to if teachers and administrators value student opinions?

$\mathrm{H}_{\mathrm{o}} 3$. There are no differences in Advanced Questionnaire responses between Gold Star and non-Gold Star Schools in regards to if teachers and administrators value student opinions. 
5. Are there differences in Advanced Questionnaire responses between Gold Star and non-Gold Star Schools in regards to if teachers will listen and help if a student has a problem?

$\mathrm{H}_{0}$ 4. There are no differences in Advanced Questionnaire responses between Gold Star and non-Gold Star Schools in regards to if teachers will listen and help if a student has a problem.

\section{Discussion of Findings}

Five research questions guided this study. In a brief discussion of findings, the research questions are restated and discussion is based on data analysis provided in Chapter 4.

\section{Research Question 1}

First, research question one addressed the question of whether there were geographic characteristics of the Missouri Gold Star Schools from 2007-2012. This study found that of the 114 counties across Missouri only 30 counties had a Gold Star School residing within them, and of those 30 counties only 12 counties had a high poverty Gold Star School. This study further determined that, although the total population of Gold Star Schools from 2007-2012 fell within 30 counties, the Gold Star Schools were dispersed across the entire state with only one small concentration on the eastern edge of the state (Appendix B). More significant is that it was found that nine of the counties with a high poverty Gold Star School were located in the southern half of the state. In fact, the majority of the counties that high poverty Gold Star Schools came from were concentrated in the south central area of Missouri (Appendix C). 
One hypothesis to these findings is that south central Missouri is primarily rural with smaller school sizes than large cities or urban areas. The schools in this study were only schools determined to have poverty levels of $50 \%$ or higher; therefore, the small rural schools in this particular area may be at an advantage over larger schools. As stated earlier in this study, high poverty schools are eligible for Title I funding to help support student achievement (U.S. Department of Education, 2010). Having access to extra funding in a small school would allow a higher financial impact on the fewer students than larger school could have. Another component often found associated with Title I funding is a staff member that supports families facing economic disparity. This position, typically referred to as family involvement support, provides culture-building activities throughout the school. Given that this study determined culture does impact achievement (Levine \& LeZotte, 1995; Sizer, 1988; Phillips, 1996; Peterson \& Deal, 1998; Frieberg, 1998), it is possible that the extra funding for the smaller schools in south central Missouri may influence the high concentration of high poverty Gold Star School in this area.

This study did not focus on the economic status of counties across the state; however, it may warrant further study to determine if there is a higher concentration of high poverty schools in south central Missouri as compared to all other counties.

\section{Research Question 2}

Research question two sought to explore if there were differences between the two subgroups in relation to the responses given when faculty responded to whether the school promotes an environment of mutual respect among students. A $t$-test analysis revealed that there was a statistically significant difference (.03) in the responses between 
Gold Star and non-Gold Star groups. In fact, the high achieving Gold Star group reported a mean score of 4.45, whereas the low-achieving non-Gold Star group reported a mean of 4.28 relative to question one.

This study has determined that faculty members of low-achieving high poverty schools were less likely to feel as though the school environment was one that provided for mutual respect. In contrast, faculty members of high achieving schools were more likely to report an environment of respect. These findings were supported by Manning (1996) who determined that relationships built on trust and respect, among the individuals in the school community, were highly important to student success.

Chapter three referenced the work of Hoy and Tarter (1992) and the importance of mutual respect. A culture of respect can be explained through dimensions of culture that Hoy and Tarter described as levels of organizational health. The first level is defined as technical and includes morale, cohesiveness, and academic emphasis. Morale suggests there is a degree of openness, trust, friendliness and mutual respect, while cohesiveness refers to the extent to which teachers and administrators identify with each other. More recent research by Marshall (2004) provided evidence that faculty behaviors that support academic feedback, caring attitudes, and opportunities for input are critical to a respectful culture.

\section{Research Question 3}

Research question three sought to explore if there were differences in Advanced Questionnaire responses between Gold Star and non-Gold Star Schools in regards to if the school makes students feel they belong. A $t$-test analysis revealed that although the high achieving Gold Star group reported a mean score of 4.29 and the low- achieving 
non-Gold Star group reported a mean of 4.20 relative to question one there was not a statistically significant difference (.32) in the responses between the Gold Star and nonGold Star groups. This survey item was the only research question in the study that did not show a statistically significant difference in responses between the two groups. It is also the only question asked on the survey that asks respondents to respond to how others may feel about the environment. As stated early in this study, there are distinct differences between climate and culture. Gruenert (2008) clearly established that climate is determined by the feelings of the group while culture is defined as long-term commitments of a group. Further studies may be needed to determine if feeling a sense of belonging can be established through embedded behaviors or is too closely tied to emotion. Based on Gruenert's (2008) research, it is conceivable that the difference in results for this question may very well be tied to the nature of the question.

\section{Research Question 4}

Research question four sought to explore if there were differences in Advanced Questionnaire responses between Gold Star and non-Gold Star Schools in regards to if Missouri public school teachers and administrators value their students' opinions. A $t$-test analysis revealed that there was a statistically significant difference (.01) in responses between the two groups. The high achieving Gold Star group reported a mean score of 4.28, whereas the low-achieving non-Gold Star group reported a mean of 4.11 relative to question one. This research question resulted in the second highest level of significant difference (.01) and establishes that schools with higher student achievement report having cultures in which teachers and administrators value student opinions, likewise, faculty from low-achieving schools reported that they were less likely to work in an 
environment with a culture that values students' opinions.

The concept of involving and valuing student opinions is well researched in educational literature. Fletcher (2005) wrote an extensive guide to encourage adults and students to take action together. The guide describes a process by which schools can develop a meaningful partnership by placing value on the thinking evoked by students as well as adults. Fletcher described a structure in which "student voice" was not contrived by a select number of students; rather it was derived through "meaningful student involvement that continuously acknowledges the diversity of students by validating and authorizing them to represent their own ideas, opinions, knowledge, and experiences" ( $\mathrm{p}$. 5). Additionally, Brownson, Kahlert, Picucci, and Sobel (2004) identified characteristics of culture in high-poverty, high-achieving schools. These characteristics included a common purpose among staff and students, thoughtful school structures, and attention to individual students.

The results of this study indicated the practice of valuing students' opinions and developing a common purpose was more prevalent in high achieving schools with economic disadvantages than it was in low-achieving schools with similar disadvantages across Missouri from 2007-2012.

\section{Research Question 5}

Research question five sought to explore if there were differences in Advanced Questionnaire responses between Gold Star and non-Gold Star Schools in regards to if teachers will listen and help if a student has a problem. A $t$-test analysis revealed that there was a statistically significant difference $(.00)$ in responses between the two groups. The high achieving Gold Star group reported a mean score of 4.56, whereas the low- 
achieving non-Gold Star group reported a mean of 4.39 .

This research question yielded the highest level of significant difference (.00) between the groups. An assumption can be made that school cultures that have embedded faculty behaviors which support students in need of help may increase the likelihood of higher response scores for research questions two and four. The assumption is that if faculty care enough about students that they routinely engage with students when they see them having a problem, the students' perception would be one of a caring faculty that respect and value them (Schein, 2010).

Schein's definition of culture was used to frame this study; however, Schein expounds upon his definition by offering three levels of culture; (1) visible structures, processes and observed behavior, (2) espoused beliefs and values including goals, values, aspirations, ideologies and rationalizations, (3) basic underlying assumptions which are viewed as unconsciously taken. Research question five was operationalized by Schein's first level of culture when students see faculty taking an interest in the needs of students and working to find solutions for students' problems.

The high level of difference in responses for this question is not due to a low average score from the non-Gold Star School group; rather a high average score for the Gold Star School group. In fact, this research question yielded the highest average score by the non-Gold Star School group as compared to all other research questions in the study. The high significance of difference was the result of a substantially higher average response by the Gold Star School group.

Finally, the study also looked at the total average for questions two-five combined. It was found that the high achieving Gold Star group reported a total average 
score of 4.34, whereas the low-achieving non-Gold Star group reported an average of 4.23. There was not a statistically significant difference (.12) between the two groups when the scores from the four questions were averaged together. A hypothesis to this finding is that the low statistical difference from research question three had a large enough impact on the overall average to produce a low significance.

\section{Conclusions}

Federal and state accountability measures such as No Child Left Behind (U.S. Department of Education, 2010) and Top 10 by 20 (DESE, 2014) have placed mandates on school leaders to increase student achievement. Extensive research has been conducted and has shown that school culture impacts student achievement (Bulach \& Berry, 2002; Marshall, 2004; Reeves, 2000; Wagner, 2007). Additionally, researchers have shown the implications of poverty on culture and student achievement (Jenson, 2009; Reeves, 2000; Payne, 2005). This study explored the possibility that there could be differences in the responses collected from two academically distinct groups on the Missouri Advanced Questionnaire (AQ) survey given to economically disadvantaged schools across Missouri from 2007-2012.

The researcher selected a quantitative research design to determine if differences in survey responses existed between high poverty Gold Star Schools and high poverty non-Gold Star Schools in Missouri schools from 2007-2012. In order to accomplish this, survey data were collected via Missouri's AQ survey and the data were statistically analyzed to determine if differences were present among faculty members of elementary, middle, and high schools across Missouri.

In order to determine if differences existed, two groups of schools had to be 
identified. Although both groups of schools for this study had the same economic barriers, one group had performed considerably higher on Missouri’s Assessment Program (MAP) assessments, while the other group had performed significantly lower. Utilizing an award program known as the Missouri Gold Star Program provided a valid study group to compare a low achieving group against.

The process for selecting the two groups was as follows: First, a high achieving group was made up of schools that had obtained Missouri's Gold Star Award. Schools that had obtained this award were either academically superior schools in the top $15 \%$ in the most recent year tested, based on student performance in both reading and math from the MAP, or the performance of all students tested in the school's subgroup in the most recent year in reading and math was in the top $40 \%$ of all schools in the state (DESE, 2014). The second group of schools was made up of lower performing schools that were identified as schools that did not qualify for the Gold Star Award and had either one or both of English language arts or math MAP scores with less than 55\% of students scoring proficient or above. There were 26 schools in Missouri that met the requirements for the high achieving subgroup and 36 schools met the requirements for the non-high achieving subgroup.

Since both groups had a common factor of poverty present, and given the research showing that culture impacts student achievement, it was hypothesized that the responses the faculty gave on the AQ survey would hold differences between the two groups when asked how the faculty perceived the existing school culture. If differences could be found it could provide insight into why some impoverished schools performed better than others from 2007-2012 across Missouri. 
Given the extensive research showing culture was an important factor in student achievement (Bulach \& Berry, 2002; Marshall, 2004; Reeves, 2000; Wagner, 2007), this study needed a valid and reliable measure to compare the culture in the two study groups. The Missouri Advanced Questionnaire (AQ) provided that tool. The AQ was administered through the Missouri Department of Elementary and Secondary Education (DESE) as part of the Missouri School Improvement Program (MSIP). The AQ contained four questions asked of faculty members that pertain to school culture. These four questions became the research questions for this study.

Findings revealed that economically disadvantaged schools in Missouri from 2007-2012 with high student achievement reported having a culture that addressed students' needs for an environment of respect (RQ 2), and support and helpfulness in times of need (RQ 4 and 5). Low-achieving schools in Missouri from 2007-2012 that are economically disadvantaged were less likely to report having the type of culture described above.

\section{Implications}

This study found that economically disadvantaged schools across Missouri from 2007-2012 with high student achievement have faculty that report having a culture with respect among students, values students' opinions, and have faculty that listen to and help students. In contrast, on the same AQ survey items, faculty members of low achieving non-Gold Star Schools did not score their school as high when asked if the environment provided respect among students, valued student opinions, and had faculty that are helpful in times of student need. In addition, the literature review for this study confirmed

all schools have some form of culture (Bolman \& Deal, 2003). However, results collected 
from Missouri's Advanced Questionnaire show there are differences on culture factors from faculty survey responses between Gold Star and non-Gold Star Schools. As a result, if school leaders of low performing, high poverty schools are to improve student achievement the faculty will not only need to understand what the components of a successful culture are, but how to develop and sustain the culture.

Reeves (2007) encouraged school leaders to identify the types of values, traditions, and relationships that need to be developed and preserved within a culture. This study provides school leaders insight into the values and relationships Reeves described in terms of lasting cultural change.

Faculty members considering a change to the school's culture must first define what the group is not willing to change (Reeves, 2007). Although faculty of non-Gold Star Schools in this study did not score the AQ survey culture related items as high as the faculties of Gold Star Schools did, it does not indicate a complete lack of the cultural components in non-Gold Star Schools. It is possible the cultural elements from the AQ may be present at some level, but simply did not garner as high of a score in comparison to the response scores of Gold Star Schools. The recommendation for leaders of high poverty, low achieving schools is to identify the elements of culture embedded in the AQ that are already in place in the school and determine not to eliminate them as other elements of culture are developed.

Since the AQ culture items of mutual resect among students, valuing student opinions, and faculty members that will listen and help if a student has a problem are key to high student achievement, the items warrant attention and development in low achieving high poverty schools. 


\section{RQ 2 Mutual Respect}

Research question two sought to explore if there were differences in Advanced Questionnaire responses between Gold Star and non-Gold Star Schools when asked if the culture promoted mutual respect among students. An analysis of data revealed that high achieving Gold Star Schools produced a higher average score on the faculty portion of the AQ as compared to low achieving non-Gold Star schools.

When teachers expect all students to value one another the instructional contribution to the classroom increases and the environment is more likely to be ones in which students can focus on understanding tasks. Therefore, students' attention is not diverted by concerns about what others might think or say. In contrast, an environment in which the teacher promotes mutual respect is expected to support students' self-regulated learning, academic efficacy, safety, and comfort (Ryan \& Patrick, 2001). As such, the level of mutual respect embedded in a school's culture can be used as a measurement of the culture (U.S. Digital Literacy, 2015).

High poverty Gold Star Schools have shown that mutual respect can be established in economically disadvantaged schools and this study has shown that mutual respect among students supports higher student achievement. Based on the findings of this study, school leaders should consider the following practices prescribed by Wiles (2015) to develop mutual respect among students:

1. Implementation of rules and procedures on how students will speak to, and treat each other on a daily basis.

2. Set expectations for staff and students to modeling respectful behaviors among each other on a daily basis. 
3. Regularly role-play the expected behaviors in class for students.

4. Reduce any reward systems that take away from behaviors becoming intrinsic.

5. Provide consistency of expectations and consequences for wrong behaviors. Leaders of low achieving schools will need to consider these practices if they are to promote mutual respect among students and see student achievement improve.

\section{RQ 3 Sense of Belonging}

Research question three sought to explore if there were differences in Advanced Questionnaire responses between Gold Star and non-Gold Star Schools in regards to if the environment makes students feel they belong. An Analysis of data revealed there was not a statistically significant difference in the responses between Gold Star and non-Gold Star Schools.

Based on the literature review for this study there may be more to this AQ survey item than just findings from the analysis of data. Although a statistically significant difference was not found, both groups reported a relatively high average score overall. The possible average score ranged from zero to five. The Gold Star group reported a mean score of 4.29 and the low-achieving non-Gold Star group reported a mean of 4.20. Given the reported averages it is conceivable that, although there wasn't a significant difference in the average scores between the two groups, having a culture with a sense of belonging is important to student achievement.

Chapter two provided a literature review that clearly showed the importance of the school environment being a place students feel safe and secure and want to be a part of. As an example, Jensen (2009) found that by changing the cultural foundation there is an identifiable impact on the students' desire to attend school and the feelings of 
acceptance and belonging within the school. Further, Evans (2004) explained that poor children confront widespread environmental inequities and are exposed to family turmoil, instability, and chaotic households and therefore seek security and belonging at school.

Although this study could not determine statistically significant differences between the response of Gold Star and non-Gold Star Schools, it is still the recommendation of this researcher for school leaders to place value on creating a culture in which students feel a sense of belonging.

\section{RQ 4 Valuing Students' Opinions}

Research question four sought to explore if there were differences in Advanced Questionnaire responses between Gold Star and non-Gold Star Schools in regards to if teachers and administrators value students' opinions. An Analysis of data illustrates the importance of valuing students' opinions in relation to student achievement.

Fletcher (2005) provided an extensive guide outlining steps for adults to use when placing value on students' thinking. Fletcher's guide describes a process by which faculty members can develop the practice of placing value on the thinking evoked by students. The process promotes meaningful student engagement that acknowledges the diversity of students. Fletcher's process is designed around a fivestep cycle that includes:

1. To listen to students' ideas and opinions.

2. To validate students as significant partners in the school setting. 
3. To authorize students' skill sharing, action planning and strategic participation.

4. To mobilize students to take action together with adults.

5. To reflect together as a group on the accomplishments as partners.

Fletcher's cycle can be used as a framework for school leaders to validate and authorize students to represent their own ideas, opinions, and knowledge. The findings of this study clearly illustrate the need for a process by which faculty members can use to promote valuing students' opinions as part of the school culture. Leaders of low achieving, non-Gold Star Schools can support high student achievement by implementing embedded practices that seek and value students' opinions.

\section{RQ 5 Teachers will listen and Help}

Research question five sought to explore if there were differences in Advanced Questionnaire responses between Gold Star and non-Gold Star Schools in regards to if teachers will listen to students and help if a student has a problem. An Analysis of data illustrates the importance of teachers and administrators listening to and helping students when the need arises.

The behaviors of faculty members play an important role as part of the school culture. In fact, the greatest impediment to meaningful cultural change is the gap between what faculty members say they value and what they actually do on a daily basis (Reeves, 2007). Research conducted by Reeves through The Leadership and Learn Center (2007) provided specific findings that link the actions of faculty to student achievement. Reeves studied elementary through high school settings of economically disadvantaged schools 
and found achievement was higher in school settings that demonstrated a culture in which faculty focused on academic achievement and had a willingness to offer support to students when needed.

Given the finding from Reeves (2007) and the impact that listening to students and offering support has on student achievement, the topic of teacher quality needs mentioning here. Evans (2004), Bennett et al. (2004), and Barton (2003) found that school environments differ among students from low-income families and their more affluent peers in part due to teacher quality. The researchers found that schools with high percentages of low-income students were at an increased risk of employing lower quality teachers. Compounding the issue is that research found that poor quality teachers are less likely to identify struggling students and therefore less likely to provide support to students. However, this study has shown that faculty in high poverty, Gold Star Schools report having an environment that listens to and helps students; therefore, the behavior of listening to and supporting students can be established in high poverty, low achieving schools as well.

This study found that high achieving Gold Star Schools across Missouri reported faculty behaviors that provide support to students in need of help; yet low achieving schools did not score as high on the AQ responses when asked if the faculty listen to and provided support to students. Therefore, faculty members of high poverty low achieving schools would see improvements in student achievement if the faculty members establish a commitment to learning and implementing the behavior of listening to and helping students.

A final culminating point to be made is concerning the gaps between 
impoverished students and affluent students. The research conducted for this study clearly showed that achievement gaps exist between economically disadvantaged and affluent schools. The school culture has an enormous influence over closing the equity gaps that continue to challenge schools today. Rather than blame conditions that are beyond our control, faculty members of impoverished schools must understand that although poverty may pose challenges, a successful culture that supports high student achievement is obtainable. Inequity is lessened in high poverty schools when teachers and administrators commit to closing the gap by changing the school culture to support respect among students, valuing students' opinions, and having faculty that help students in tome of need.

\section{Recommendations}

This study provides evidence that there are differences in the Advanced Questionnaire survey responses from faculty members in high poverty schools across Missouri from 2007-2012 and the level of student achievement. The language arts and math portions of the Missouri Assessment Program determined achievement levels for this study. However, it may be important to note that other factors could impact the findings. The following comments outline some of the possible implications.

This study included all schools across Missouri; however no consideration was given to the size of the schools or districts. Schools are identified by locale codes that are assigned by the National Center for Education Statistics (NCES, 2012). The Center

categorizes districts into the following four categories: (a) city, (b) suburban, (c) town, and (d) rural. This study did not take school size into consideration; therefore, future researchers should explore potential relationships between school culture, student 
achievement, and school sizes.

Finally, this study sought findings from the faculty portion of the Advanced Questionnaire (AQ) survey. The AQ survey given to students and parents also contains questions pertaining to school culture. Collecting and analyzing data from parents and students may provide new insight into the relationship between the perceived culture and student achievement. Addition survey data may also provide qualitative researchers the ability to triangulate the information from this qualitative study. Even if student achievement was not an area of interest, a comprehensive study could seek potential differences on the perceived culture by comparing AQ results collected from faculty, parents, and students within the same school site to determine if there are similarities and differences. If discrepancies were found among the three groups it could provide another dimension to this study.

\section{Summary}

This quantitative research study set out to determine if culture factor differences from AQ survey responses existed between high poverty Gold Star Schools and high poverty non-Gold Star Schools in Missouri schools from 2007-2012. As part of this study, survey data were collected via Missouri's AQ survey and the data were statistically analyzed to determine in differences existed among faculty members of elementary, middle, and high schools across Missouri.

The premise behind this study was that research had clearly established the importance of school culture as it related to student achievement (Bulach \& Berry, 2002; Marshall, 2004; Reeves, 2000; Wagner, 2007); however, research also established that poverty posed barriers to the culture and to student learning. Knowing the background on 
the research this study was designed to explore if it could be determined if the type of culture found in high poverty schools was different between those that performed well on student achievement tests and those that did not by examining how the faculty perceived the culture. Faculty perceptions were captured through their responses about culture on the AQ survey between the years of 2007-2012.

In order to establish the two study groups the Missouri Gold Star Program was used as it provided a valid high performing study group to compare against. Gold Star Schools were schools that were either academically superior schools in the top $15 \%$ in the most recent year tested, or the performance of all students tested in the school's subgroup in the most recent year in reading and math was in the top $40 \%$ of all schools in the state (DESE, 2014). The group used to compare against the Gold Star group was schools made up of lower performing schools that were identified as schools that did not qualify for Gold Star and had either one or both of English language arts or math MAP scores with less than $55 \%$ of students scoring proficient or above.

Since both groups had a common factor of poverty present, and given the level of research showing that culture impacts student achievement, it was hypothesized that the responses the faculty gave on the AQ survey would hold differences between the two groups when asked how the faculty perceived the existing school culture.

The AQ is administered through the Missouri Department of Elementary and Secondary Education (DESE) as part of the Missouri School Improvement Program (MSIP). The AQ contained four questions asked of faculty members that pertain to school culture. These four questions became research questions for this study.

For this study there were five research questions. Research question one was 
developed for the purpose of determining if there were location characteristics of the Gold Star Schools between 2007-2012. This study found that the Gold Star Schools were concentrated in 30 of the 114 counties across Missouri and of those 30 counties only 12 contained a high poverty Gold Star School. The total population of Gold Star Schools was dispersed across the entire state; however, the high poverty Gold Star School population was concentrated in the south central area of Missouri.

Research questions two-five were extracted directly from the Advanced Questionnaire survey. All four questions explored if there were differences in Advanced Questionnaire responses between Gold Star and non-Gold Star Schools between 20072012. Economically disadvantaged schools represented both groups, which reported having $50 \%$ or more students on free and reduced lunch. Research question two determined there was a statistically significant difference (.03) in the responses when asked whether the school promotes an environment of mutual respect among students. Then, research question three determined there was not a statistically significant difference (.32) in responses when asked if the school makes students feel they belong. Next, research question four explored if Missouri public school teachers and administrators value their students' opinions. There was a statistically significant difference (.01) in responses between the two groups. Research question five explore if there were differences in responses in regards to if teachers will listen and help if a student has a problem. A $t$-test analysis revealed that there was a statistically significant difference (.00) in responses between the two groups.

Finally, the study also looked at the total average for questions two through five combined. It was found that the high achieving Gold Star group reported a total average 
score of 4.34, whereas the low-achieving non-Gold Star group reported an average of 4.23. There was not a statistically significant difference (.12) between the two groups when the scores from the four questions were averaged together.

The findings described above provide the basis for the final statements about this study. The research for this study provided a clear representation of school culture, poverty and student achievement. As such, the Missouri Advanced Questionnaire provided a valid means to allow this study to investigate an idea that had not been studied, a study that could determine if differences existed in the AQ responses of impoverished Gold Star and non-Gold Schools across Missouri from 2007-2012.

Findings revealed that schools in Missouri from 2007-2012 with free and reduced lunch rates of $50 \%$ and above with high student achievement have faculty that perceive the school's cultures that have respect among students, students' opinions that are valued, and have faculty that are helpful in times of need. Low-achieving schools in Missouri from 2007-2012 that are economically disadvantaged are less likely to report having the same elements embedded in their culture. These findings however, come with additional challenges; Barth (2002) stated, "Probably one of the most important and most difficult jobs of a leader is to change the prevailing culture of a school" (p.1). In most cases it is up to the school leader to identify the need for change and to encourage change in collaboration with the members of the school community.

Reeves (2007) maintained that changing school culture is a priority that can immediately impact student achievement. Meaningful school improvement begins with cultural change. This study has clearly shown that some high poverty school in Missouri from 2007-2012 were able to overcome the impact of poverty and were able to obtain a 
level of achievement that qualified the schools for Missouri's Gold Star Award. This study analyzed faculty response from the Advanced Questionnaire survey and determined that there are differences in the responses between Gold Star and non-Gold Star Schools. Therefore, it can be assumed that schools with cultures that have respect among students, value students' opinions, and have faculty that help student when they need support will have higher student achievement than schools that do not have these same cultures. 


\section{References}

Armario, C. (5/27/2010). Percentage of high-poverty schools rises. Retrieved January 11, 2012, from http://www.msnbc.msn.com/id/37380825/ns/us_newslife/t/percentage-high-poverty-schools-rises/\#.Tw3LR5hYF-A

Armstrong, A. \& Daft, R.L. (2009). Organization theory and design. Toronto: Nelson.

Barth, R. (2002). Beyond instructional leadership. Educational Leadership, 59(8), 6-11.

Barton, P. E. (2003, October). Parsing the achievement gap: Baselines for tracking progress classroom (Policy Information Report). Princeton, NJ: Educational Testing Service, Policy Information Center. Retrieved June 8, 2014, from http://www.ets.org/Media/Education_Topics/pdf/parsing.pdf

Bennett, A., Bridglall, B. L., Cauce, A. M., Everson, H. T., Gordon, E. W., Lee, C. D., et al. (2004). All students reaching the top: Strategies for closing academic achievement gaps. Naperville, IL: Learning Point Associates. Retrieved February 17, 2014, from http://files.eric.ed.gov/fulltext/ED483170.pdf

Bolman, L. G., \& Deal, T. E. (1997). Reframing organizations: Artistry, choice and leadership (2nd ed.). San Francisco, CA: Jossey-Bass.

Bolman, L. G. \& Deal, T. E. (2003). Reframing organizations: Artistry, choice, and leadership (3rd ed.). San Francisco: Jossey-Bass.

Brownson, A., Kahlert, R., Picucci, A., \& Sobel, A. (2002). Driven to succeed: Highperforming, high-poverty, turnaround middle schools. Austin, TX: The Charles A. Dana Center. Retrieved from ERIC database. (ED476108)

Bulach, C. R. \& Berry, J. (2001). The impact of demographic factors on school culture and climate. Paper presented at the Southern Regional Council of Educational 
Administrators, Jacksonville, FL November 3, 2001.

Bulach, C. R., Malone, B., \& Castleman, C. (1995). An investigation of variables related to student achievement. Midwestern Educational Researcher, 8(2), 3-9.

Bush, T. (2003). Theories of educational leadership and management (3rd ed.). Thousand Oaks, CA: Sage Publications, Inc.

Casbarro, J. (2005). The politics of high-stakes testing. Education Digest, 70(6), 20-24.

Center on Education Policy, (2011). State policy differences greatly impact AYP numbers. Washington, DC: Author.

Coleman, J. S., Campbell, E. Q., Hobson, C. J., McPartand, J., Moody, A. M., Wienfeld, F. D., et al. (1966). Equity of Educational Opportunity. Washington, DC: U.S. Government Printing Office.

Connell, N. (1999). Beating the odds: High-achieving elementary schools in high-poverty neighborhoods. New York: New York Community Trust. Retrieved from ERIC database. (ED441913).

Daggett, W. (2014). A Daggett system for effective instruction. International Center for Leadership in Education. Retrieved October 20, 2014, from http://www.leadered.com/our-philosophy/dsei.php

Deal, T. E., \& Peterson, K. D. (1999). Shaping school culture: The heart of leadership. San Francisco, CA: Jossey Bass.

DuFour, R., \& Eaker, R. (1998). Professional learning communities at work. Alexandria, VA: Association for Supervision and Curriculum Development.

Duncan, A. (2011, March 9). Winning the future with education: Responsibility, reform and results. Testimony before the House Committee on Education and the Workforce. Retrieved September 23, 2011, from 
http://www.ed.gov/news/speeches/winning-future-educationresponsibility-reformand-results

Edmonds, R. R. (1979) Effective schools for the urban schools. Educational Leadership $37: 15-24$.

Evans, G. W. (2004, February/March). The environment of childhood poverty. American Psychologist, 59(2), 77-92.

Field, A. (2005). Discovering statistics with SPSS (2nd ed.). Thousand Oaks, CA: Sage Publications.

Field, A. (2009). Discovering statistics with SPSS (3rd ed.). Thousand Oaks, CA: Sage Publications.

Fink, A. (2009). How to conduct surveys: A step-by-step guide (4th ed.). Thousand Oaks, CA: Sage Publications.

Fletcher, A. (2005). Meaningful student involvement: Guide to students as partners in school change (2 $2^{\text {nd }}$ ed.). Olympia, WA: The Freechild Project.

Fraenkel, J. R., \& Wallen, MN. E. (2003). How to design and evaluate research in education ( $5^{\text {th }}$ ed.). New York, NY: McGraw Hill.

Frieberg, H. J. (1998). Measuring school climate: Let me count the ways. Educational Leadership, 56(1), 22-26.

Folz, D. (1996). Survey research for public administration. Thousand Oaks, CA: Sage Publications.

Fullan, M. (2005). Leadership and sustainability: System thinkers in action. Thousand Oaks, CA: Corwin Press. 
Green, M. (2011). Are high-poverty schools educating the poor to remain so? Huff Post Education, Internet Newspaper. Retrieved January 11, 2012, from http://www.huffingtonpost.com/mike-green/high-poverty-schools_b_862869.html Gruenert, S. (2008). School culture, school climate: They are not the same thing. Principal, 90(4), 10-13.

Gruenert, S. \& Valentine, J.W. (1998). The school culture survey. Columbia, MO: University of Missouri-Columbia.

Guerra, P. L., \& Nelson, S. W. (2012). Cultural proficiency means having the courage to act despite risks. The Learning Forward Journal JSD, 33(2), 51-52.

Hirase, S. K. (2000). School climate. Dissertation Abstracts International, 61(2), 439 (Publication Number ATT 9963110).

Hodgkinson, H. L. (1995). What should we call people? Race, class, and the census for 2000. Phi Delta Kappan, 77(2), 173-176, 178-179.

Hoy, W.K., Tarter, C.J., \& Kottkamp, R.B. (1991). Open schools/ healthy schools: Measuring organizational climate. Newbury Park, CA: Sage.

Hoy, W. \& Tarter, J. (1992). Measuring the health of the school climate: A conceptual framework. NASSP Bulletin, 70-77.

Houston, P.D. (1997). Articles of faith and hope for public education. Arlington, VA: American Association of School Administrators (AASA).

Issaacs, J. B. (2011). The recession's ongoing impact on america's children: Indicators of children's economic well being through 2011. Brookings. Retrieved April 12, 2012, from http://www.brookings.edu/papers/2011/1220_children_wellbeing_isaacs.aspx 
Jensen, E. (2009). Teaching with poverty in mind: what being poor does to kids' brains and what schools can do about it. Alexandria, VA: ASCD.

Kirby, S.N., McCombs, J.S., Murry, S.E., Naftel, S. (2003) A snapshot of title I schools, 2000-01. Policy and Program Studies Service, U.S. Department of Education. Arlington, VA: Doc \#2003-12.

Levine, D., \& LeZotte, L. (1995). Effective schools research. In J. A. Banks \& C. A. M. Banks (Eds.), Handbook of research on multicultural education (pp. 525-547). New York: Macmillan.

Lippman, L., Burns, S., McArthur, E. (1996). Urban schools: The challenge of location and poverty. Washington, DC: U.S. Department of Education, Office of Educational Research and Improvement. Retrieved October 21, 2013, from http://www.wcpss.net/results/reports/1999/9920_poverty.pdf

Manning, M. L. (1996). Developing a sense of community in secondary schools. NASSP Bulletin, 41-48.

Manwaring, R. (2012). School turnaround success: Focus on implementation. Principal, $90(4), 10-13$.

Marshall, M. L. (2004). Examining school climate: Defining factors and educational influences. Georgia State University Center for School Safety, School Climate and Classroom Management.

McNeil, M. (2012). AYP glass half full for states. Education Week. April 14, 2012, p. 20. Missouri Department of Elementary and Secondary Education (2011). Advanced Questionnaire Survey Information. Retrieved June 30, 2011, from 
http://dese.mo.gov/quality-schools/mo-school-improvement-program/advancequestionnaire

Missouri Department of Elementary and Secondary Education (2014). Description of the Gold Star and Blue Ribbon Schools Programs. Retrieved October 20, 2014, from http://dese.mo.gov/quality-schools/school-improvement-initiatives/gold-star-blueribbon-schools

Missouri Department of Elementary and Secondary Education (2014). About top 10 by 20. Retrieved October 20, 2014, from http://dese.mo.gov/top-10-20/about-top-1020

Moore, R. (2001). Philosophies of leadership and management and its influence on change. (ERIC Document Reproduction Service No. ED031017).

Muhammad, A. (2009). Transforming school culture: How to overcome staff division. Bloomington, IN: Solution Tree Press.

National Center of Education Statistics (2010). The condition of education, 2010 spotlight. High poverty schools. Retrieved February 21, 2015, from http://nces.ed.gov/programs/coe/analysis/2010-index.asp

National Center for Education Statistics (n.d.). Common core of data (CCD). Retrieved February 13, 2012, from http://nces.ed.gov/ccd/rural_locales.asp

Neill, M. (2003). The dangers of testing. Educational Leadership, 60(5), 43-46.

Noguera, P. (2014). Bolder, broader strategy to ending poverty's influence on education. Huff Post Education, April 1, 2014. 
Office of Social and Economic Data Analysis (2014). Strategic direction of the office of social and economic data analysis (OSEDA). Retrieved October 20, 2014, from http://oseda.missouri.edu/mission.shtml

Pascopella, A. (2005). Inside the law: Analyzing, debating and explaining No Child Left Behind. District Administration, 41(2), 25.

Patrick, H. \& Ryan, A. (2001). The classroom social environment and changes in adolescents' motivation and engagement during middle school. American Educational Research Journal, 38(2), 437-460.

Payne, R. K. (1998). A Framework for understanding poverty. Highlands, TX: RFT Publishing.

Payne, R. K. (2005). A Framework for understanding poverty. Highlands, TX: RFT Publishing.

Peery, A. (2010). Writing to Learn. Englewood, CO: Advanced Learning Centers

Peterson, K., \& Deal, T. (1998). How leaders influence culture of schools. Educational Leadership, 56(1), 28-30.

Peterson, K. D., \& Deal, T. E. (2002). The shaping school culture fieldbook. San Francisco, CA: Jossey-Bass.

Phillips, G. (1996). Classroom rituals for at-risk learners. Vancouver, BC: Educserv, British Columbia School Trustees Publishing.

Preis, S. (2009). A study of the public schools of Missouri. Retrieved April 16, 2012, from http://www.senate.mo.gov/jced/Public_School_Study.pdf 
Rafaeli, A., \& Worline, M. (2000). Symbols in organizational culture. In N.M. Ashkanasy, C. P., Wilderom, M., \& Peterson, M. F. (Eds.), Handbook of organizational culture \& climate (71-84). Thousand Oaks, CA: Sage Publications.

Reeves, D. B. (2000). Accountability in action; A blueprint for learning organizations. Denver, CO: Advanced Learning Press.

Reeves, D. (2007). Leading to change / How do you change school culture. Educational Leadership, 64(4), 92-94.

Sapru, R.K. (2008). Administrative theories and management thought. New Delhi: Prentice-Hall of India Private Limited, 276.

Schein, E. H. (2000). Sense and nonsense about culture and climate. In N.M. Ashkanasy, C. P. M. Wilderom, \& M.F. Peterson (Eds.), Handbook of organizational culture \& climate (pp. xxiii-xxx). Thousand Oaks, CA: Sage Publications.

Schein, E. H. (2004). Organizational culture and leadership (3rd ed.). New York: JosseyBass.

Schein, E. H. (2010). Organizational culture and leadership (4th ed.). New York: JosseyBass.

Schiff, T. (2001). Priorities and barriers in high school leadership: A survey of principals. Reston, VA: National Association of Secondary School Principals.

Scott, W.R. (1981). Organizations: rational, natural, and open systems. Englewood Cliffs NJ: Prentice Hall Inc.

Shafritz, J. M., Ott, J. S. \& Jang, Y. S. (Eds.). (2005). Classics of organization theory $\left(6^{\text {th }}\right.$ ed.). Belmont, CA: Thomson Wadsworth.

Sizer, T. (1988). A visit to an "essential" school. School Administrator, 45(10), 18-19. 
Snowden, P.E., \& Gorton, R.A. (2002). School leadership and administration: Important concepts, case studies, and simulations (6th ed.). New York: McGraw Hill.

Stolp, S. and Smith, S. (1995) Transforming School Culture: Stories, symbols, values \& the leader's role. Oregon: ERIC Clearinghouse on Educational Management (ERIC No. ED386783).

Strauss, V. (2010). 1 in 6 U.S students in high-poverty schools. The Washington Post. Retrieved February 15, 2012, from http://www.washingtonpost.com/blogs/answer-sheet

Thompson, S. (2003). Creating a high-performance school system. Phi Delta Kappan, 84(7), 488-495.

Trochim, M. (2001). The research methods knowledge base, 2nd ed. Cincinnati, OH: Atomic Dog Publishing.

Turner, L.H. \& West, R. (2007). Introducing communication theory: analysis and application. New York, NY: McGraw-Hill.

Ury, G. G. (2003). Missouri public school principals' computer usage and conformity to technology standards. Dissertation Ed. D. University of Missouri-Columbia.

US Department of Agriculture. Food and nutrition service. Retrieved October 28, 2014, from http://www.fns.usda.gov/school-meals/child-nutrition-programs

US Department of Education (n.d.). Four pillars of NCLB. Retrieved July 7, 2012, from http://www.ed.gov/print/nclb/overview/intro/4pillars.html

U. S. Department of Education. (2007). Stronger accountability. Retrieved January 12, 2011, from http://www2.ed.gov/policy/elsec/leg/esea02/index.html 
U. S. Department of Education. (2010). Stronger accountability. Retrieved August 29, 2011, from http://www2.ed.gov/policy/elsec/leg/esea02/index.html

U. S. Department of Education. (2011). Ed data express. Retrieved September 25, 2012, from http://eddataexpress.ed.gov/state-report.cfm/state/US/

U.S. Digital Literacy. (2015). A culture of mutual respect. Retrieved April 18, 2015, from http://digitalliteracy.us/a-culture-of-mutual-respect/

Walonick, D.S. (1993). Organizational theory and behavior. Retrieved January 7, 2013, from http://www.statpac.org/walonick/organizational-theory.htm

Wagner, C. R. (2007). The school leader's tool for assessing and improving school culture. Principal Leadership, 7(4), 41-44.

Whitaker, M. (2004). Thinking Contextually About Accountability. The Teacher Educator, 39(4), 267-80. doi: 10.1080/08878730409555346 


\section{APPENDIX A1}

\section{Advanced Questionnaire Survey}



MO 500-1972 (09-06) 


\title{
APPENDIX A2
}

\section{Advanced Questionnaire Survey}

\author{
13. Teachers in our school use effective practices to keep all students actively engaged in \\ learning. \\ 14. Educators in our school respond to inappropriate behaviors quickly and effectively. \\ 15. Norms for conduct that foster collegiality and professionalism among professional \\ staff and administrators are clear and routinely followed. \\ 16. Teachers in my school are routinely involved in formulating schoolwide decisions and \\ policies. \\ 17. Teachers are routinely engaged in collaborative problem solving around instructional \\ issues. \\ 18. Effective vehicles are in place for parents and community to communicate with the \\ school. \\ 18. In our school we communicate effectively to parents and the community. \\ 20. Parents are encouraged to discuss their child's educational needs with the school. \\ Indicate how much you agree or disagree with each statement by clicking one of the \\ circles. If you have no experience on which to base a response or the item is not \\ applicable to you, leave it blank.

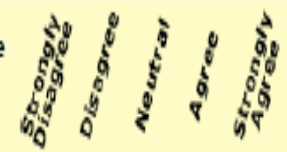 \\ 21. I routinely analyze disaggregated student data and use it to plan my instruction. \\ 22. An assessment system is used that provides timely feedback on specific knowledge \\ and skills for individual students. \\ 23. My school administers assessments througout the school year that are used to guide \\ instruction. \\ 24. My school uses assessment data to evaluate and align the curriculum. \\ 25. Emphasis is placed on valuing and respecting differences among students and their \\ families in our school. \\ 26. Student opinions are valued by teachers and administrators. \\ 27. Faculty and staff solict input from diverse student groups regarding the improvement \\ of our school. \\ 28. I feel comfortable having discussions regarding racia / ethnic issues with my \\ colleagues. \\ 28. Individual student differences are appreciated at our school. \\ 30. Students are provided with opportunities to construct and work on long-term projects \\ of their own design.
}




\section{APPENDIX A3}

\section{Advanced Questionnaire Survey}

Indicate how much you agree or disagree with each statement by clicking one of the circles. If you have no experience on which to base a response or the item is not applicable to you, leave it blank.

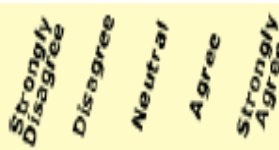

31. In our school teachers are encouraged to be instructional leaders.

32. My school's principal fosters shared beliefs and a sense of community and cooperation.

33. My school's principal monitors the effectiveness of school practices and their impact on student learning.

34. Our principal identifies issues in the school that could potentially become problems.

35. My school's principal systematically engages faculty and staff in discussions about current research on teaching and learning.

36. Our school teaches and reinforces student self-discipline and responsibility.

37. Students who are prone to violence are systematically identified.

38. Our school promotes an environment of mutual respect among students.

39. The content considered essential for all students to learn versus that considered supplemental has been identified and communicated to teachers.

40. My school systematically ensures that teachers address essential content.

Indicate how much you agree or disagree with each statement by clicking one of the circles. If you have no experience on which to base a response or the item is not applicable to you, leave it blank.

41. The amount of essential content that has been identified can be addressed in the instructional time available to teachers.

42. The essential content is organized and sequenced in a way that students have ample opportunity to learn it.

43. Our principal promotes innovation.

44. I have the skills necessary to meet the needs of all learners in my classroom.

45. I believe that I can positively impact student performance.

46. I have received violence prevention training.

47. Our professional development improves student achievement.

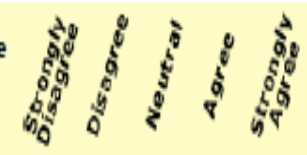

0000
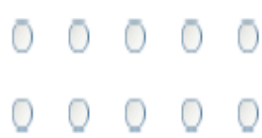

$\begin{array}{lllll}0 & 0 & 0 & 0 & 0\end{array}$

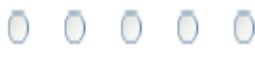

00000

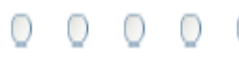




\title{
APPENDIX A4
}

\section{Advanced Questionnaire Survey}

\author{
48. I have received adequate training in using computers and other technology to support \\ my work with students. \\ 48. The professional development activities I attend are related to my district's \\ Comprehensive School Improvement Plan. \\ 50. I have received professional development on differentiating instruction for leamers. \\ Indicate how much you agree or disagree with each statement by clicking one of the \\ circles. If you have no experience on which to base a response or the item is not \\ applicable to you, leave it blank. \\ 51. My school adequately prepares all students for post-secondary education, and/or \\ successful entry into the workforce. \\ 52. Students are held accountable for doing quality work. \\ 53. The mission of this school is clearly defined. \\ 54. All staff in our school hold high expectations for student learning. \\ 55. There are open channels of communication among students, staff and administrators. \\ 56. There are avenues for recognizing and rewarding the accomplishments of all \\ students. \\ 57. There are sufficient library media materials to support my program. \\ 58. Career-Technical education is an essential part of the district's program of studies. \\ 59. I feel safe at this school. \\ 60. The library media center materials are current and in good condition.
}

00000

00000

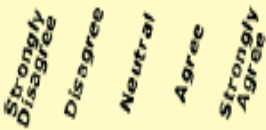

00000

$0 \quad 0 \quad 0 \quad 0 \quad 0$

000000

00000

00000

0000

00000

00000

0000

Indicate how much you agree or disagree with each statement by clicking one of the circles. If you have no experience on which to base a response or the item is not applicable to you, leave it blank.

00000

61. In our community, people tend to trust each other.

62. My professional development has improved the way I teach.

63. My school provides suggestions to parents on ways to assist at home with their child's learning.

64. My school views parents as partners in the educational process.

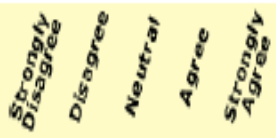

0.0000

00000

00000

MO 500-1972 (09-06) 


\title{
APPENDIX A5
}

\section{Advanced Questionnaire Survey}

\author{
65. My school has created specific strategies to better involve parents in the education of \\ their child. \\ 66. The board has high expectations for student achievement. \\ 87. Students are treated failly in this school. \\ 68. The community is proud of this school. \\ 69. This school makes students feel they belong. \\ 70. If students in this school have a problem, teachers will listen and help.
}

Indicate how much you agree or disagree with each statement by clicking one of the circles. If you have no experience on which to base a response or the item is not applicable to you, leave it blank.

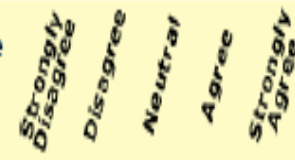

71. I usually look forward to each working day as a teacher.

72. Discipline is handled fairly in this school.

73. Collaboration with classroom teachers to integrate library and media resources and skills into classroom instruction is adequate.

74. The librarian/media specialist requests my input into the selection of resources.

75. There is adequate instruction in the use of library and media resources for classes and individual students.

76. There is systematic collaboration across subject areas in our building.

77. Individual counseling services are available to students.

78. The board establishes policies and permits administrators to implement these policies on a day to day basis.

79. The community provides enough money to adequately provide quality educational programs to children.

80. Overall, my school building is in good condition.

81. If I had a chance to choose all over again, I would still choose teaching as a career.

82. There is systematic collaboration between the academic and career education programs in our district.

83. How much homework time do you assign your students each day:

MO 500-1972 (09-06) 


\section{APPENDIX A6}

\section{Advanced Questionnaire Survey}

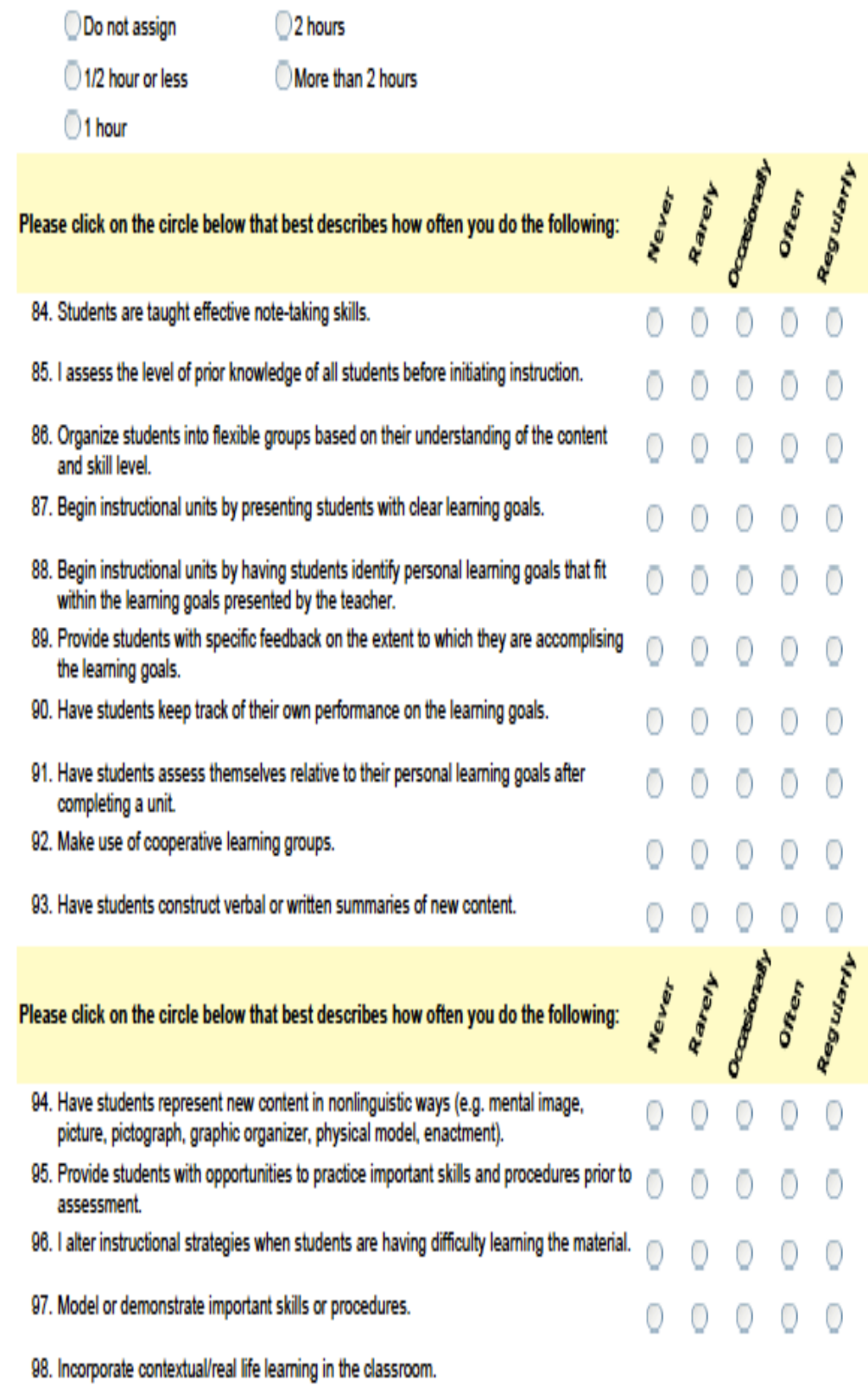

MO 500-1972 (09-06) 


\section{APPENDIX A7}

\section{Advanced Questionnaire Survey}

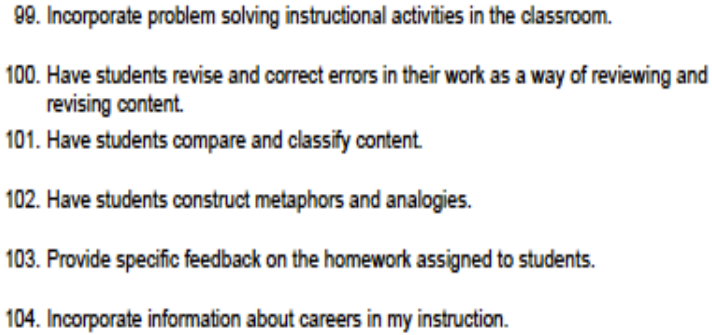

Submit Survey

MO 500-1972 (09-06) 


\section{APPENDIX B1}

\section{Complete List of Missouri Schools Recognized as Gold Star between 2007-2012}

\begin{tabular}{|c|c|c|c|}
\hline School Name & District & Year(s) & County \\
\hline Academie Lafayette & Academie Lafayette & 2009 & Jackson \\
\hline Avenue City Elementary School & Avenue City R-XI & 2007 & Andrew \\
\hline Avery Elementary School & Webster Groves & 2007 & St. Louis \\
\hline Bakersfield Elementary School & Bakersfield R-IV & 2011 & Ozark \\
\hline Ballard High School & Ballard R-II & 2008 & Bates \\
\hline Blue Springs High School & Blue Springs R-IV & 2008 & Jackson \\
\hline Bradleyville High School & Bradleyville R-I & 2012 & Taney \\
\hline Brennan Woods Elementary School & Northwest R-I & 2007 & Jefferson \\
\hline Brentwood High School & Brentwood & $2006 / 2008$ & St. Loius \\
\hline Brentwood Middle School & Brentwood & 2010 & St. Loius \\
\hline Carver Middle School & Springfield R-XII & 2008 & Greene \\
\hline Cedar Springs Elementary School & Northwest R-I & 2009 & Jefferson \\
\hline Center Elementary School & Ralls R-II & 2011 & Ralls \\
\hline Center Sr. High School & Center 58 & 2012 & Jackson \\
\hline Century Elementary School & Nixa R-II & 2009 & Christian \\
\hline Chadwick High School & Chadwick R-I & 2010 & Christian \\
\hline Clearview Elementary School & Washington & 2009 & Franklin \\
\hline Conway Elementary School & Ladue & 2007 & St. Loius \\
\hline Crane High School & Crane R-III & 2012 & Stone \\
\hline Crestwood Elementary School & Lindbergh & 2011,2009 & St. Loius \\
\hline Ellison Elementary School & St. Joseph & 2007 & Buchanan \\
\hline Espy Elementary School & Nixa R-II & 2009 & Christian \\
\hline Eugene Field Elementary School & St. Joseph & 2009 & Buchanan \\
\hline Fairview Elementary School & Columbia 93 & 2007 & Boone \\
\hline Franklin Elementary School & Liberty & 2011 & Clay \\
\hline Glenwood Elementary School & Glenwood R-VIII & 2007 & Howell \\
\hline Hartville Elementary School & Hartville R-II & 2007 & Wright \\
\hline Hixson Middle School & Webster Groves & 2008 & St. Loius \\
\hline Jefferson Elementary School & Farmington R-VII & 2007 & St. Francois \\
\hline Jefferson High School & Jefferson C-123 & 2008 & Nodaway \\
\hline Kearney High School & Kearney R-I & 2008 & Clay \\
\hline Kehrs Mill Elementary School & Rockwood R-VI & 2009 & St. Loius \\
\hline Kennard Classical Jr. Academy & St. Louis & 2009 & St. Louis City \\
\hline Kirbyville Elementary School & Kirbyville R-VI & 2011 & Taney \\
\hline Lawson High School & Lawson R-XIV & 2012 & Ray \\
\hline Lee's Summit Sr. High School & Lee's Summit R-VII & 2008 & Jackson \\
\hline Leopold High School & Leopold R-III & 2008 & Bollinger \\
\hline Lincoln College Prep & Kansas City 33 & 2008 & Jackson \\
\hline Lindbergh Sr. High School & Lindbergh & 2012 & St. Loius \\
\hline Mark Twain Elementary School & Brentwood & 2009 & St. Loius \\
\hline Maryville High School & Maryville R-II & 2012 & Nodaway \\
\hline
\end{tabular}




\section{APPENDIX B2}

\section{Complete List of Missouri Schools Recognized as Gold Star between 2007}

$\begin{array}{llrr}\text { School Name } & \text { District } & \text { Year(s) } & \text { County } \\ \text { McKinley/Classical Jr. Academy } & \text { St. Louis City } & 2008 & \text { St. Louis City } \\ \text { Metro High School } & \text { St. Louis City } & 2008 & \text { St. Louis City } \\ \text { Nike Elementary School } & \text { Meramec Valley R-III } & 2007 & \text { Franklin } \\ \text { North Shelby High School } & \text { North Shelby } & 2010 & \text { Shelby } \\ \text { Norwood High School } & \text { Norwood R-I } & 2010 & \text { Wright } \\ \text { Oran High School } & \text { Oran R-III } & 2010 & \text { Scott } \\ \text { Ott Elementary School } & \text { Independence 30 } & 2007 & \text { Jackson } \\ \text { Park Hill South High School } & \text { Park Hill } & 2012 & \text { Platte } \\ \text { Portland Elementary School } & \text { Springfield R-XII } & 2007 & \text { Greene } \\ \text { Ridge Meadows Elementary School } & \text { Rockwood R-VI } & 2011 & \text { St. Loius } \\ \text { Roosevelt Elementary School } & \text { Farmington R-VII } & 2011 / 2009 & \text { St. Francois } \\ \text { Skyline Elementary School } & \text { Hickory County R-I } & 2009 & \text { Hickory } \\ \text { South Nodaway Elementary School } & \text { South Nodaway County } & 2009 & \text { Nodaway } \\ \text { South Nodaway High School } & \text { South Nodaway County } & 2008 & \text { Nodaway } \\ \text { Spokane Middle School } & \text { Spokane R-VII } & 2010 & \text { Christian } \\ \text { Stanberry High School } & \text { Stanberry R-II } & 2008 & \text { Gentry } \\ \text { Stewartsville High School } & \text { Stewartsville C-2 } & 2008 & \text { DeKalb } \\ \text { Stoutland R-II } & \text { Stoutland Elementary Sc } & 2007 & \text { Camden } \\ \text { Thornfield Elementary School } & \text { Thornfield F-I } & 2007 & \text { Ozark } \\ \text { Truman Elementary School } & \text { Lindbergh R-VIII } & 2009 & \text { St. Loius } \\ \text { Valley Park Sr. High School } & \text { Valley Park } & 2012 & \text { St. Loius } \\ \text { W.W. Keysor Elementary School } & \text { Kirkwood R-VII } & 2013 / 2011 & \text { St. Loius } \\ \text { Washington-Franklin Elementary School } & \text { Farmington R-VII } & 2009 & \text { St. Francois } \\ \text { Westchester Elementary School } & \text { Kirkwood R-VII } & 2007 & \text { St. Loius } \\ \text { Wright City Elementary School } & \text { Wright City R-II } & 2007 & \text { Warren }\end{array}$




\section{APPENDIX C}

\section{T-test Analysis}

\section{T-TEST}

T-TEST /V A RIA BLES $=$ q69 q38 q26 q70 avg

$/$ GROUPS $=$ gold $\operatorname{star}(0,1) / \mathrm{MISSIN} G=\mathrm{A} N$ A LY SIS

$/$ CRITERIA $=\mathrm{CIN}(0.95)$.

\section{Group Statistics}

\begin{tabular}{llllll}
\multicolumn{2}{l}{ Gold Star } & $\mathrm{N}$ & Mean & Std. Deviation & S.E. Mean \\
\hline $\mathrm{q} 69$ & .00 & 39 & 4.28 & .32 & .05 \\
& 1.00 & 26 & 4.45 & .28 & .05 \\
$\mathrm{q} 38$ & .00 & 39 & 4.20 & .38 & .06 \\
& 1.00 & 26 & 4.29 & .31 & .06 \\
$\mathrm{q} 26$ & .00 & 38 & 4.11 & .28 & .05 \\
& 1.00 & 26 & 4.28 & .20 & .04 \\
$\mathrm{q} 70$ & .00 & 39 & 4.39 & .25 & .04 \\
& 1.00 & 26 & 4.56 & .21 & .04 \\
avg & .00 & 39 & 4.23 & .31 & .05 \\
& 1.00 & 26 & 4.34 & .27 & .05
\end{tabular}

Independent Samples Test

\begin{tabular}{|c|c|c|c|c|c|c|c|c|c|}
\hline & \multicolumn{2}{|c|}{$\begin{array}{l}\text { Levene's Test } \\
\text { for Equality of } \\
\text { Variances }\end{array}$} & \multicolumn{7}{|c|}{ t-test for Equality of Mean } \\
\hline & \multirow[t]{2}{*}{$F$} & \multirow[t]{2}{*}{ Sig. } & \multirow[t]{2}{*}{$t$} & \multirow[t]{2}{*}{$d f$} & \multirow[t]{2}{*}{$\begin{array}{l}\text { Sig. (2- } \\
\text { tailed) }\end{array}$} & \multirow[t]{2}{*}{$\begin{array}{c}\text { Mean } \\
\text { Diff }\end{array}$} & \multirow[t]{2}{*}{$\begin{array}{l}\text { Std. } \\
\text { Error } \\
\text { Diff }\end{array}$} & \multicolumn{2}{|c|}{$\begin{array}{c}95 \% \text { Confidence } \\
\text { Interval of the } \\
\text { Difference }\end{array}$} \\
\hline & & & & & & & & Lower & Upper \\
\hline $\begin{array}{l}\text { q69 Equal variances } \\
\text { assumed }\end{array}$ & .13 & .72 & -2.20 & 63.00 & .03 & -.17 & .07 & -.32 & -.02 \\
\hline $\begin{array}{l}\text { Equal variances not } \\
\text { assumed }\end{array}$ & & & -2.27 & 58.67 & .03 & -.17 & .07 & -.32 & -.02 \\
\hline $\begin{array}{l}\text { q38 Equal variances } \\
\text { assumed }\end{array}$ & .51 & .48 & -1.00 & 63.00 & .32 & -.09 & .09 & -.26 & .08 \\
\hline $\begin{array}{l}\text { Equal variances not } \\
\text { assumed }\end{array}$ & & & -1.04 & 60.31 & .30 & -.09 & .09 & -.26 & .08 \\
\hline $\begin{array}{l}\text { q26 Equal variances } \\
\text { assumed }\end{array}$ & 1.86 & .18 & -2.70 & 62.00 & .01 & -.17 & .06 & -.29 & -.05 \\
\hline $\begin{array}{l}\text { Equal variances not } \\
\text { assumed }\end{array}$ & & & -2.87 & 61.86 & .01 & -.17 & .06 & -.29 & -.05 \\
\hline $\begin{array}{l}\text { q70Equal variances } \\
\text { assumed }\end{array}$ & 1.10 & .30 & -2.85 & 63.00 & .01 & -.17 & .06 & -.28 & -.05 \\
\hline $\begin{array}{l}\text { Equal variances not } \\
\text { assumed }\end{array}$ & & & -2.95 & 59.58 & .00 & -.17 & .06 & -.28 & -.05 \\
\hline $\begin{array}{l}\text { Avg Equal } \\
\text { variances assumed }\end{array}$ & .13 & .72 & -1.53 & 63.00 & .13 & -.11 & .07 & -.26 & .03 \\
\hline $\begin{array}{l}\text { Equal variances not } \\
\text { assumed }\end{array}$ & & & -1.57 & 58.03 & .12 & -.11 & .07 & -.26 & .03 \\
\hline
\end{tabular}


Vita

Brian D. Shindorf was born and raised in Oakley, Michigan. He attended Chesaning High School in Chesaning, Michigan. In 1994 Brian graduated from Missouri Western State University with a Bachelor of Science in Education- Special education emphasis. He earned a Master's of Science in Educational Leadership degree in 1998 and an Educational Specialist- Elementary Administration degree in 2001 from Northwest Missouri State University. In 2015 Brian earned a Doctorate in Education degree from the University of Missouri- Columbia.

Brian's personal mission is to live a life of integrity. He is married to Carrie S. Shindorf. He has 4 children; Ashley, Jessica, Hannah and Caleb. Brian currently serves as the Director of Elementary Education for the St. Joseph School District; the same district he has severed in for 29 years. 